\title{
The odd one out : exploring the nature of the association between minority status and psychosis
}

Citation for published version (APA):

Gevonden, M. J. (2015). The odd one out : exploring the nature of the association between minority status and psychosis. [Doctoral Thesis, Maastricht University]. Maastricht University. https://doi.org/10.26481/dis.20150925mg

Document status and date:

Published: 01/01/2015

DOI:

10.26481/dis.20150925mg

Document Version:

Publisher's PDF, also known as Version of record

\section{Please check the document version of this publication:}

- A submitted manuscript is the version of the article upon submission and before peer-review. There can be important differences between the submitted version and the official published version of record.

People interested in the research are advised to contact the author for the final version of the publication, or visit the DOI to the publisher's website.

- The final author version and the galley proof are versions of the publication after peer review.

- The final published version features the final layout of the paper including the volume, issue and page numbers.

Link to publication

\footnotetext{
General rights rights.

- You may freely distribute the URL identifying the publication in the public portal. please follow below link for the End User Agreement:

www.umlib.nl/taverne-license

Take down policy

If you believe that this document breaches copyright please contact us at:

repository@maastrichtuniversity.nl

providing details and we will investigate your claim.
}

Copyright and moral rights for the publications made accessible in the public portal are retained by the authors and/or other copyright owners and it is a condition of accessing publications that users recognise and abide by the legal requirements associated with these

- Users may download and print one copy of any publication from the public portal for the purpose of private study or research.

- You may not further distribute the material or use it for any profit-making activity or commercial gain

If the publication is distributed under the terms of Article $25 \mathrm{fa}$ of the Dutch Copyright Act, indicated by the "Taverne" license above, 


\section{THE odd ONE OUT}

Exploring the nature of the association between minority status and psychosis

PROEFSCHRIF T

Ter verkrijging van de graad van doctor aan de Universiteit Maastricht, op gezag van de Rector Magnificus, Prof. dr. L.L.G. Soete, volgens het besluit van het College van Decanen, in het openbaar te verdedigen op vrijdag 25 september 2015 om 12:00 uur

door

Martinus Johannes Gevonden

Geboren op 26 december 1983 te Naarden 


\section{Promotores:}

Prof. dr. J-P. Selten

Prof. dr. J. Booij (Academisch Medisch Centrum, Amsterdam)

Prof. dr. I. Myin-Germeys

\section{Beoordelingscommissie:}

Prof. dr. T.A.M.J. van Amelsvoort (voorzitter)

Prof. dr. P.A.E.G. Delespaul

Prof. dr. L. de Haan (Academisch Medisch Centrum, Amsterdam)

Prof. dr. K. van Laere (KU Leuven, België)

The research presented in this thesis was performed at the School for Mental Health \& Neuroscience (MH\&NS), department of Psychiatry \& Psychology of Maastricht University, the department of Nuclear Medicine of Amsterdam Medical Center, and Rivierduinen Institute for Mental Health Care. 
Voor mijn ouders 
Paranimfen:

Elsje van der Ven

Claudia Vingerhoets 


\section{Contents}

CHAPTER 2: SEXUAL MINORITY STATUS AND PSYCHOTIC SYMPTOMS:

FINDINGS FROM THE NETHERLANDS MENTAL

HEALTH SURVEY AND INCIDENCE STUDIES (NEMESIS)

CHAPTER 3: SOCIAL STRESS RESPONSE IN SECOND-GENERATION MOROCCAN DUTCH MEN

CHAPTER 4: INCREASED RELEASE OF DOPAMINE IN THE STRIATA OF YOUNG ADULTS WITH HEARING IMPAIRMENT AND ITS RELEVANCE FOR THE SOCIAL DEFEAT HYPOTHESIS OF SCHIZOPHRENIA

CHAPTER 5: PSYCHOTIC REACTIONS TO DAILY LIFE STRESS AND DOPAMINE FUNCTION IN PEOPLE WITH SEVERE HEARING IMPAIRMENT

CHAPTER 6: SUMMARY AND GENERAL DISCUSSION

Nederlandse samenvatting 



\section{Introduction}

Psychosis - from subtly altered experiences to schizophrenia 
Psychosis refers to a mental state which is characterized by severe reality distortion. Schizophrenia, as defined by the Diagnostic and Statistical Manual for Mental Disorders (DSM-5) (American Psychiatric Association, 2013) is the most known psychotic disorder. The defining symptoms of psychotic disorders are the so-called positive symptoms, which refer to hallucinatory experiences and delusions. Hallucinations are internally generated perceptions in any sensory modality and commonly include hearing voices or seeing apparitions. Delusions are false yet irrefutable beliefs, which may be related to those hallucinations or are independent from them. Additional symptoms taken into account when diagnosing schizophrenia include negative symptoms (e.g. social withdrawal, flat affect), cognitive decline, disorganized behaviour and catatonia.

Diagnostic manuals such as DSM-5 include criteria on the constellation, severity and persistence of aforementioned symptoms and steer the practitioner to make an either/or decision on whether the individual has the disease or not. While such a dichotomy has its place in clinical practice, when studying the pathogenesis of such a disorder it may be more useful to consider psychosis as a continuum (van Os et al. 1999; Linscott \& van Os, 2013) on which people may shift when they are exposed to risk factors. This continuum would run from transient and subtle psychotic experiences, through more pronounced symptoms not meeting diagnostic criteria, and mild manifestations of clinical disorder, to finally the most severe cases of schizophrenia.

\section{EPIDEMIOLOGY OF SCHIZOPHRENIA}

Schizophrenia is estimated to affect $0.7 \%$ of the global population during their lifetime, although lifetime morbid risk has been found to vary between populations (McGrath et al. 2008). Onset is generally in adolescence or early adulthood and disease trajectories vary greatly, though having residual symptoms despite long-term medication 
treatment is more common than complete recovery (Rössler et al. 2005). Research from twin studies has led to heritability estimates for schizophrenia of about 70-85\% (Cardno et al. 1999; Sullivan et al. 2003), making family history a major risk factor. The most important other risk factors are migration (Cantor-Graae \& Selten, 2005; Bourque et al. 2011), urban upbringing (Krabbendam \& van Os, 2005), childhood trauma (Varese et al. 2012), low Intelligence Quotient (IQ) (Zammit et al. 2004), cannabis use (Henquet et al. 2008) and obstetric complications (Cannon et al. 2002).

The prevalence of psychotic experiences in the general population is estimated to be about $7 \%$ (Linscott \& van Os, 2013), although the vast majority of those individuals will never move up the continuum as far as to cross the threshold for clinical disorder (Kaymaz et al. 2012). In all the studies that constitute this dissertation we studied sub-clinical symptoms in healthy populations exposed to risk factors. This allows for larger sample sizes, and eliminates important confounders which are present in patient-based research, including possible drug-treatment effects and effects of stigmatization on the basis of having a psychiatric diagnosis.

\section{THE DOPAMINE HYPOTHESIS OF SCHIZOPHRENIA}

Dopamine has long been implicated in the pathogenesis of schizophrenia, and has been a focus of research efforts on the pathogenesis of the disorder. Two early and consistently replicated findings, that dopamine releasing drugs such as dexamphetamine can cause the occurrence of psychotic symptoms (Lieberman et al. 1987; Strakowski et al. 1996) and that all known effective antipsychotics block dopamine receptors, have steered the field in this direction (Miyamoto et al. 2004). The role that dopamine is thought to play has changed over time, and its most recent influential reformulation was published by Howes and Kapur (2009). The core tenet of their version of the hypothesis is that dopamine dysregulation forms a final common pathway in the pathogenesis of schizophrenia, specifically of positive psychotic symptoms. All risk factors should eventually alter dopamine function, most likely starting at the level of presynaptic dopamine synthesis and then working throughout interconnected dopaminergic projections. These changes are supposed to include the up- or down-regulation of dopamine receptors in a regionally specific pattern. While the mesolimbic dopamine system is hypothesized to be hyperactive in psychosis, the mesocortical system is believed to be hypoactive. Finally, on the connection between biology and symptoms, it has been hypothesized that dopaminergic dysregulation alters the salience of stimuli, which may then give rise to delusional interpretations (Kapur, 2003).

The evidence that hyperactivity of the mesolimbic dopamine system is related to psychotic symptoms and disorders includes meta-analyses which confirm that patients with schizophrenia show both elevated presynaptic dopamine activity (dopamine synthesis) (Fusar-Poli \& MeyerLindenberg, 2013) and elevated striatal dopamine $D_{2 / 3}$ receptor availability, although there is no convincing evidence for the latter in medicationnaive patients (Howes et al. 2012). Furthermore, patients with schizophrenia show greater dexamphetamine-induced dopamine release in the striatum than controls (Laruelle et al. 1996), but this does not apply to patients in remission (Laruelle et al. 1999). Patients with schizotypal personality disorder (Abi-Dargham et al. 2004) and individuals with schizotypal traits (Woodward et al. 2010) also show such increased striatal dopamine release as compared to controls, although to a lesser extent. Finally, presynaptic striatal dopamine synthesis has been found elevated in a population at ultra-high risk for the development of psychosis, and dopamine synthesis capacity in that population was predictive for transition to a psychotic disorder (Howes et al. 2011). 


\section{THE SOCIAL DEFEAT HYPOTHESIS OF SCHIZOPHRENIA}

The social defeat hypothesis (Selten \& CantorGraae 2005; Selten et al. 2013) is an attempt to find a common mechanism for several important risk factors for schizophrenia and delineates a mechanism whereby social factors can disturb dopamine function in the brain. The studies which constitute this dissertation were designed to assess the validity of predictions derived from the social defeat hypothesis.

Concerning aetiology, the central tenet of the hypothesis is that long-term social exclusion, specifically the "negative experience of being excluded from the majority group" (Selten et al. 2013), is the underlying risk factor for various groups of outsiders. The experience associated with outsider status is considered to be the common denominator of several schizophrenia risk factors. These include: migration, with higher risk for immigrants from low-income countries (Cantor-Graae \& Selten, 2005; Bourque et al. 2011); urban upbringing (Krabbendam \& van Os, 2005), possibly owing to greater inequality and relative deprivation in cities (Zammit et al. 2010; Kirkbride et al. 2014); and low IQ (Zammit et al. 2004), as problems with reading, writing and math may restrict participation in society (Hall et al. 2005). Following this line of reasoning, any minority population which does not have rights, opportunities or status equal to the majority population is expected to show increased prevalence of psychotic disorders. The study described in chapter 2 was conducted to investigate that prediction, looking at sexual minorities in the Netherlands.

Concerning pathogenesis, the hypothesis proposes that long-term social exclusion leads to increased baseline activity and/or sensitization of the mesolimbic dopamine system. Sensitization implies that repeated exposure to a given stimulus, in this case the negative experience of exclusion, results in subsequent exposures eliciting enhanced responses, in this case increased mesolimbic dopamine release. Such dopaminergic sensitization can be achieved by repeated exposures to a variety of drugs and stressors (Boileau et al. 2006; Egerton et al. 2009). Sensitization as a result of social defeat is supported by results of animal studies, most notably using a resident-intruder paradigm in rodents (Tidey \& Miczek, 1996; Berton et al. 2006; Burke et al. 2010). It should be noted that the authors of the social defeat hypothesis posit that the experience of social exclusion is not a necessary, sufficient, or specific cause of schizophrenia. The majority of people who experience social exclusion, even when it is severe, never present with a psychotic disorder.

\section{AETIOLOGY: SOCIAL EXCLUSION AND MINORITY STRESS}

The negative experience of social exclusion is considered to be hard to measure, as people tend to keep up appearances (Selten et al. 2013). The studies in this dissertation all include minority populations which are likely to have such experiences, and an attempt was made to measure them guided by the minority stress model (Meyer, 2003). The model distinguishes two forms of minority stress exposures which may both contribute to social defeat: (1) exposure to external prejudice events such as discrimination or bullying and (2) exposure to internally generated thoughts such as expectations of rejection and self-loathing. Such thoughts may take the form of cognitive biases, which have been suggested to be further involved in the pathogenic process (Howes \& Murray, 2014). Both aspects were measured in the various chapters of this dissertation by: (1) interviews and questionnaires on childhood maltreatment, bullying and experiences of discrimination and (2) questionnaires including scales of social defeat (Gilbert \& Allan, 1998) and social comparison (Allan \& Gilbert, 1995). 


\section{PATHOGENESIS: STRESS, DOPAMINE AND PSYCHOTIC EXPERIENCES}

The social defeat hypothesis does not specify any observable behavioural expressions of dopaminergic sensitization other than that it may result in schizophrenia. However, it is interesting to consider if such dopaminergic sensitization may have a behavioural counterpart other than outright psychotic disorder. Changes in the way individuals respond to stress may constitute a behavioural mechanism involved in the development of psychotic symptoms and disorders as a result of social exclusion. Minor stresses, including social stress, lead to increases in negative affect and, either directly or through affective mediation, to increases in momentary psychotic experiences. This phenomenon is called stress reactivity and is subtle and proportional to the triggering event in a healthy population. However, using the Experience Sampling Method (ESM), an instrument which allows for the assessment of moment-to-moment changes in symptomatology (Myin-Germeys et al. 2009), stress reactivity has repeatedly been found to be stronger in individuals with psychotic disorders and in their first-degree family members (Myin-Germeys et al. 2001, 2005a). Therefore, increased stress reactivity may represent a vulnerability marker for psychotic disorder (MyinGermeys \& van Os, 2007).

Stress reactivity may increase through repeated exposure to stressors by the process of sensitization (Collip et al. 2008). Since experimental exposure to social stress causes measurable dopamine release (Soliman et al. 2008; Mizrahi et al. 2012), we hypothesize that increased psychotic stress reactivity is a behavioural expression of dopaminergic sensitization.

Exposures that may lead to the experience of social defeat can be considered as repeated episodes of social stress, such as actual or expected discrimination, bullying, and microaggressions. Sensitization implies that with every defeating experience the dopaminergic response to a subsequent social stress exposure is increased. Later exposures to acute psychosocial stress may be associated with more striatal dopamine release in the sensitized system which in turn causes aberrant processing of stimuli, paranoid interpretations of those stimuli and, consequently, more psychosocial stress. A vicious cycle may occur, resulting a psychotic episode. While not directly predicted by the social defeat hypothesis, we propose that at intermediate stages in this process, in healthy individuals exposed to social defeat, dopaminergic dysregulation and increased psychotic reactions to stressful stimuli are likely both present.

Daily life reactivity to social stress was measured in young Moroccan-Dutch men in chapter 3 and stress reactivity was studied jointly with dopamine release in young adults with severe hearing impairment in chapter 5 .

\section{OUTLINE AND AIMS}

The overarching aim of the studies in this thesis was to test the social defeat hypothesis of schizophrenia and predictions derived from this hypothesis. An attempt was made to trace the pathogenic process in non-clinical minority populations. Starting with measures of the aetiological factor, social exclusion, through biological and behavioural alterations associated with psychosis, towards the occurrence of non-clinical positive psychotic symptoms. This led to the following studies relevant to different aspects of the social defeat hypothesis:

\section{1 - Is the prevalence of psychosis elevated in any} minority group experiencing exclusion?

The social defeat hypothesis predicts that psychotic symptoms and disorders should occur more frequently in any minority population which experiences social exclusion. Lesbian, Gay and Bisexual men and women (LGBs) form such a population for which only limited evidence of 
increased prevalence of psychotic disorders was available (Bolton \& Sareen, 2011; Chakraborty et al. 2011), and in which the possible aetiology had not been investigated. In chapter 2 , a study in two large general population samples is presented to test the predictions that: (1) the cumulative incidence of psychotic symptoms would be greater among LGBs and (2) that minority stressors, i.e. experiences of social exclusion, would mediate the association between sexual preference and psychotic symptoms.

\section{2 - Do minorities known to be at increased risk for} psychosis show increased stress reactivity?

Chapter 3 describes a study of 50 MoroccanDutch and 50 controls of Dutch descent, in which an attempt was made to measure social exclusion in daily life. Stress reactivity, which may be a vulnerability marker for psychosis, was measured in response to social stress in daily life and experimental negative social evaluation. The aim of the study was to test the prediction that Moroccan-Dutch participants would show greater reactivity to social stress than peers of Dutch descent. As already mentioned above, this hypothesis is not an element of the social defeat hypothesis, but a prediction derived from it. Similar analyses of reactivity to social stress in daily life are described in chapter 5 , in a population of young adults with serious hearing impairment.

\section{3 - Does an excluded population known to be at} increased risk for psychosis show dopaminergic sensitization?

While the social defeat hypothesis predicts mesolimbic hyperdopaminergia in members of minority populations, this had not been previously investigated in humans. In chapter $\mathbf{4}$ dopamine function in a group of young adults with severe hearing impairment is compared to that in a group of normal hearing peers. People with hearing impairment have repeatedly been demonstrated to be at increased risk for psychotic experiences (Stefanis et al. 2006; van der Werf et al. 2010) and psychotic disorders (David et al. 1995; Fors et al. 2013), and are known to have higher unemployment and lower social status (Järvelin et al. 1997; Pierre et al. 2012; Stam et al. 2013). Striatal dopamine release in response to amphetamine was measured using Single Photon Emission Computed Tomography (SPECT) with [123I]iodobenzamide, a radiotracer highly selective to dopamine $\mathrm{D}_{2 / 3}$ receptors, in order to test whether individuals with severe hearing impairment show greater amphetamine-induced dopamine release than normal hearing peers.

4 - Is there evidence for dose response-relationships between social defeat, striatal hyperdopaminergia and psychotic experiences?

Finally, to chart the pathway from minority stress to psychosis, we used cross-sectional data and ESM data in an attempt to find dose-response relationships between social defeat exposure, striatal hyperdopaminergia and psychotic experiences in individuals with severe hearing impairment. In chapter 4 , we tested whether dopamine release was associated with both self-reported social exclusion and dexamphetamine-induced psychotic experiences. In chapter 5, we tested whether reactivity to social stress was associated with baseline dopamine $D_{2 / 3}$ receptor availability and/or dopamine release.

Chapter 6 summarizes and integrates the findings from the different paradigms and populations presented in the preceding chapters.

Overall, the studies offer partial support for the predictions of the social defeat hypothesis. This is followed by a discussion of how the findings inform us about the development of psychotic disorders, places them in a broader context of clinical practice and global mental health, and gives suggestions on future studies to further understand the nature of the association between minority status and psychosis 


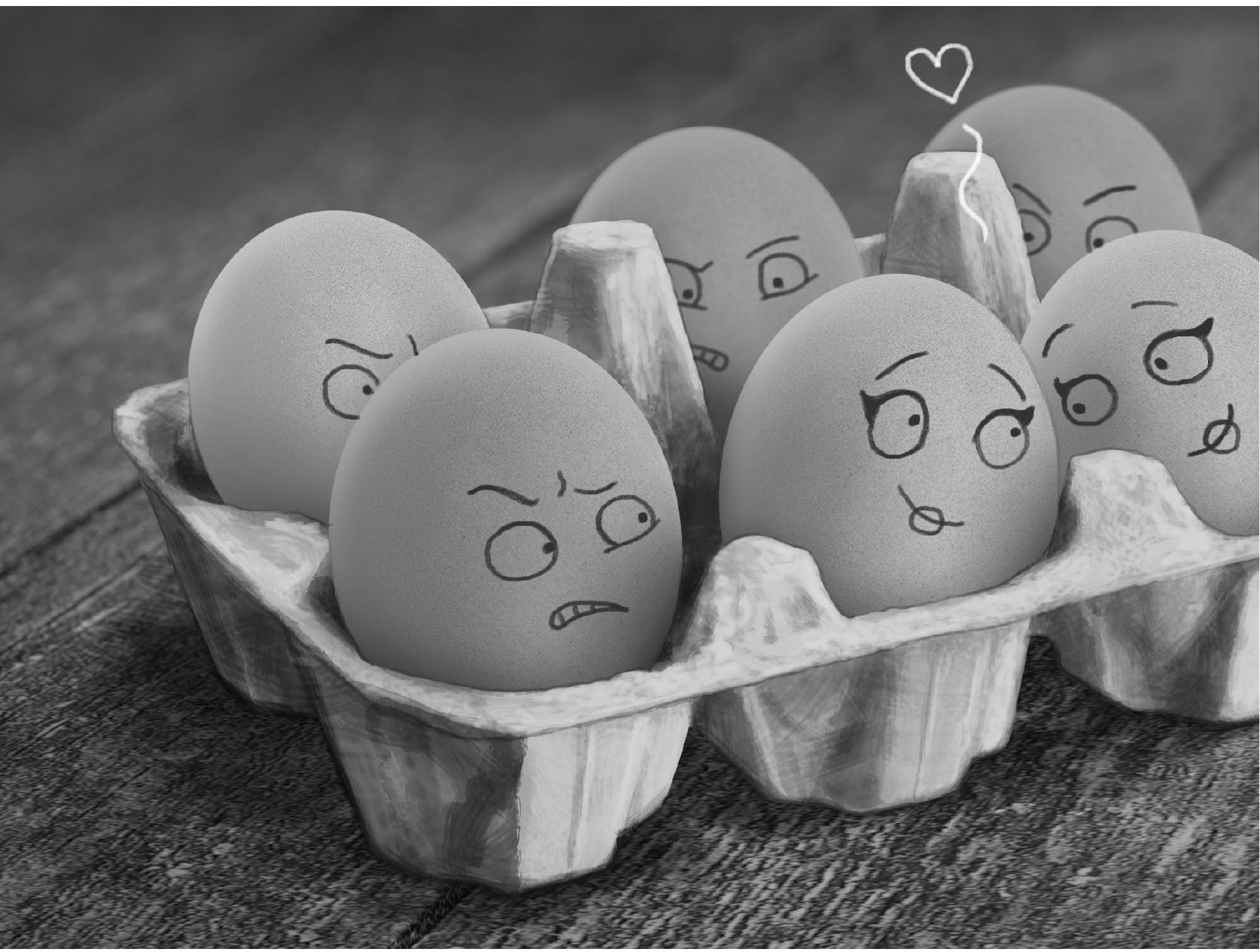




\section{Chapter 02: Sexual minority status and psychotic symptoms}

Findings from the Netherlands Mental Health Survey and Incidence Studies (NEMESIS)

Martin Gevonden

Jean-Paul Selten

Inez Myin-Germeys

Ron de Graaf

Margreet ten Have

Saskia van Dorsselaer

Jim van Os

Wim Veling

Psychological Medicine, 2014. 44 (02): 421-433

Financial support for NEMESIS-1 and NEMESIS-2 was received from the Ministry of Health, Welfare and Sport, with supplement support from the Netherlands Organization for Health Research and Development (ZonMw), the Genetic Risk and Outcome of Psychosis (GROUP) Investigators, and the National Institute for Public Health and Environment (RIVM). The funding organisations or sponsors had no role in the design and conduct of the study; collection, management, analysis, and interpretation of the data; or preparation, review, or approval of the manuscript. 
ABSTRACT

Background: Ethnic minority position is associated with increased risk for psychotic outcomes, which may be mediated by experiences of social exclusion, defeat and discrimination. Sexual minorities are subject to similar stressors. The aim of this study is to examine whether sexual minorities are at increased risk for psychotic symptoms and to explore mediating pathways.

Methods: Cross-sectional survey assessing cumulative incidence of psychotic symptoms with the Composite International Diagnostic Interview (CIDI) in two separate random general population samples (NEMESIS-1 and NEMESIS-2). Participants were sexually active and aged 18-64 years $(n=5927, n=5308)$. Being lesbian, gay or bisexual (LGB) was defined as having sexual relations with at least one same-sex partner during the past year. Lifetime experience of any psychotic symptom was analysed using logistic regression, adjusted for gender, educational level, urbanicity, foreign born parents, living without partner, cannabis use and other drug use.

Results: The rate of any psychotic symptom was elevated in the LGB population as compared to the heterosexual population both in NEMESIS-1 [odds ratio (OR) 2.56, 95\% confidence interval (CI) 1.71-3.84] and NEMESIS-2 (OR 2.30, 95\% CI 1.42-3.71). Childhood trauma, bullying and experience of discrimination partly mediated the association.

Conclusions: The finding that LGB orientation is associated with psychotic symptoms adds to the growing body of literature linking minority status with psychosis and other mental health problems, and suggests that exposure to minority stress represents an important mechanism. 


\section{INTRODUCTION}

The well-replicated association between ethnic minority position and psychotic disorder is thought to reflect the impact of environmental factors (van Os et al. 2010). The specific environmental elements remain unknown, but may involve social stress. Ethnic minorities are more often exposed to socioeconomic disadvantage and experience of social exclusion, social defeat and discrimination, factors that have been suggested to mediate the association with psychotic outcomes (Selten \& Cantor-Graae, 2005; Morgan et al. 2010). If stress related to minority position mediates risk for psychosis, similar associations likely apply to other social minority groups, including sexual minorities. Lesbian, gay and bisexual individuals (LGBs) more often report mental health problems than heterosexuals, including suicidal ideation, depression, anxiety, substance use, and eating disorders (see King et al. 2008; Marshal et al. 2008 for recent metaanalyses). In the Netherlands, where attitudes towards homosexuality comparatively are most positive among European countries (Keuzenkamp, 2011), homosexual men, compared to their heterosexual counterparts, were three times more likely to present with depression or anxiety disorder (Sandfort et al. 2001), and up to ten times more likely to have suicidal thoughts and behaviour (de Graaf et al. 2006). To the authors' knowledge, only two studies have examined the association between sexual orientation and psychosis. General population surveys in the United Kingdom and the United States reported that people who were attracted to their own gender, who indicated ever having had a same-sex partner or who self-identified as a sexual minority, had three to four times higher odds of probable psychosis than heterosexual respondents (Bolton \& Sareen, 2011; Chakraborty et al. 2011). These studies did not explore what factors may underlie the association.

The minority stress model (Meyer, 1995, 2003) offers an explanatory framework for how sexual minority status is associated with mental health problems. It identifies several types of minority stress, including experiences of victimisation, such as trauma, bullying, discrimination and rejection. These experiences may mediate the association between sexual minority status and mental health problems. The model further suggests that having a positive minority identity and finding support in the minority community can moderate the effects of stress on mental health. Several studies in LGB populations provide evidence in support of elements of the minority stress model, showing, for example, an association between discrimination and suicidality (de Graaf et al. 2006), and between childhood maltreatment and depression (Zietsch et al. 2012). Also, LGBs more often report childhood trauma than heterosexuals (Sandfort et al. 2003). During childhood and adolescence sexual identity is still under development. Those individuals who will later identify as LGB may in this developmental process display behaviour which causes them to be singled out and bullied by their peers, or misunderstood and maltreated by their parents. There is preliminary evidence for a dose-response relationship between victimisation and mental health problems in adolescent and young adult LGBs (D'Augelli, 2002). None of the studies in this field however, has investigated psychosis as outcome. Minority stressors such as perceived discrimination (Janssen et al. 2003), bullying (Lataster et al. 2006), and childhood trauma (Janssen et al. 2004) have been associated with psychosis in the general population. In the current study, these types of victimisation experiences are examined together as a possible minority stress pathway in a model for explaining the association between non-heterosexual orientation and psychosis (see Figure 1). While minority stress is of primary interest, two other possible pathways to psychosis are considered. Since LGBs are more likely to use drugs than heterosexuals (Marshal et al. 2008) and since cannabis use (Moore et al. 2007) and other illicit drug use 
(Miller et al. 2001) have been associated with psychosis risk, a substance abuse pathway is included in the model (Figure 1). Furthermore, sociodemographic factors such as urban environment and single marital status, both associated with increased risk for psychosis (Kendler et al. 1996; van Os et al. 2001), could be important. Homosexuality has long been associated with urban rather than rural environments (Aldrich, 2004), and the presence of visible LGB communities as well as the possibility of living in relative anonymity make cities a more attractive place to live for LGBs (Annes \& Redlin, 2012). Additionally, LGBs are less likely to live together with a partner than heterosexuals, and same-sex marriages are not permitted in most countries.

Therefore these factors may jointly be considered as a sociodemographic pathway to psychosis

(Figure 1).

Clinicians distinguish between psychotic symptoms, which are prevalent in the general population and often present without need for care, and psychotic disorder, which requires care. Although psychotic symptoms are often transient and lack clinical relevance, psychotic symptoms are an indicator of more severe psychopathology (van Os et al. 1999; Hanssen et al. 2003; Perlis et al. 2011) and meta-analytic work indicates that they

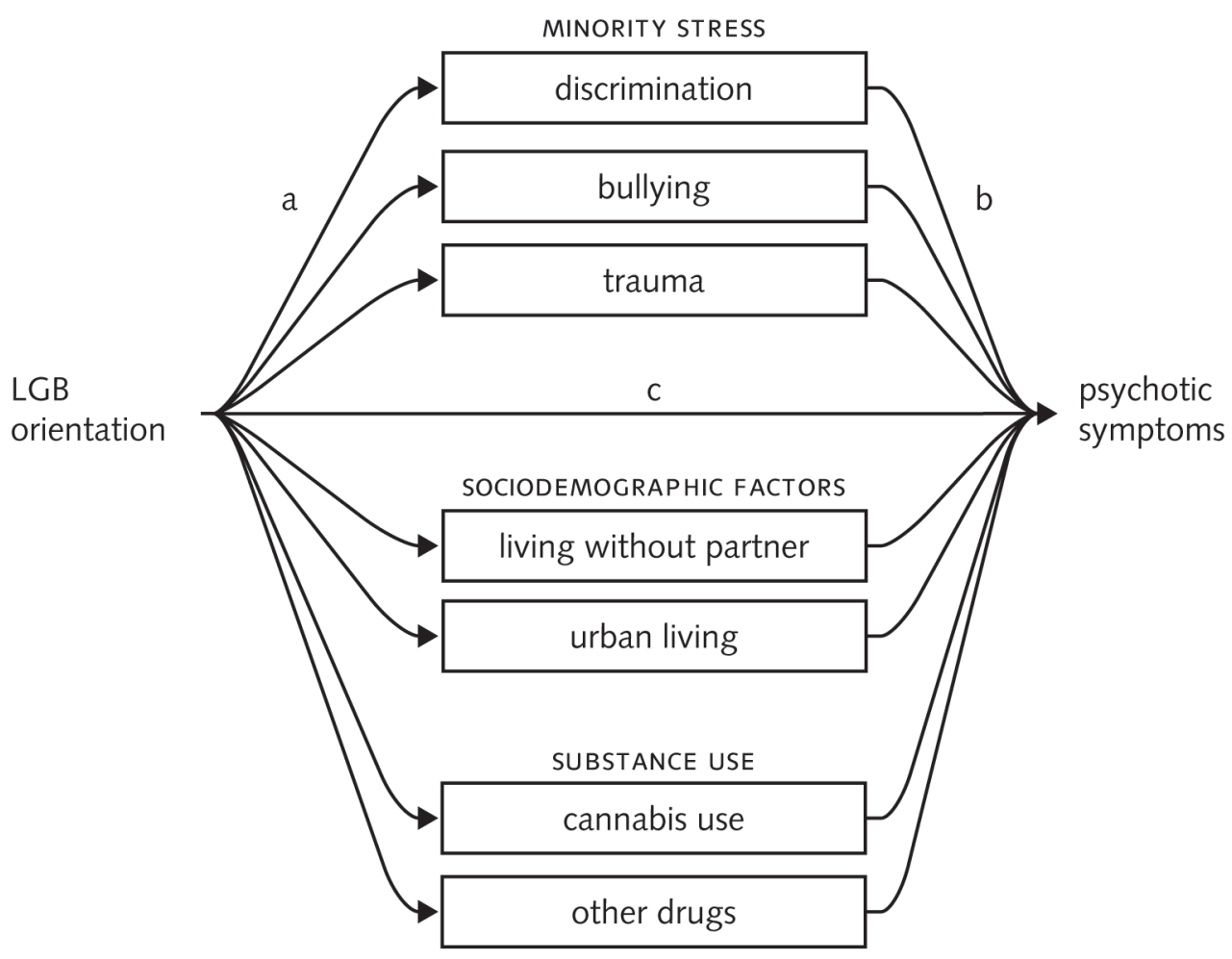

Figure 1. Possible pathways by which non-heterosexual orientation can lead to psychotic symptoms. Central boxes represent possible mediators of the association between LGB orientation and psychotic symptoms, split in three different pathways. Arrows marked with letters $(a, b, c)$ represent the different parameters tested in a mediation analysis. Parameter $c^{\prime}$ is not represented by an arrow in the figure. 
do constitute a risk factor for developing psychotic disorder and other severe mental illness (Kaymaz et al. 2012).

The aim of this study is to examine whether sexual minorities are at increased risk of developing psychotic symptoms and, if this proves to be the case, to explore the contribution of the minority stress, substance use and sociodemographic pathways. It is predicted that, in two large independent general population samples in the Netherlands, past-year homosexual behaviour and self-reported same-sex attraction are both associated with lifetime experience of psychotic symptoms. Furthermore this association will be mediated by minority stressors such as perceived discrimination, bullying and trauma. It is expected that minority stress mediates more of the association between sexual orientation and psychosis than either the sociodemographic or the substance use pathway.

\section{METHODS}

\section{Sample}

Data were acquired from the baseline measurements of both Netherlands Mental Health Survey and Incidence Studies (NEMESIS), two longitudinal studies focusing on the incidence, prevalence, course and consequences of mental health problems in the general population. Baseline data were collected in 1996 for NEMESIS-1 (hereafter referred to as Study 1) and in 2007-2009 for its successor (NEMESIS-2, hereafter referred to as Study 2). Individuals between 18-64 years, who had sufficient mastery of the Dutch language, were contacted on the basis of a stratified random sampling procedure, which was designed to generate a representative sample of the Dutch adult population. The response rate for Study 1 was $69.7 \%$ and for Study $265.1 \%$ of the selected sample, resulting in respectively 7075 and 6646 participating subjects. Young people and ethnic minorities were somewhat underrepresented (Bijl et al. 1998; de Graaf et al. 2010, 2012). For details on the sampling procedure, representativeness, instruments and statistical methods see the respective baseline publications of Study 1 (Bijl et al. 1998) and Study 2 (de Graaf et al. 2010, 2012). 


\section{Instruments}

Composite International Diagnostic Interview (CIDI)

All subjects were interviewed with the lifetime version of the CIDI (Dutch version, Study 1: v1.1, Study 2: v3.0), a comprehensive, standardised diagnostic interview originally developed by the World Health Organization (Robins et al. 1988; World Health Organization, 1990). The CIDI has been found to show good inter-rater reliability (Cottler et al. 1991; Wittchen et al. 1991) and test-retest reliability (Wittchen, 1994). The CIDI is designed to be administered by trained interviewers who are not trained as clinicians.

\section{Sexual orientation}

Participants were classified as either heterosexual or LGB using two different criteria. The primary classification was based on sexual behaviour, while the second classification was based on same-sex attraction. Since the CIDI does not include a section on sexuality, data came from an additional questionnaire administered after the CIDI interview.

For classification based on sexual behaviour, participants were asked if they had had sexual contact (defined as at least touching the genitals of another person) in the preceding year, and about the gender of their partner(s). Conform previous work in this sample (Sandfort et al. 2001), participants who reported sexual contact with at least one same-sex partner in the preceding year were categorised as LGB, regardless of any additional heterosexual contacts. All other sexually active participants were categorised as heterosexual. Since respondents who did not have sex in the preceding year could not be classified, analyses based on behaviour were restricted to the sexually active sub-population.

Of the initial 7075 participants in Study 1, 30 did not answer questions regarding sexual behaviour. Of the remaining 7045 participants, $85.2 \%$ reported sexual activity in the preceding year. Men were slightly more often sexually active than women $(87.6 \%$ vs $83.1 \%)$. Of the 6002 participants reporting sexual activity, 5 could not be classified as heterosexual or LGB because of missing data. Another 70 participants could not be included in the analyses because of missing data on other predictors. The analyses thus were conducted on the remaining 5927 participants, among which $2.7 \%$ of men were homosexually active $(n=76)$ and $1.3 \%$ of women $(n=39)$.

Of the initial 6646 participants in Study 2, 279 did not answer questions regarding sexual behaviour. Of the remaining 6367 participants, $83.7 \%$ reported sexual activity in the preceding year. Men were marginally more often sexually active than women (85.4\% vs $82.4 \%$ ). Of the 5331 participants reporting sexual activity, 3 could not be classified as heterosexual or LGB because of missing data. Another 28 participants could not be included in the analyses because of missing data on other predictors. The analyses thus were conducted on the remaining 5300 participants, among which $2.4 \%$ of men were homosexually active $(n=58)$ and $2.0 \%$ of women $(n=56)$.

In Study 2 only, an additional questionnaire with questions on sexual attraction followed those on sexual behaviour. Respondents were asked to indicate whether they were sexually attracted to women only, predominantly to women, equally to women and men, predominantly to men, or to men only. Respondents who were equally, predominantly or only attracted to their own gender were classified as being LGB, while the remainder were classified as heterosexual. The correlation between homosexual behaviour and same-sex attraction in the sexually active subpopulation was strong $(r=0.81, p<0.0001)$.

\section{Psychotic symptoms}

The psychosis section (G-section CIDI 1.1) of the CIDI contains questions on 4 types of hallucinations 
(visual, auditory, haptic, olfactory) and 13 types of delusions (e.g. being spied upon, can read thoughts, influenced by a strange force). As the psychosis section included in CIDI 3.0 was less comprehensive, it was replaced by a psychosis add-on instrument based on the original G-section. This instrument retained the original 17 psychotic experiences and added 3 more. In order to maintain a consistent outcome variable over Study 1 and Study 2, the new items were ignored in the current analyses. Each of the 17 items was coded as either not present (1), psychotic symptom present but not clinically relevant (no impairment or help-seeking) (2), psychotic symptom resulting from drug use (3), symptom is the result of somatic disease (4), true psychotic symptom (5), or interviewer is uncertain because there appears to be a plausible explanation for the reported symptom (6). In Study 1, clinical re-interviews were conducted over the telephone by an experienced resident in psychiatry for all individuals who had at least 1 rating of 5 or 6 , using questions from the Structured Clinical Interview for DSM-III-R (SCID), an instrument with proven reliability and validity in diagnosing schizophrenia (Bak et al. 2003). In Study 2, all individuals who endorsed at least 1 lifetime psychotic experience, regardless of cause or severity, were approached for a clinical re-interview (van Nierop et al. 2012). Again, interviews were conducted over the phone by an experienced clinician, either at the level of psychologist or psychiatrist, now using questions from SCID-I for DSM-IV. The CIDI ratings in both studies were revised on the basis of these clinical interviews. In case of non-response to the re-interview (Study 1 25.9\%; Study 2: 26.0\%), the original CIDI rating was used. As the different ratings for the presence of psychotic symptoms were shown to underlie a single psychotic symptom construct (van Os et al. 2000), they were combined into a single rating. Thus, if any of the psychosis items on the interview was rated as present (value $>1$ ), the participant was categorised as having, or having had, psychotic experiences (1), otherwise a rating of 'no psychotic experience' (0), applied. To allow for sensitivity analyses on clinical outcomes, respondents were additionally rated as either likely (1) or not likely (0) to meet the criteria for a clinical diagnosis of non-affective psychotic disorder, based on CIDI generated diagnoses and the re-interview.

\section{Minority stress}

Three different dichotomous measures of minority stress were used: discrimination in Study 1, bullying in Study 2, and childhood trauma in both studies. These were hypothesised to represent a minority stress pathway to psychosis, which is depicted in Figure 1. Discrimination was rated as present when participants answered 'yes' when they were asked if they had experienced any discrimination over the past year because of their sexual orientation. Bullying was rated as present when participants answered 'yes' when they were asked if they had been bullied regularly before the age of 16 years. Trauma was assessed using a semi-structured interview on whether participants had experienced any kind of emotional, physical, psychological or sexual trauma before age 16 years. When respondents reported any kind of trauma they then indicated the frequency of the traumatic experience on a 6-point scale. Conform previous work in this sample (Janssen et al. 2004), trauma was rated as present if any type of trauma had occurred regularly, often or very often.

\section{Substance use and sociodemographic} measures

A dichotomous variable was created for both lifetime cannabis use, and other drug use, which included amphetamine, cocaine, ecstasy, angel dust, opiates, glue or other drugs of abuse. Urbanicity of current residence was also classified dichotomously: rural (the $20 \%$ of the country with the lowest address density), and urban. A proxy variable for single status was created by 
classifying respondents according to whether they were living without a partner.

\section{Statistical analyses}

All analyses were carried out using STATA version 11.0 (2009). Logistic regression procedures were applied with past-year same-sex behaviour and same-sex attraction as the independent variables and any psychotic symptom as the dependent variable, yielding unadjusted odds ratios for the presence of psychotic symptoms. Subsequently, adjusted models were computed by adding the following a priori selected covariates, guided by previous work: age (in years), gender, educational level (five levels) and foreign birth of at least 1 parent. Age was considered an important covariate because the psychosis measure used in the current study was defined over the lifetime, not over a specific interval. Higher rates of psychotic symptoms have been observed in men (McGrath et al. 2004), people with lower premorbid IQ (Woodberry et al. 2008) and migrants (CantorGraae \& Selten, 2005). People living in urban environments (van Os et al. 2001), unmarried people (Kendler et al. 1996), cannabis users (Moore et al. 2007) and other illicit drug users (Miller et al. 2001) are also at increased risk for psychosis. These latter factors can be grouped into two other possible pathways to psychosis and are depicted as a separate sociodemographic and a substance use pathway in Figure 1. As these pathways were separate from the main mechanism of interest in the current analysis, they were included in the adjusted model as the dichotomous covariates of lifetime cannabis use, other illicit drug use, urban living, and living without partner. By including covariates which may actually mediate the effect of the variable of interest, a conservative estimate of the relationship between sexual minority status and psychosis was ensured.

Mediation analyses were carried out using the Sobel-Goodman procedure with STATA's
SGMEDIATION (Ender, 2008), allowing for a comparison between the proposed pathways. Such an analysis follows 4 steps (Baron \& Kenny, 1986) (Figure 1). First, the association between homosexual behaviour and psychotic symptoms is tested (Figure 1, path c). Second, the association between homosexual behaviour and the proposed mediator is tested (Figure 1, path a). Third, the association between the mediator and psychotic symptoms is tested (Figure 1, path b) whilst controlling for homosexual behaviour. Fourth, the coefficient of the first step should be larger than the coefficient of the third step. The steps are represented by the arrows labelled with letters in Figure 1. A case-resampling bootstrapping procedure with 1000 repetitions was employed to obtain bias-corrected 95\% confidence intervals for the direct and indirect effects. Bootstrapping is recommended for testing indirect effects (Preacher \& Hayes, 2004). Mediation analyses were conducted in the combined sample of Study 1 and Study 2 for each of the predictors which are part of the minority stress, substance use and sociodemograpic pathways separately. Analyses of discrimination and bullying could not be conducted in the combined sample and were done in Study 1 and Study 2 respectively. In the regression analyses, each model included age, gender, educational level and foreign birth of parent. Additionally, each model included the predictors which were not considered to lie on the same pathway. For example: analyses for bullying, discrimination and childhood trauma were adjusted for cannabis and other illicit drug use, and for urban living and living without partner. When adjusting for the minority stress pathway, only childhood trauma could be included in the model, since bullying and discrimination were not available in the combined sample. The proportion of the total effect of LGB status on psychotic symptoms mediated by each predictor was computed in order to facilitate a comparison of the three pathways. 
Table 1. Sample characteristics by sexual behaviour for Study 1 and Study 2

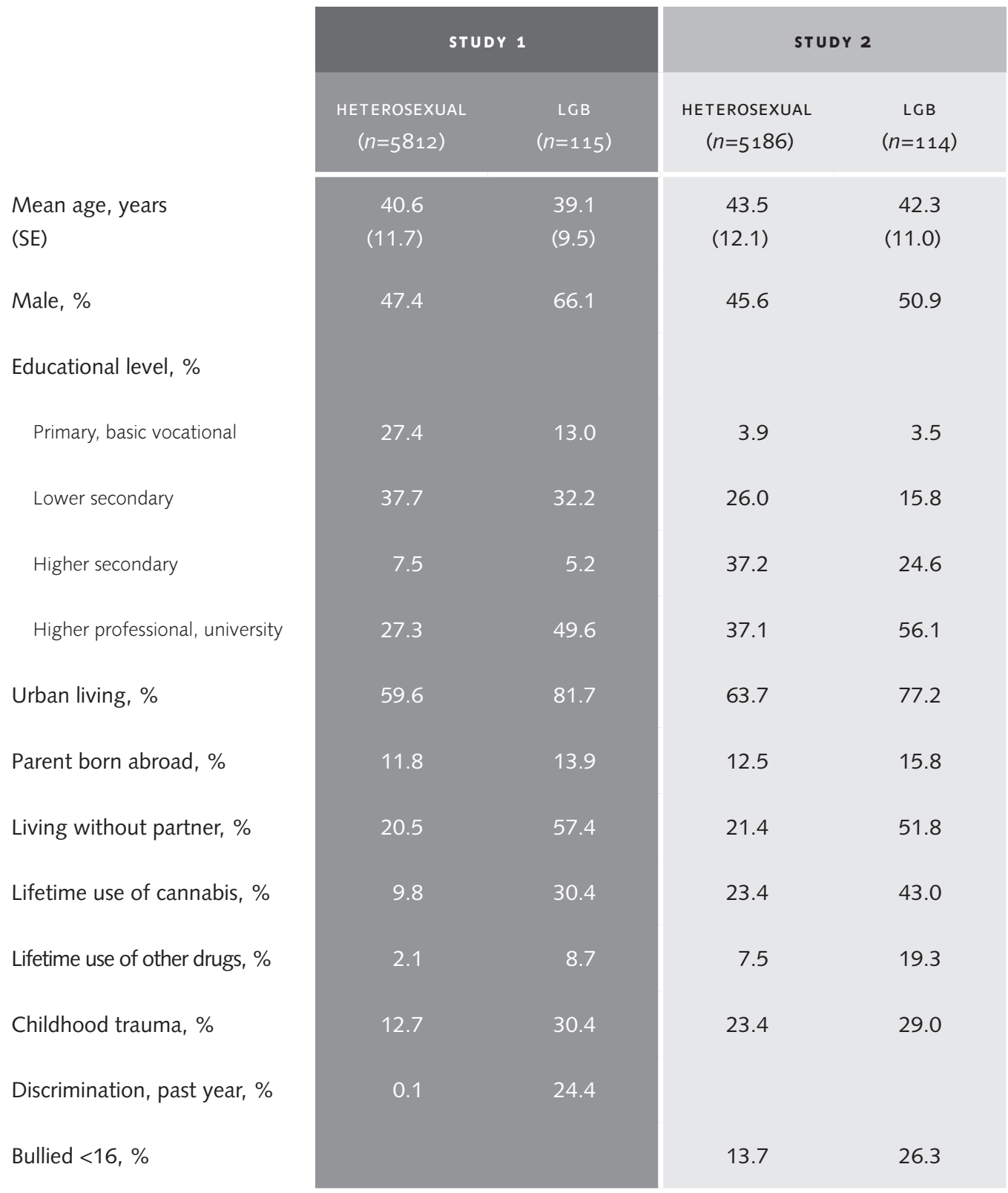

Study 1, Netherlands Mental Health Survey and Incidence Study 1 (NEMESIS-1);

Study 2, NEMESIS-2; LGB, lesbian, gay and bisexual; SE, standard error. 
Table 2. Base model and adjusted model for studies 1 and 2

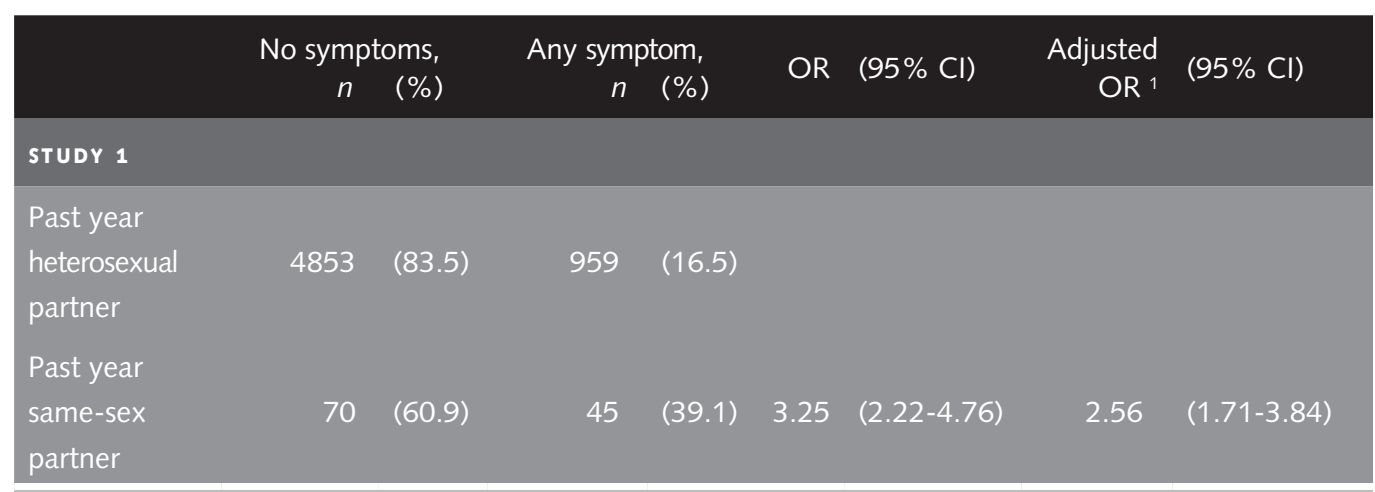

\section{STUDY 2}

Past year heterosexual $4725 \quad(91.1)$ $461 \quad(8.9)$

partner

Past year same-sex partner $90 \quad(79.0)$ 24 (21.0)

Same-sex attraction

$\mathrm{OR}=$ Odds Ratio; $\mathrm{Cl}=$ Confidence Interval

${ }^{1}$ Adjusted for: gender, education level, urbanicity, foreign born parents, living without partner, cannabis use, other illicit drug use

\section{RESULTS}

Homosexually active respondents differed from heterosexually active respondents in several ways. They were more likely to be highly educated, to live in an urban environment, to live without a partner and to have used cannabis or other drugs. They were also more likely to report childhood trauma (Study 1 only), to report having been discriminated against in the past year (data only available in Study 1) or to have been bullied frequently during childhood (data only available in Study 2). The demographics for both samples are shown in Table 1.

The cumulative incidence of psychotic symptoms was elevated in the LGB population as compared 
Figure 2. Psychotic symptom types by sexual behaviour. Percentages of heterosexual and same-sex partnered respondents across the two studies reporting each of the 13 delusions and 4 hallucinations.

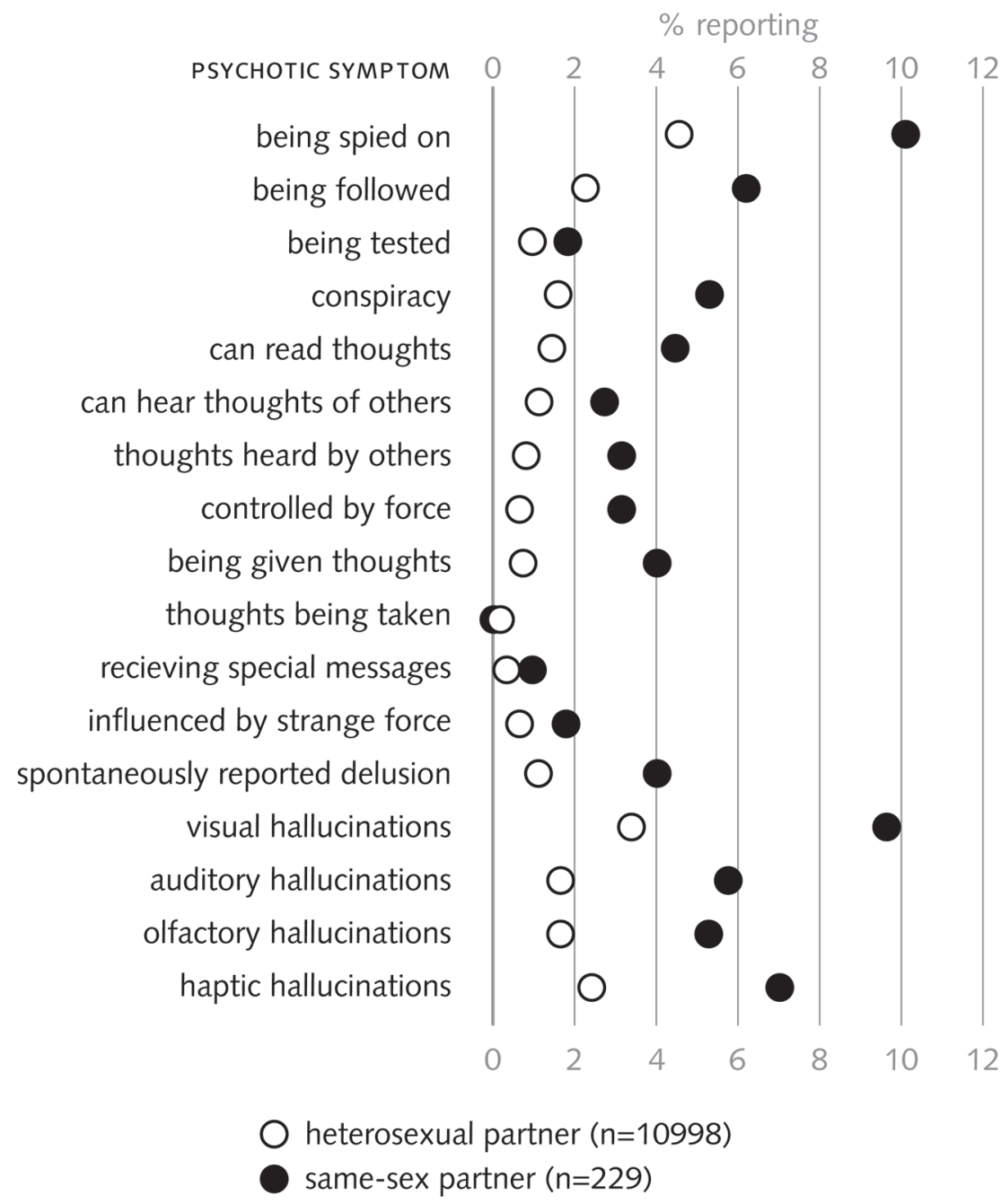

to the heterosexual population in both samples. Respondents who had had same-sex partners were more likely to report psychotic symptoms than those who had had only heterosexual partners. In Study $139.1 \%$ of LGBs reported psychotic experiences as compared to $16.5 \%$ of heterosexuals ( $\mathrm{OR}=3.25,95 \% \mathrm{CI} 2.22-4.76)$, and in Study $221.0 \%$ of LGBs reported such experiences as compared to $8.9 \%$ of heterosexuals $(\mathrm{OR}=2.73$, 95\% CI 1.72-4.33) (Table 2). When adjusting for demographic characteristics (age, gender, educational level and foreign birth of parent) and known risk factors for psychosis (lifetime cannabis use, other illicit drug use, urban living, and living without partner), LGB respondents remained more likely to report psychotic symp- 
Table 3. Mediation analysis results with sexual orientation defined by behaviour ${ }^{1}$

\begin{tabular}{|c|c|c|c|c|c|c|}
\hline Mediator & Path a & $(95 \% \mathrm{Cl})$ & Path b & $(95 \% \mathrm{Cl})$ & $\begin{array}{r}\text { Total effect: } \\
\text { path c }\end{array}$ & $(95 \% \mathrm{Cl})$ \\
\hline \multicolumn{7}{|l|}{ MINORITY STRESS } \\
\hline Childhood trauma $2,3,4)$ & 0.07 & $(0.02-0.12)$ & 0.11 & $(0.09-0.13)$ & 0.15 & $(0.10-0.19)$ \\
\hline $\begin{array}{l}\text { Past year } \\
\text { discrimination } 3,4,5 \text { ) }\end{array}$ & 0.24 & $(0.23-0.25)$ & 0.25 & $(0.11-0.39)$ & 0.17 & $(0.11-0.24)$ \\
\hline Childhood bullying $3,4,6)$ & 0.12 & $(0.05-0.18)$ & 0.06 & $(0.04-0.08)$ & 0.10 & $(0.05-0.15)$ \\
\hline \multicolumn{7}{|l|}{ SUBSTANCE USE } \\
\hline Lifetime cannabis $2,3,7)$ & 0.11 & $(0.07-0.16)$ & 0.04 & $(0.03-0.06)$ & 0.15 & $(0.10-0.19)$ \\
\hline $\begin{array}{l}\text { Lifetime other illicit } \\
\text { drugs } 2,3,7)\end{array}$ & 0.06 & $(0.03-0.09)$ & 0.06 & $(0.04-0.10)$ & 0.15 & $(0.10-0.19)$ \\
\hline \multicolumn{7}{|l|}{ SOCIODEMOGRAPHIC } \\
\hline Urban living $2,4,7)$ & 0.12 & $(0.06-0.19)$ & 0.03 & $(0.02-0.04)$ & 0.16 & $(0.11-0.20)$ \\
\hline $\begin{array}{l}\text { Living without } \\
\text { partner } 2,4,7)\end{array}$ & 0.28 & $(0.22-0.33)$ & 0.06 & $(0.05-0.08)$ & 0.16 & $(0.12-0.20)$ \\
\hline
\end{tabular}

${ }_{1}^{1}$ All analyses adjusted for age, gender, education level, foreign-born parent.

${ }^{2}$ Across both studies ( $\mathrm{n}=11227$ ).

${ }^{3}$ Additionally adjusted for urbanicity and living without a partner.

${ }^{4}$ Additionally adjusted for lifetime cannabis and other illicit drug use.

5 Study 1 only $(n=5927)$.

6 Study 2 only $(n=5300)$.

7 Additionally adjusted for childhood trauma.

${ }^{*} p<0.01$. 


\section{Direct effect:} path $c^{\prime}$

(BC 95\% Cl)
Indirect effect:
$c-c^{\prime}$
(BC 95\% Cl)

Proportion

of total effect

Sobel's z

mediated
$0.13 \quad(0.07-0.19)$
$0.009 \quad(0.003-0.017)$
0.08
$2.76^{*}$

$0.11 \quad(0.03-0.22)$

$0.059 \quad(0.021-0.108)$

0.34

$3.52^{*}$

$0.09 \quad(0.02-0.17)$

$0.007 \quad(0.003-0.016)$

0.07

$2.96^{*}$

$0.14 \quad(0.09-0.20)$

$0.005 \quad(0.002-0.010)$

0.03

$3.41^{*}$

$0.14 \quad(0.08-0.20)$

$0.004 \quad(0.001-0.009)$

0.03

$3.05 *$

$0.15 \quad(0.10-0.21)$

$0.14 \quad(0.08-0.20)$
$0.004 \quad(0.002-0.006)$

$0.017 \quad(0.011-0.024)$
0.02

0.11
$2.91^{*}$

$6.13^{*}$ 
toms than heterosexual respondents. In neither Study 1 (OR=2.56, 95\% CI 1.71-3.84) nor Study $2(\mathrm{OR}=2.30,95 \%$ CI 1.42-3.71) did the relation between homosexual behaviour and psychotic symptoms disappear when testing a model chosen to provide a conservative estimate of the odds ratio (Table 2).

\section{Same-sex attraction}

The results for the analyses based on sexual attraction in Study 2 followed the same pattern as those for sexual behaviour. LGB participants were more likely to report psychotic symptoms $(19.5 \%)$ than the heterosexual population $(9.6 \%$, $\mathrm{OR}=2.28,95 \% \mathrm{CI} 1.53-3.41)$ and the association remained in the adjusted model ( $\mathrm{OR}=1.88,95 \%$ CI 1.24-2.85) (Table 2).

\section{Mediation analyses}

The coefficients for the separate steps in the mediation analysis are summarised in Table 3. All mediators tested were found to satisfy the conditions for mediation and had positive outcomes on the Sobel test.

All of the predictors in the minority stress pathway mediated a substantial part of the total effect. Past-year discrimination mediated 34\% of the total effect of homosexual behaviour on the occurrence of psychotic symptoms in Study 1 $(z=3.52, p<0.001)$ and a history of being bullied in childhood mediated 7\% $(z=2.99, p=0.003)$ of the total effect in Study 2. In the data for both studies combined, childhood trauma mediated about $5 \%(z=2.76, p=0.006)$ of the effect.

In the substance use pathway, both cannabis use $(z=3.41, p<0.001)$ and other illicit drug use $(z=3.05, p=0.002)$ mediated $3 \%$. In the sociodemographic pathway, urban living accounted for $2 \%(z=2.91, p=0.004)$ of the total effect, while living without partner mediated $11 \%(z=6.13$, $p<0.001)$ of the total effect. The contribution of the substance use pathway was relatively small compared to the minority stress pathway, while living without partner mediated a similar percentage of the total effect as the minority stress predictors.

\section{Sensitivity analyses}

In the sexually active sample across two studies $(\mathrm{n}=10837) 3$ homosexually active respondents, $1.35 \%$ of the total, had a likely lifetime diagnosis of non-affective psychotic disorder. This applied to $37(0.35 \%)$ of the heterosexually active respondents. Figure 2 shows that all psychotic symptoms, with the exception of 'thought extraction', were reported more frequently by LGB respondents.

To check the validity of the findings in the sexually active subpopulation as compared to the entire adult population, a planned sensitivity analysis was conducted. Sexual orientation was recoded so that respondents who were not sexually active were all classified as heterosexual. In the combined sample including sexually inactive respondents $(n=13288)$ homosexual behaviour remained the strongest predictor in the model (adjusted OR=2.50, 95\% CI 1.85-3.37). 


\section{DISCUSSION}

The main finding of this study is a higher lifetime cumulative incidence of psychotic symptoms in LGB participants compared to heterosexuals. This association was found in two large independent general population samples and remained statistically significant using different definitions of sexual minority status and after adjustment for a wide range of confounding factors. Minority stressors such as bullying, discrimination and trauma partly mediated the association between sexual minority status and psychotic symptoms. This finding is consistent with the notion that the experience of minority stress is an important mechanism by which sexual and other minorities are at increased risk for psychosis.

It is important to note that the present study concerns psychotic symptoms, not psychotic disorder. However, as stated above, psychotic symptoms are an indicator of severity of psychopathology (van Os et al. 1999; Hanssen et al. 2003; Perlis et al. 2011) and predict transition to psychotic disorder with substantial burden to society in terms of healthy life years lost and costs for care (Kaymaz et al. 2012). The main strength of this study is that similar results were found in two independent samples of more than 5000 individuals, using very similar methods, collected with a 12-year interval. Other strengths include the use of the CIDI, a well-validated diagnostic instrument, with clinical re-interview procedures for psychosis, and random sampling from the general population. Many studies on LGB mental health rely on convenience samples for adequate numbers of sexual minority respondents. Often these are help- or support-seeking populations which likely biases results. Such samples have more morbidity than LGB individuals in the general population and/or may benefit more from the protective effects of LGB community support. The definitions used to classify respondents as LGB were conservative and consistent across samples, in order to minimise misclassifi- cation. Classification was based on past year same-sex behaviour instead of lifetime sexual experience to avoid erroneously classifying people based on experimenting behaviour in childhood or adolescence. A cut-off of at least equal samesex to other-sex attraction was implemented in order to make it likely that those classified as LGB would also identify themselves as such.

Several limitations should be taken into account. First, the study was cross-sectional and is not conclusive about the direction of the relationship between sexual minority status and psychotic symptoms. There is no evidence, however, that psychotic symptoms influence the development of sexual identity. Second, it is possible that same-sex behaviour and attraction were underreported. Especially LGB individuals for whom their social environment is not aware of their sexual orientation may consider such information too sensitive to share with researchers. However, this could only explain the present findings if concealing one's sexual orientation were associated with a lower rate of psychotic symptoms. This is unlikely since there is evidence that the mental health of LGB youth is better if parents know of their sexual preference (D'Augelli, 2002) and that cortisol levels and psychiatric symptoms are lower in adult LGBs who have disclosed their sexual identity (Juster et al. 2013). Third, while measures of sexual behaviour and attraction were collected, these remain only proxy measures for LGB status. Little is known about the stability of same-sex attraction and behaviour in adulthood, but there is substantial variability in early life (Savin-Williams \& Ream, 2007). A direct question about self-declared sexual identity in response to which people indicate if they see themselves as lesbian, gay or bisexual could have been informative. However, such a question also involves a greater risk of underreporting since such categories may appear more stigmatising to respondents than questions about behaviour or attraction. A final possible concern 
is that the time frames of the mediating and outcome variables do not match. The discrimination question only referred to the past year while a lifetime measure of psychotic experiences was used. However, a recent review suggests that discrimination measures which leave the time frame unspecified or consider the past year (or a shorter period) are most predictive of health outcomes (Paradies, 2006). Moreover, lifetime discrimination experiences and rate of currently perceived discrimination were found to be correlated $(r=0.44)$ (Kessler et al. 1999). The majority (76\%) of respondents in the current study who had experienced discrimination during the past year reported on a subsequent question that this had occurred more than once. Thus, the discrimination measure used can be considered, at least to a degree, a proxy measure for earlier (chronic) exposure and was found to be a strong mediator of the relationship between sexual minority status and psychotic symptoms. The measures of bullying and trauma were retrospectively assessed and only refer to events before age 16 years, when people typically do not yet (openly) identify themselves as lesbian, gay or bisexual. It can therefore be argued that the minority stress predictors used covered a period in life that was too early, and are not a result of being LGB. However, this argument cannot explain why large differences exist between LGBs and heterosexuals in experience of bullying or trauma before the age of 16 years. Subtle differences in childhood or adolescent behaviour could be the source of these differences. LGBs are more likely than heterosexuals to show behaviour which does not conform to traditional gender roles in childhood (Rieger et al. 2008) and such gender nonconformity in pre-LGB children has been found to be associated with experiences of victimisation (Landolt et al. 2004). Since psychotic symptoms usually first manifest themselves during late adolescence or early adulthood (Verdoux et al. 1998), it is plausible that early life experiences play an important role in the hypothesised direction for the outcome under investigation.
This study is the first to explore possible mechanisms by which LGB status may be related to psychotic symptoms. There is growing evidence that discrimination or other minority stressors play a key role in LGB mental health problems. For example, LGB individuals who reported multiple kinds of discrimination had four times higher odds for substance use disorder than LGBs who reported no discrimination (McCabe et al. 2010). Similarly, LGBs in the Netherlands who encounter more negative reactions to their sexuality score worse on a mental health indicator (Kuyper \& Fokkema, 2011). The current study shows that minority stressors mediate part of the relationship between sexual orientation and psychotic symptoms. The most important single mediator was discrimination (34\%). Full mediation of effects by minority stressors was not expected in this study as this type of stress involves a multitude of processes, which are hard to measure comprehensively. Moreover, the substance abuse and sociodemographic pathways were expected to play a role as well. The proportions mediated by minority stressors were larger than those mediated by illicit drug use and sociodemographic variables, with the exception of living without a partner $(11 \%)$. It should be noted that the proportions reported cannot be summed within or between pathways since multiple mediator models were not tested in this study.

The findings confirm recent preliminary evidence that higher rates of mental health problems in sexual minorities include psychotic symptoms. One of the two previous studies (Chakraborty et al. 2011) was conducted with data pertaining to the Adult Psychiatric Morbidity Survey, a UK general population sample. Using less conservative definitions of non-heterosexual orientation, the authors found a wide range of mental disorder outcomes to be elevated in LGBs, including probable psychosis as measured with a combination of screening measures and SCAN interview. However, the study did not have enough power 
to control for important confounders. The other previous study, using the National Epidemiologic Survey on Alcohol and Related Conditions data from the US, came to similar conclusions while controlling for confounders including psychiatric comorbidity (Axis I and Axis II), but the psychosis measure used was a self-report of ever receiving a diagnosis of any psychotic disorder or episode (Bolton \& Sareen, 2011). The current study replicates these results, and adds to the literature by showing that the rate of psychotic symptoms remains increased after adjustment for potential confounders in a study which included data from clinical interviews. Additionally it demonstrates that discrimination as well as other forms of victimisation can be considered as mediators between sexual orientation and mental health. These results underline the importance of social context in the development of psychopathology. Minority stress can be internalised but is by definition initialised through interactions with the social environment. In the US, an ecological experiment involving institutional discrimination demonstrated that the level of gay-friendliness of an environment affected mental health. Mental disorders became more prevalent among LGB respondents in states that had introduced legislation to ban gay marriage as compared to states that did not pass such laws (Hatzenbuehler et al. 2010). Also, LGB health is better in states where there is a larger LGB population (Hatzenbuehler et al. 2011), a finding which mirrors ethnic density effects for common mental disorders (Das-Munshi et al. 2010) and psychosis among ethnic minorities (Veling et al. 2008). The finding that LGB individuals are at greater risk of experiencing psychotic symptoms adds to the growing body of literature linking minority status and psychosis. The current study illustrates that LGB mental health is relatively poor even in a reputedly gay-friendly country and extends to a severe type of pathology associated with reality distortion. Therefore the study underlines the need for more research and adds an additional justification for programmes to improve the position of LGBs in societies around the world. Programmes aimed at creating a more equal, accepting, and healthy environment for ethnic minorities or LGBs would reduce their chronic exposure to minority stress, a strong candidate mechanism for explaining the mental health alterations in both groups. Such programmes could prove a cost-efficient way of reducing the burden of psychosis as compared to investments in treatment of affected individuals. 


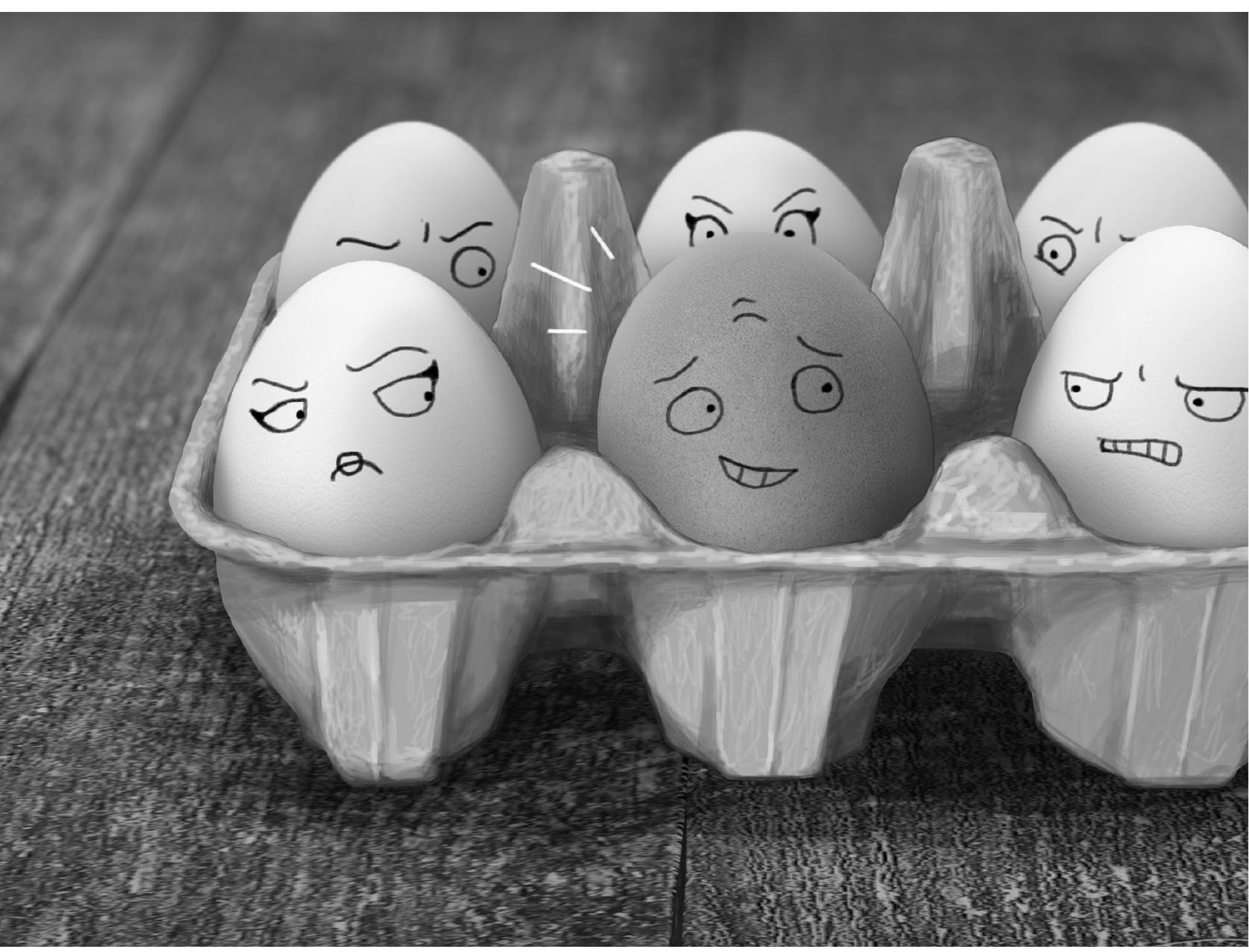


Chapter 03:

Reactivity to social stress in second-generation Moroccan-Dutch men

\author{
Martin Gevonden \\ Inez Myin-Germeys \\ Marieke Wichers \\ Jan Booij \\ Wim van den Brink \\ Ruud van Winkel \\ Jean-Paul Selten
}

Manuscript in preparation 


\section{A BST RACT}

Background: The increased psychosis risk for ethnic minority groups may be due, at least in part, to the experience of social exclusion. We hypothesized that repeated exposures to social exclusion, through a process of sensitization, may result in larger responses to experiences of social stress. The current study used a within-study cross-paradigm design to test the hypothesis that Moroccan-Dutch men, as a proxy for social defeat, respond stronger to social stress than Dutch controls 1) in daily life, and 2) in an experimental set-up.

Methods: Experience sampling study of stress reactivity in daily life and experimental exposure to negative social evaluation in a general population sample of 50 Moroccan-Dutch and 50 Dutch young adult males.

Results: In the course of daily life, no differences were found in affective ( $\mathrm{B}=-0.01,95 \% \mathrm{CI}-0.08$ to $0.06, p=0.77)$ or psychotic $(\mathrm{B}=0.03,95 \% \mathrm{CI}-0.02$ to $0.08, p=0.28$ ) reactivity to social stress between Moroccan-Dutch and Dutch participants. When exposed to a negative social evaluation in a lab environment, a blunted affective ( $\mathrm{B}=-0.31,95 \%$ CI -0.52 to $0.10, p=0.004$ ) response was found in the Moroccan-Dutch group, while the psychotic response $(B=-0.16,95 \% C I-0.36$ to $0.04, p=0.11$ ) did not differ between groups.

Conclusions: These findings suggest that Moroccan-Dutch men are not sensitized to social stress. Their blunted affective response to negative social evaluation may signify the occurrence of habituation as a result of repeated exposures to social exclusion instead. 


\section{INTRODUCTION}

\section{Outsider status: risk factor for psychosis}

Social defeat (Selten \& Cantor-Graae, 2005), more specifically "the negative experience of being excluded from the majority group" (Selten et al. 2013), may be the common etiological factor underlying the increased psychosis risk found in various outsider groups including migrants (Cantor-Graae \& Selten, 2005; Bourque et al. 2011), individuals with low IQ (Kendler et al. 2014), sexual minorities (Chakraborty et al. 2011; Gevonden et al. 2014b) and people with hearing impairment (Smeets et al., in press). In the Netherlands, second generation Moroccan-Dutch men are a migrant group with a particularly vulnerable and insecure position (Crul \& Heering, 2009). Unemployment for Moroccan-Dutch men is $19 \%$, which is four times higher than that of men of Dutch descent, and the highest rate of all nonrefugee migrant groups in the Netherlands (Huijnk et al. 2014). Moroccan-Dutch men and women experience more discrimination than other ethnic groups, and Moroccan-Dutch men specifically report more exposure to ethnic profiling by the police than men from other minority ethnic groups (Andriessen et al. 2014). Unemployment and discrimination rates are also higher for the second generation Moroccan-Dutch than the first (Huijnk \& Dagevos, 2012; Huijnk et al. 2014). In parallel, studies show a higher risk for psychotic disorders among Moroccan-Dutch men as compared to native Dutch men, the risk increase is consistently higher compared to other ethnic minority groups, and it appears to be at least as high in the second generation as in the first (Selten \& Sijben, 1994; Schrier et al. 2001; Selten, 2001; Veling et al. 2006). Being a second generation Moroccan-Dutch man may therefore be considered as a proxy for exposure to social defeat.

\section{Sensitization: mechanism for increase in psychosis risk}

Minor stresses, including social stress, are associated with increases in negative affect (Myin-Germeys et al. 2001; Myin-Germeys \& van Os, 2007) and, either directly or through affective mediation, with increases in momentary psychotic experiences (Myin-Germeys et al. 2005a, 2005b; Gevonden et al. 2015). This phenomenon is called stress reactivity and is subtle and proportional to the triggering event in a healthy population. However, using the Experience Sampling Method (ESM), an instrument which allows for the assessment of moment-to-moment changes in symptomatology (Myin-Germeys et al. 2009), stress reactivity has repeatedly been found to be stronger in individuals with psychotic disorders and in their first-degree family members (Myin-Germeys et al. 2001, 2005a). Previous studies have suggested that this increased stress reactivity in persons vulnerable to psychosis may result from a process of sensitization through which exposure to large stressors such as childhood trauma and recent life events increases reactivity to smaller stressors in daily life (Myin-Germeys et al. 2003; Collip et al. 2008; Lardinois et al. 2011). In the current study, we will investigate whether exposure to social defeat, consisting of repeated episodes of social stress, including actual or expected discrimination, bullying, and microaggressions, may equally be associated with increased reactivity to smaller social hassles in daily life. With every defeating experience the affective and psychotic response to a subsequent social stress exposure would increase, with a sensitized individual with higher stress reactivity as an intermediate result and in extremis a psychotic episode as a clinical outcome.

While stress responses as measured with ESM are of great interest because of their ecological validity, stress reactivity may also be measured in an experimental setting with more control over the stress exposure. This can take the shape of social exposure, such as in the widely used Trier Social Stress Test (Kirschbaum et al. 1993), where participants have to give a speech and perform arithmetic in front of an audience. This test has been 
proven to be an acute and powerful psychological stressor and has been successfully applied to study brain and behavioural responses. In the Montreal Imaging Stress task, a social evaluative component has been added to an arithmetic task, with the experimenters giving negative feedback on the task performance of the participant (Dedovic et al. 2005). Increased reactivity to such evaluative stress has been found in individuals at high risk for schizophrenia and schizophrenia patients, who report an increase in psychotic experiences after exposure to evaluation (Mizrahi et al. 2012). A prior study comparing non-psychotic migrants and controls also reported evidence of differential neural processing of social evaluative stress, however, the authors did not find any group differences in emotional reactivity (Akdeniz et al. 2014). Importantly, performing in front of an audience and receiving negative feedback on task performance may be slightly different in nature from rejection on the basis of your identity, which is the core experience of social defeat. Therefore we selected a recently developed negative social evaluation task for use in the current study, which was specifically designed to model the exposure to social exclusion (Lothmann et al., submitted). In this paradigm participants receive mild negative feedback on their appearance, intelligence and congeniality from peers in a digital social platform. Since the use of social networks throughout the day is commonplace among this age group, it effectively mimics exclusion experiences as they may be encountered in every day life.

\section{Study rationale}

In the current study we used a within-study cross-paradigm design to test the hypothesis that Moroccan-Dutch men, as a proxy for social defeat, respond stronger to social stress than Dutch men 1) in daily life, and 2) in an experimental set-up. Such increased stress reactivity may be an expression of sensitization due to repeated exposures to social stress associated with their outsider status. It is worthwhile to note that this hypothesis differs from the social defeat hypothesis, which posits that repeated exposures to social stress lead to sensitization of the mesolimbic dopamine system. Stress reactivity was operationalized as increase in negative affect and psychotic experiences in reaction to exposure to social stress, either in real life using ESM, or in an experimental study explicitly exposing individuals to mild social exclusion. 


\section{METHODS}

\section{Participants}

The sample consisted of 100 men aged 18-30 years in two groups: 50 Moroccan-Dutch males and 50 males of Dutch descent. Participants were recruited through advertisements in print and on-line media, as well as through community centres and sports clubs in the urbanized Randstad area of the Netherlands. The MoroccanDutch had been born in the Netherlands to at least one Moroccan-born parent, conform the definition of second-generation migrants used by the Netherlands' Bureau of Statistics. Seven Moroccan-born individuals who had migrated to the Netherlands before age 5 were also included. Dutch participants were born in the Netherlands to Dutch-born parents. We further assessed to what extent participants self-identified as Moroccan or as Dutch with the Multigroup Ethnic Identity Measure (MEIM) (Phinney, 1992) and we assessed the lifetime presence of psychotic experiences with the Community Assessment of Psychic Experiences (CAPE) (Konings et al. 2006).

Exclusion criteria were (1) mental retardation $(\mathrm{IQ}<70)$ and/or illiteracy (2) diagnosis of psychotic disorder, and (3) having a first-degree family member with a history of treatment for psychotic disorder as assessed with a shortened version of the Family Interview for Genetic Studies (Nurnberg et al. 1994).

Participants were seen twice, according to their preference in their own home, at a location in their neighbourhood, or at the research institute. For a timeline of the study see Figure 1.

The study was approved by the local medical ethics committee of the Maastricht University Medical Center. All participants gave written informed consent and received a remuneration of $€ 65$,-. The study protocol was registered prior to inclusion of the first subject in the Dutch Trial Registry under number NTR2963.

\section{Experience Sampling Method (ESM)}

Participants received an e-diary, the PsyMate, which was programmed to emit a beep-signal and vibrate at random moments in each of ten 90-min time blocks between 7.30 am and 10.30 pm on eight consecutive days (Myin-Germeys et al. 2009; Palmier-Claus et al. 2011). After each beep, participants were asked to start the selfassessment promptly, thus collecting reports on the current context (activity, social context, location), appraisals of their current situation and affect and the presence of psychotic symptoms. Appraisals were measured with 7-point Likert scales labelled "not at all" to "very much". Participants with fewer than 27 valid reports (out of 80) were excluded from the analyses (Delespaul, 1995).

\section{Social stress measure}

Social stress was measured only when the respondent indicated that he was in the company of others, using the ESM items "I like the present company" (reverse-coded so that higher scores mean less pleasant company) and "I would rather be alone" (Cronbach's alpha in present study: 0.53) (Myin-Germeys et al. 2001).

\section{Psychotic experiences and negative affect} As in earlier work (Myin-Germeys et al. 2005b), a scale representing momentary psychotic experiences was constructed from the mean score of eight ESM items: "I feel suspicious", "My thoughts are difficult to express", "I can't let go of my thoughts", "My thoughts are influenced by other people", "I feel unreal", "I see things that aren't really there", "I hear voices", "I am afraid of losing control” (Cronbach's alpha: 0.84). A negative affect scale was constructed based on the mean score of the mood items "down", "guilty", "insecure", "lonely" and "anxious" (Cronbach's alpha: 0.77) (Myin-Germeys et al. 2001). 


\section{Experimental Social Evaluation Exposure}

To investigate the effects of a negative social evaluation on affect and psychotic experiences in a controlled setting, participants were exposed to experimental Social Evaluation Exposure (eSEE) (Lothmann et al. submitted). Participants created a profile of the type used on social networks and dating sites, including a short videoclip. They were told that their profile would be shown to and rated by 5 peers and that the results would be presented to them after a week. Participants were also asked to view and rate the profiles of those particular peers. The sham peers were matched in age to the participant (+/- 2 years) and their ethnicity was systematically varied. By random assignment respondents saw the profiles of either 5 Moroccan-Dutch men, or 5 men of Dutch descent, which meant that approximately half of the participants were paired with in-group peers and the other half with out-group peers. After one week of experience sampling, the participants were exposed to the experimental social stressor: negative feedback. They first completed baseline measures of negative affect and psychotic experiences, and provided saliva samples as described in greater detail below. They were then presented with the same type of feedback they themselves generated in the initial session: 3 grades and 3 short comments, by each of the five sham peers. The feedback was moderately negative and included figures to make them believe that their ratings fell below the average of the ratings for the rest of the study population. To further process the feedback, the participants had to rate to what extent they agreed with each of the 15 comments. They then again completed the measures of negative affect and psychotic experiences and provided more saliva samples. Directly after the end of data collection the participants were thoroughly debriefed about the deception, and were asked whether they had believed the task was real. For an overview of the timing of measurements see Figure 1.

\section{Negative affect and psychotic experiences}

Consistent with the daily life ESM measures, negative affect and psychotic experiences were measured using the same set of questions as described in the section on ESM above. During the experiment the questions were completed on a personal computer instead of the PsyMate.

\section{Cortisol}

Five saliva samples were obtained from each participant using Salivettes (Sarstedt AG \& Co): two baseline measurements before negative social evaluation, two measurements to assess task effect, and a final measurement after debriefing (Figure 1). Saliva samples were frozen and stored at $-18^{\circ} \mathrm{C}$ until analysis at Technische Universität Dresden using commercially available chemiluminescence-immunoassay with high sensitivity.

\section{Potential confounders}

Since it is conceivable that low IQ and cannabis use influence stress reactivity, these variables were considered potential confounders. IQ was estimated using a short version of the Wechsler Adult Intelligence Scale (WAIS) (Velthorst et al. 2013) and cannabis use was registered using the B-J-L sections of the Composite International Diagnostic Interview (Cottler et al. 1989).

\section{Statistical Analysis}

All analyses were carried out in Stata12 for Windows with the significance level set at 0.05 (twotailed). Group comparisons on questionnaires and cognitive tests were performed with $\chi^{2}$-tests for categorical data and $t$-tests for continuous data. To compare the group averages of ESM variables an individual mean was first calculated over all reports; these values were then aggregated to obtain the group mean and SD. Central tendency and variance are reported as mean \pm SD unless otherwise specified.

\section{Stress reactivity}

ESM data have a hierarchical structure with 
Figure 1: Timeline of the study

session 1

session 2

\section{interview \\ and eSEE preparation}

day 1

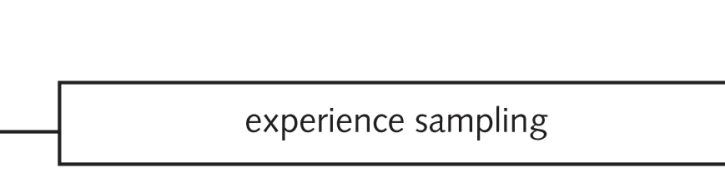

day 2 - 9

session 2 
Table 1. Demographics

\begin{tabular}{|c|c|c|c|c|c|c|}
\hline & Dutch & $\sigma$ & $\begin{array}{r}\text { Moroccan- } \\
\text { Dutch }\end{array}$ & $\sigma$ & $\begin{array}{c}\text { test } \\
\text { statistic }\end{array}$ & $p$ \\
\hline QUESTIONNAIRES & $(n=50)$ & & $(n=50)$ & & & \\
\hline Age in years, months & $22 \mathrm{yOm}$ & (3y10m) & $21 \mathrm{y} 6 \mathrm{~m}$ & (3y5m) & $t(98)=0.64$ & 0.53 \\
\hline IQ estimate & 101.90 & $(16.6)$ & 90.00 & $(12.6)$ & $t(96)=4.00$ & 0.0001 \\
\hline 'I feel Moroccan' (1-5)* & & & 4.43 & $(0.42)$ & & \\
\hline 'I feel Dutch’ & 4.54 & $(0.96)$ & 3.54 & $(1.11)$ & $t(94)=4.71$ & $<0.0001$ \\
\hline EXPERIENCE SAMPLING & $(n=47)$ & & $(n=38)$ & & & \\
\hline Negative Affect & 1.56 & $(0.60)$ & 1.44 & $(0.41)$ & $t(83)=1.04$ & 0.30 \\
\hline $\begin{array}{l}\text { Momentary Psychotic } \\
\text { Experiences }\end{array}$ & 1.22 & $(0.40)$ & 1.22 & $(0.28)$ & $t(83)=-0.05$ & 0.96 \\
\hline Social Stress & 2.06 & $(0.67)$ & 1.96 & $(0.64)$ & $t(83)=0.73$ & 0.47 \\
\hline
\end{tabular}

$\mathrm{IQ}=$ Intelligence Quotient.

${ }^{*}$ Moroccan-Dutch felt less Dutch than they felt Moroccan, paired samples $\left.t(48)=5.12, p<0.0001\right)$. For the daily life experience sampling variables, which included multiple observations over time from each participant, an individual mean was first calculated over all reports. These values were then aggregated to obtain the group mean and standard deviation.

\section{RESULTS}

\section{Demographics and means of daily}

life measures

In the Moroccan-Dutch group 11 (22\%) participants were unemployed as compared to $4(8 \%)$ in the Dutch group. Forty Moroccan-Dutch participants reported having experienced discrimination $(80 \%)$, while this applied to only $16(32 \%)$ of Dutch participants. Moroccan-Dutch (5.5 \pm 4.2$)$ and Dutch (5.5 \pm 5.2$)$ groups did not differ in the life time prevalence of psychotic experiences as measured by the CAPE $(t(96)=0.05, p=0.958)$. The Moroccan-Dutch participants scored 12 points lower on the WAIS than the Dutch participants (Table 1). The main between-group analyses were therefore repeated with WAIS scores as a covariate. Since the rates of recent cannabis use were similar in both ethnic groups, 16 (32\%) Moroccan-Dutch and 17 (34\%) Dutch participants had used cannabis in the past 12 months, cannabis use was not included as a covariate in further analyses. 
Figure 2. Psychotic symptoms and negative affect as a function of exposure to social stress

\section{$\bullet--$ Moroccan-Dutch $\mathrm{O} \longrightarrow$ Dutch controls}
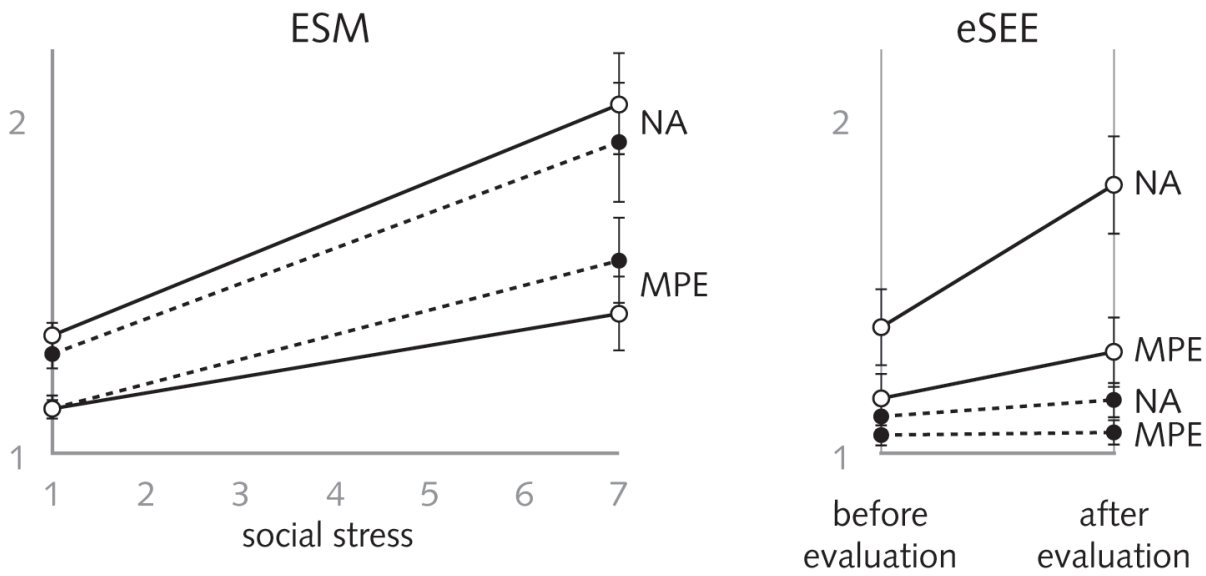

Left panel: Predicted ratings on the basis of multilevel linear regression of Negative Affect (NA) and Momentary Psychotic Experiences (MPE) as a function of social stress in the Experience Sampling Method (ESM) data for Moroccan-Dutch (dashed lines) and Dutch controls (solid lines).

Right panel: Ratings of Negative Affect (NA) and Momentary Psychotic Experiences (MPE) before and after experimental Social Evaluation Exposure (eSEE) for Moroccan-Dutch (dashed lines) and Dutch controls (solid lines).

Error bars represent Standard Deviations.

Two Moroccan-Dutch individuals refused to participate in the experience sampling part of the study. 10 Moroccan-Dutch and 3 Dutch participants were dropped from the ESM analysis because they had completed fewer than 27 beeps. The remaining 38 Moroccan-Dutch and 47 Dutch participants completed a total of 4858 valid ESM observations (mean $\pm S D=57 \pm 15$ ). Dutch participants on average filled in 6 more beeps than Moroccan-Dutch participants

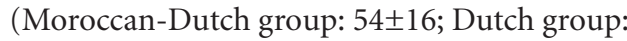

$60 \pm 13 ; t(83)=2.08, p=0.04)$. During 2867 observations (59\%) respondents were not alone. Averaged over all beeps Moroccan-Dutch participants and Dutch participants did not differ in negative affect ratings or level of psychotic experiences, nor did they differ in average appraisals of social stress (Table 1).

\section{Stress reactivity in daily life}

Social stress in daily life led to increases in both negative affect and momentary psychotic experi- 
Table 2: Multilevel linear regression results for the response to social stress

\begin{tabular}{|c|c|c|c|c|c|c|c|}
\hline & B & $95 \%$ Conf & iden & Interval & SE & Z & $p$ \\
\hline SOCIAL STRESS ( 2866 beeps) & & & & & & & \\
\hline Negative affect & & & & & & & \\
\hline Group & -0.04 & -0.22 & to & 0.14 & 0.09 & -0.43 & 0.67 \\
\hline Social stress & 0.12 & -0.07 & to & 0.16 & 0.02 & 4.98 & $<0.001$ \\
\hline Group * social stress & -0.01 & -0.08 & to & 0.06 & 0.03 & -0.30 & 0.77 \\
\hline Momentary Psychotic Expe & & & & & & & \\
\hline Group & -0.03 & -0.13 & to & 0.07 & 0.05 & -0.60 & 0.55 \\
\hline Social stress & 0.05 & -0.01 & to & 0.08 & 0.02 & 2.87 & 0.004 \\
\hline Group * social stress & 0.03 & -0.02 & to & 0.08 & 0.03 & 1.08 & 0.28 \\
\hline NEGATIVE SOCIAL EVALUATION & UP $(N$ & ccan-Du & tch & $3 ; \mathrm{co}$ & 22) & & \\
\hline Negative affect & & & & & & & \\
\hline Group & -0.41 & -0.83 & to & 0.02 & 0.22 & -1.88 & 0.06 \\
\hline Social evaluation & 0.35 & 0.20 & to & 0.49 & 0.08 & 4.53 & $<0.001$ \\
\hline Group * social evaluation & -0.31 & -0.52 & to & -0.10 & 0.11 & -2.91 & 0.004 \\
\hline Psychotic experiences & & & & & & & \\
\hline Group & -0.17 & -0.49 & to & 0.14 & 0.16 & -1.08 & 0.28 \\
\hline Social evaluation & 0.16 & 0.02 & to & 0.30 & 0.07 & 2.30 & 0.02 \\
\hline Group * social evaluation & -0.16 & -0.36 & to & 0.04 & 0.10 & -1.59 & 0.11 \\
\hline NEGATIVE SOCIAL EVALUATION & ROUP & oroccan-D & utc & $\mathrm{n}=21 ; \mathrm{co}$ & $n=19)$ & & \\
\hline Negative affect & & & & & & & \\
\hline Group & -0.09 & -0.37 & to & 0.19 & 0.14 & -0.62 & 0.53 \\
\hline Social evaluation & 0.52 & 0.26 & to & 0.77 & 0.13 & 3.98 & $<0.001$ \\
\hline Group * social evaluation & -0.46 & -0.81 & to & -0.11 & 0.18 & -2.57 & 0.01 \\
\hline Psychotic experiences & & & & & & & \\
\hline Group & -0.04 & -0.16 & to & 0.08 & 0.06 & -0.65 & 0.51 \\
\hline Social evaluation & 0.10 & -0.01 & to & 0.21 & 0.06 & 1.76 & 0.08 \\
\hline Group * social evaluation & -0.09 & -0.24 & to & 0.06 & 0.08 & -1.12 & 0.26 \\
\hline
\end{tabular}

Multilevel linear regression results for the effects of social stress in daily life, negative social evaluation by in-group peers and negative social evaluation by out-group peers on negative affect and momentary psychotic experiences in Moroccan-Dutch participants and Dutch. Listed are the main effects of social evaluation and group and the interaction effect of social evaluation and group (Moroccan-Dutch vs. Dutch) on negative affect and psychotic experiences; When adding Wechsler Adult Intelligence Scale score as a covariate in any of these models, it is not a significant predictor and the pattern of results remains unchanged.

$\mathrm{SE}=$ Standard Error. 
Table 3. Mean salivary cortisol values by group in $\mathrm{nmol} / \mathrm{ml}$ over the course of the negative social evaluation experiment

\begin{tabular}{|c|c|c|c|c|}
\hline & Dutch & SD & $\begin{array}{r}\text { Moroccan- } \\
\text { Dutch }\end{array}$ & SD \\
\hline Negative social evaluation by in-group & $(n=22)$ & & $(n=23)$ & \\
\hline \multicolumn{5}{|l|}{ Before social evaluation } \\
\hline Cortisol $t_{1}$ & 10.94 & $(8.14)$ & 10.35 & $(6.87)$ \\
\hline Cortisol $t_{2}$ & 10.88 & $(10.86)$ & 9.77 & $(5.98)$ \\
\hline \multicolumn{5}{|l|}{ After social evaluation } \\
\hline Cortisol $t_{3}$ & 9.63 & $(10.22)$ & 8.04 & $(4.96)$ \\
\hline Cortisol $t_{4}$ & 9.83 & $(9.69)$ & 8.42 & $(4.73)$ \\
\hline Cortisol $t_{5}$ & 8.93 & $(8.03)$ & 8.13 & $(5.31)$ \\
\hline Negative social evaluation by out-group & $(n=19)$ & & $(n=20)$ & \\
\hline \multicolumn{5}{|l|}{ Before social evaluation } \\
\hline Cortisol $t_{1}$ & 12.11 & $(6.77)$ & 10.87 & $(8.07)$ \\
\hline Cortisol $t_{2}$ & 9.70 & $(4.31)$ & 9.15 & $(6.01)$ \\
\hline \multicolumn{5}{|l|}{ After social evaluation } \\
\hline Cortisol $t_{3}$ & 8.86 & $(3.80)$ & 8.54 & $(5.66)$ \\
\hline Cortisol $t_{4}$ & 8.67 & (5.01) & 7.77 & (4.59) \\
\hline Cortisol $t_{5}$ & 8.64 & $(4.28)$ & 7.34 & (4.39) \\
\hline
\end{tabular}

$\mathrm{SD}=$ Standard Deviation .

ences across groups, as evidenced by a significant main effect for both outcome measures (Table 2; Figure 2, left panel). In contrast to our hypothesis there was no evidence for higher reactivity to social stress in the Moroccan-Dutch group. The interaction between group and social stress was not significant in the model of momentary psychotic experiences or negative affect (Table 2; Figure 2, left panel). The results remained similar after controlling for IQ as a potential confounder.

\section{Stress reactivity in the negative social evaluation experiment}

Most participants reported during debriefing that they believed that the task was real (58.8\% had no doubts at all about the task's authenticity, 28.9\% had doubts, but believed the task was real, and $11.3 \%$ had doubts and believed the task was not real, $1.0 \%$ had no doubts that the task was not real). The following analyses are restricted to the 44 Moroccan-Dutch and 41 Dutch participants who believed the task was real.

The main effect of social evaluation on negative affect was significant, regardless of whether it came from the in-group or out-group (Table 2). Negative affect was higher after than before evaluation (Figure 2, right panel). Additionally, the interaction term between group and social evaluation was significant for negative affect, both 
when the evaluators belonged to the in-group and when they belonged to the out-group (Table 2). However, again in contrast to our expectations, these significant interactions signified a rise in negative affect ratings only in the Dutch group while negative affect remained low in the MoroccanDutch group (Figure 2, right panel).

The main effect of social evaluation on momentary psychotic experiences was significant when it came from the in-group, but not when it came from the out-group (Table 2). When pooling the data of the in-group and out-group condition participants on average reported more psychotic experiences after than before evaluation (Figure 2 , right panel). The interaction term between group and social evaluation was not significant, neither for evaluations from the in-group nor for those from the out-group (Table 2).

Salivary cortisol concentrations decreased over the course of the experiment (Table 3), accounting for the significant main effect of time $\left(F_{4,74}=9.50, p=<0.001\right)$. There was, however, no significant interaction effect between time and group $\left(F_{4,74}=1.40, p=0.241\right)$. Cortisol curves were similar for Moroccan-Dutch and Dutch participants.

The results of the analyses of the experimental paradigm remained similar after controlling for IQ as a potential confounder.

\section{DISCUSSION}

\section{Main findings}

This is the first study of responses to both experimental and daily life social stress exposures in an ethnic minority population known to be at high risk for psychosis. Our findings do not support our hypothesis that Moroccan-Dutch men show increased reactivity to social stress. In daily life Moroccan-Dutch men did not differ in affective or psychotic reactivity to social stress from Dutch men. When experimentally exposed to negative social evaluation, Moroccan-Dutch men showed a blunted affective response as compared to Dutch men.

\section{Validity of findings and interpretation}

Against expectations, we did not find an increase in stress reactivity in the Moroccan-Dutch group. This negative finding was not attributable to the lower IQ scores we found in the Moroccan-Dutch population, which were similar to differences found in other studies (Nijenhuis et al. 2004). While several studies have now shown increased stress reactivity in patients with psychotic disorder and their first-degree relatives (Myin-Germeys et al. 2005a, 2005b; Lataster et al. 2013), studies on stress reactivity in general population samples exposed to environmental psychosis risk factors possibly related to social defeat show mixed results. In an ESM study of young adults with severe hearing impairment, we recently found increased psychotic reactivity to social stress in daily life (Gevonden et al. 2015). In another ESM study, frequent attenders of general practitioners who were also exposed to childhood trauma showed increased affective reactivity to stressful activities and events than those without trauma exposure (Glaser et al. 2006). Contrary evidence comes from an ESM study which reported that affective stress responses in urban participants were blunted as compared to those of rural controls (Frissen et al. 2014). Unfortunately the study did not report on psychotic reactivity, but the latter finding is similar to the blunted affec- 
tive stress response we found for MoroccanDutch men in the social evaluation experiment. There are a few possible explanations for this phenomenon. One is that repeated exposure to social stress leads to habituation in some cases and to sensitization of the affective response in others. Another possibility is that affective dysregulation is not on a causal pathway to psychosis but a co-occurring phenomenon.

However, these explanations do not account for the negative finding concerning psychotic reactivity, the moment-to-moment expression of non-clinical psychotic experiences in response to stress. Increased levels of psychotic experiences would be expected to be present in any at-risk population, and ethnic minority groups at increased risk for psychotic disorder have generally been found to be also at increased risk for psychotic experiences (King et al. 2005). The results for Moroccan-Dutch populations specifically are mixed: two studies found increased rates, among school children (Adriaanse et al. 2015) and young adult males (Vanheusden et al. 2008), while another study found a lower rate among school children (Eilbracht et al. 2015). The measure of lifetime psychotic experiences in the current study, the CAPE questionnaire, showed no difference in either direction. Whether these contradictory findings on the occurrence of psychotic experiences in healthy Moroccan-Dutch populations are attributable to the use of different instruments, differences in recruitment, or another factor remains to be established.

Possibly, the current negative finding can be accounted for by selection bias. The MoroccanDutch population in this study may not be a good proxy for social defeat due to self-selection of participants, which was evident by a very high rate of Moroccan-Dutch individuals for whom no data could be collected as they did not arrive at their scheduled appointments. This group that could not be included in the study may have represented a lower-functioning and more symptomatic part of the population, while the participants in the final sample may be relatively well-integrated and comfortable with their position in Dutch society. However, the prevalence of reports of perceived discrimination among the Moroccan-Dutch in our sample was high. Eighty percent had ever experienced any form of discrimination as opposed to $32 \%$ of the Dutch participants, which can be taken as evidence that the Moroccan-Dutch group has been frequently exposed to the experience of social defeat.

\section{Limitations}

The main strength of this study is that it measures stress reactivity in two distinct ways, using both naturalistic observations in daily life, and experimental exposure to a powerful psychosocial stressor, negative social evaluation. However, our study has several limitations to consider. A first issue concerns the experimental social exclusion paradigm. It is possible that the chosen form of experimental negative social evaluation was not an effective stressor for the population of the current study. We did not observe an increase in salivary cortisol concentrations after evaluation in either group. In the first investigation to use this paradigm stress responses were largest for female participants and for those under 18 (Lothmann et al. submitted), while our population only included adult males. This also meant participants were only evaluated by other men, while they may be more sensitive to evaluations by females. However, main task effects were observed on both the negative affect and psychosis measures. For the Dutch participants the stress exposure appears to have been sufficient, but for the Moroccan-Dutch group it cannot be ruled out that they did not perceive the negative evaluations as very stressful.

Second, since the ESM analyses in this study are cross-sectional and do not incorporate a time 
factor, there is the possibility of reverse causality. The current level of negative affect or MPE may alter the appraisal of stressfulness of the current social environment, but this still would be a meaningful response. More importantly, we observed a similar pattern of stress responses in the experimental design which did incorporate a time factor.

\section{Conclusion}

The current study suggests that second-generation Moroccan-Dutch men do not differ in response to daily life social stress from Dutch men and may even have a blunted affective response to negative social evaluation. It remains to be established whether this means that Moroccan-Dutch men are habituated rather than sensitized to social stress. 


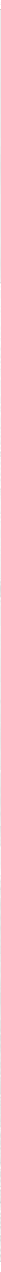




\section{Chapter 04:}

\section{Increased release of}

dopamine in the striata of young adults with hearing impairment and its relevance for the social defeat hypothesis of schizophrenia

Martin Gevonden

Jan Booij

Wim van den Brink

Dennis Heijtel

Jim van Os

Jean-Paul Selten

JAMA psychiatry, 2014. 71 (12): 1364-1372

This work was supported by a grant from the Stichting J.M.C.

Kapteinfonds to Jean-Paul Selten, and supported by the European Community's Seventh Framework Program under grant agreement No. HEALTH-F2-2009-241909 (Project EU-GEI). Scanning costs in part funded by the Amsterdam Brain Imaging Platform (ABIP), Amsterdam, the Netherlands. The authors declare no conflict of interest. 


\section{A BST RACT}

Importance: An increased risk for psychosis is observed in people with hearing impairment. According to the social defeat hypothesis, the long-term experience of exclusion leads to enhanced baseline activity and/or sensitization of the dopamine system and puts the individual at increased risk for psychosis.

Objective: To investigate whether young adults with severe hearing impairment (SHI) experience more feelings of social defeat, show greater dopamine release in response to dexamphetamine and report a stronger subjective reaction to this substance than normal-hearing young adults and to examine whether dopamine release is associated with both self-reported social exclusion and dexamphetamine-induced psychotic experiences.

Design, Setting, and Participants: A sample of 19 participants with SHI and 19 smoking-, ageand sex-matched healthy controls underwent single photon emission computed tomography with iodine 123-labeled iodobenzamide as a radiotracer before and after an amphetamine challenge at an academic hospital.

Exposures: Dexamphetamine sulphate $(0.3 \mathrm{mg} / \mathrm{kg})$ administered intravenously.

Main Outcomes and Measures: Baseline $\mathrm{D}_{2 / 3}$ receptor binding and endogenous dopamine release.

Results: The participants with SHI reported experiencing more feelings of social defeat ( $U=109, z=-2.09, p=0.037$ ) and loneliness $(U=87.5, z=-2.72, p=<0.001)$ than did healthy controls, but they did not differ from healthy controls with regard to baseline psychotic symptoms ( $U=156.5, z=-0.70, p=0.48$ ). There were no significant group differences in baseline $\mathrm{D}_{2 / 3}$ receptor binding. However, repeated-measures multivariate analysis of covariance with age (in 
months) and tobacco smoking (in pack-years) as covariates showed that there was a greater amphetamine-induced striatal dopamine release among the participants with SHI than among the healthy controls $\left(F_{1,34}=4.55, p=0.04\right)$. After amphetamine administration, the participants with SHI reported more changes in affect than the healthy controls, but not a greater increase in psychotic symptoms. Likewise, reports of social exclusion and increase in psychotic symptoms were not associated with dopamine release.

Conclusions and Relevance: Our study presents preliminary evidence of dopamine sensitization in a socially excluded group of people with hearing impairment. If replicated by future studies in other excluded groups, this finding may have major implications for our understanding of the underlying mechanism and for prevention of psychotic disorders.

\section{INTRODUCTION}

According to the social defeat hypothesis (Selten \& Cantor-Graae, 2005; Selten et al. 2013) longterm exposure to the experience of being excluded from the majority group may lead to increased activity and/or sensitization of the mesolimbic dopamine system and thereby increase the risk for schizophrenia. The hypothesis posits that social defeat is the common denominator of 5 major schizophrenia risk factors: urban upbringing (which is associated with a higher level of competition), migration, childhood trauma, low IQ, and drug abuse (Zammit et al. 2004; CantorGraae \& Selten, 2005; Krabbendam \& van Os, 2005; Varese et al. 2012). Animal studies provide evidence of this sensitization by showing that repeated episodes of social defeat lead to changes in mesolimbic dopamine release and in the behavioral reaction to amphetamine (Tidey \& Miczek, 1996; Burke et al. 2010). Hearing impairment is another risk factor for psychotic experiences (Stefanis et al. 2006; van der Werf et al. 2010) and psychotic disorders (David et al. 1995; Fors et al. 2013), of which social defeat could well be the underlying mechanism. However, other explanations for this association, such as brain abnormalities due to meningitis, a common cause of severe hearing impairment (SHI), are also possible (van der Werf et al. 2010).

Social position, psychotic symptoms, and dopamine function have not yet been jointly studied, although several studies have reported associations between 2 of the 3 . For example, a positron emission tomography study of healthy volunteers found a positive association between striatal dopamine $\mathrm{D}_{2 / 3}$ receptor availability and social status (Martinez et al. 2010). In addition, 2 recent meta-analyses confirmed that patients with schizophrenia show both elevated presynaptic dopamine activity (dopamine synthesis)

(Fusar-Poli \& Meyer-Lindenberg, 2013) and higher striatal dopamine $\mathrm{D}_{2 / 3}$ receptor availability compared with healthy controls, although there 
is no convincing evidence for the latter in medication-naive patients (Howes et al. 2012). Furthermore, patients with schizophrenia show more dexamphetamine-induced dopamine release in the striatum (Laruelle et al. 1996). The same has been shown (to a lesser extent) in patients with schizotypal personality disorder (Abi-Dargham et al. 2004) and healthy individuals with schizotypal traits (Woodward et al. 2010). Finally, a recent study reported elevated presynaptic striatal dopamine function in a population at ultra-high risk for the development of psychosis, and the dopamine synthesis capacity in that population was predictive for transition to a psychotic disorder (Howes et al. 2011).

The present imaging study is the first experimental investigation of the social defeat hypothesis with regard to humans. Our study compares dexamphetamine-induced dopamine release in 2 groups that are assumed to differ substantially in terms of social exclusion: young adults with SHI and normal-hearing healthy controls. Dopamine release was measured by use of single photon emission computed tomography (SPECT) with iodine 123-labeled iodobenzamide ([123I]iodobenzamide) as the dopamine $\mathrm{D}_{2 / 3}$ radiotracer. The following 4 hypotheses were tested: (1) participants with SHI report having more feelings of exclusion than do healthy controls; (2) the reduction in striatal [ $\left.{ }^{123} \mathrm{I}\right]$ iodobenzamide binding potential after the amphetamine challenge (representing endogenous dopamine release) is significantly larger in participants with SHI than in healthy controls; (3) participants with SHI show a stronger subjective (psychotic and affective) response to amphetamine than do healthy controls; and (4) dexamphetamine-induced dopamine release is positively associated with both self-reported social exclusion and dexamphetamine-induced psychotic experiences, regardless of group membership.

\section{METHODS}

\section{Participants}

The participants with SHI were recruited through local media advertising and from audiology services and patient organizations. Severe hearing impairment was diagnosed for participants having a Fletcher Index (ie, pure-tone audiometry threshold averaged over 500, 1000, 2000, and $4000 \mathrm{~Hz}$ in the best ear) of higher than $60 \mathrm{~dB}$ for at least three years. The participants with SHI were individually matched to normal-hearing healthy controls (with a Fletcher Index of $<20$ $\mathrm{dB}$ ) on sex, age ( \pm 2 years), and tobacco smoking (number of pack-years $<1$ or $\geq 1$ ) who were recruited via advertisements in the local media.

Inclusion criteria were (1) age between 18 and 30 years; (2) completed primary school, and (3) white skin color and Dutch descent. Exclusion criteria were applied to ensure a healthy population that could be scanned safely, with minimal confounding influences on the dopamine system. These exclusion criteria were: (1) past or present history of neurological disorder (e.g. epilepsy, meningitis, structural brain damage); (2) abnormal ECG; (3) past or present history of substance abuse, psychosis, bipolar disorder or ADHD; (4) current major depression or use of antidepressant medication; (5) past or present use of medication known to affect $\mathrm{D}_{2 / 3}$ receptor binding (including all antipsychotics and methylphenidate); (6) history of use of any illicit drug other than cannabis; (7) past year radiation exposure for research purposes; (8) family history (first-degree) of psychotic disorder; (9) positive urine drug screen prior to SPECT; and (10) for females, a positive urine pregnancy test or breast feeding. Additionally, individuals with SHI were excluded if they had attended a primary or secondary school in which they actively learned or used Dutch Sign Language, because being part of a signing deaf community could be protective against social exclusion (Fellinger et al. 2007). Control participants were excluded if they had 
any form of impairment that could lead to social exclusion (e.g. wheelchair user).

Before the scanning day, participants were interviewed using an adapted version of the Comprehensive Assessment of Symptoms and History (CASH) (Andreasen et al. 1992) by a trained psychologist to screen for the presence of a personal and family history of psychiatric disorders. Handedness was established using the Edinburgh Handedness Inventory. A physician took the person's medical history and performed a brief physical examination.

In control participants, hearing was tested with an AC40 audiometer (Interacoustics, Assens, Denmark) using an automated HughsonWestlake procedure. Participants with SHI were tested by an audiometrician at the audiology department of the Academic Medical Center of the University of Amsterdam. Unaided pure-tone perception measurements were acquired to calculate Fletcher Indices (FI), as well as free field speech-in-noise measurements with hearing aids to quantify impairment in daily life situations. In addition, participants with SHI were interviewed about the history of their hearing loss.

For SHI participants, a high-resolution $\mathrm{T}_{2}$ weighted Magnetic Resonance Imaging (MRI) scan was acquired to exclude major brain lesions or abnormalities. For 4 SHI participants with an implanted hearing device (1 Bone Anchored Hearing Aid, 3 Cochlear Implants) no MRI scan could be acquired, but their pre-operative medical history contained no indication of brain lesions. While placement of a cochlear implant requires surgery under anesthesia, brain lesions as a result of surgery are unlikely since the implant is placed in the mastoid and inner ear, and only interfaces with the auditory nerve in the cochlea (Hamerschmidt et al. 2013). Importantly, the pertinent participants did not report post-operative neurological complications.
Our study was approved by the local medical ethics committee of the Academic Medical Center, Amsterdam, the Netherlands. All participants provided written informed consent and received a remuneration of $€ 140$.

\section{Behavioral assessments}

Before the start of the SPECT session, all participants completed the Community Assessment of Psychic Experiences (CAPE) (Konings et al. 2006), a questionnaire to assess the lifetime presence of positive, negative and depressive symptoms associated with psychotic disorders. To measure the subjective experience of social exclusion, the participants completed the Social Comparison Scale (Allan \& Gilbert, 1995), the Social Defeat Scale (Gilbert \& Allan, 1998), and the UCLA Loneliness Scale (Russell, 1996).

\section{Measurement of Baseline $D_{2 / 3}$ Receptor Availability and Dopamine release}

On a single day, participants underwent two SPECT scans measuring the non-displaceable binding potential $\left(\mathrm{BP}_{\mathrm{ND}}\right)$ of $\left[{ }^{123} \mathrm{I}\right]$ iodobenzamide (Booij et al. 1997; Figee et al. 2014); the first scan was performed to quantify baseline $\mathrm{D}_{2 / 3}$ receptor availability, and the second scan was performed to quantify dopamine release after intravenous administration of dexamphetamine. A schematic overview of the procedure during the scanning day is presented in Figure 1.

Participants were asked to fast from midnight until the end of the second SPECT scan (no smoking, food, caffeine or alcohol). Participants were offered a small breakfast (1-4 slices of bread or equivalent) 3-4 hours before scanning. One day prior to the SPECT scans and on the day of imaging, participants were given potassium iodide to prevent free radioactive iodine from entering the thyroid. All participants received approximately $80 \mathrm{MBq}\left[{ }^{123} \mathrm{I}\right]$ iodobenzamide (specific activity $>200 \mathrm{MBq} / \mathrm{nmol}$; radiochemical purity $>95 \%$ ) as an intravenous bolus, followed 
Figure 1. Timeline of scanning day.

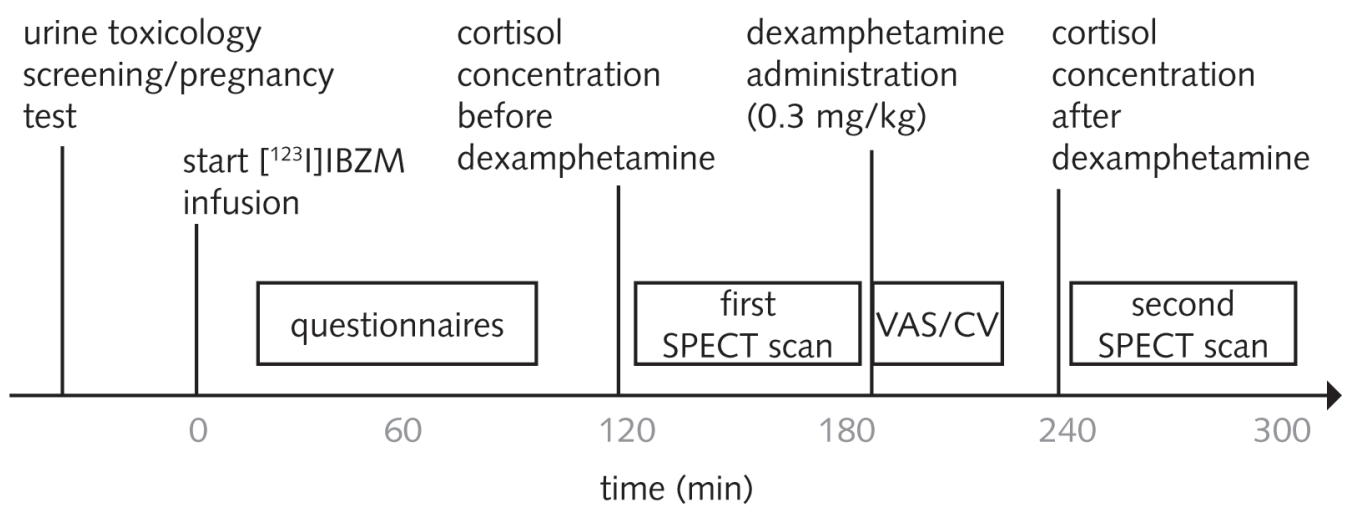

Time is represented on the $x$-axis and is relative to the start of iodine 123-labeled iodobenzamide ([123I]IBZM) infusion. SPECT indicates single photon emission computed tomography; $\mathrm{VAS} / \mathrm{CV}=$ Visual Analog Scale and cardiovascular measurements.

by continuous infusion of $20 \mathrm{MBq} /$ hour for the duration of the experiment (300 minutes). To induce a state of sustained binding equilibrium after 120 minutes, the bolus to hourly infusion ratio was approximately 4.0 (Booij et al. 1997). Scans were performed using a 12-detector single-slice brain-dedicated scanner (Neurofocus 810, Inc., Medfield, Massachusetts, USA) with a full-width at half maximum resolution of 6.5 $\mathrm{mm}$, throughout the $20 \mathrm{~cm}$ field-of-view. After positioning of the participants with the head parallel to the orbitomeatal line, axial slices parallel and upward from the orbitomeatal line to the vertex were acquired in 5-mm steps (300 sec scanning time per slice). The energy window was set at 135-190 keV. SPECT data were acquired for approximately 60 minutes per scan, starting from 120 minutes and 240 minutes after the initiation of [123I] iodobenzamide administration (Booij et al. 1997; Figee et al. 2014). Approximately 15 minutes after the first SPECT scan, dexamphetamine sulphate $(0.3 \mathrm{mg} / \mathrm{kg}$ body weight; Spruyt Hillen BV, IJsselstein, the
Netherlands) was administered intravenously over 2 minutes.

Attenuation correction of all images was performed as earlier described (Boot et al. 2010). Images were reconstructed in 3D mode. A SPECT template was computed from all scans (76 scans from 38 participants) with the Diffeomorphic Anatomical Registration using Exponentiated Lie Algebra (DARTEL) procedure in the Statistical Parametric Mapping 8 (SPM8) package running on Matlab for Windows (Mathworks, Natick, MA). Scans were normalized to the same space as the template by applying the individual flow fields generated in the DARTEL procedure. A region-of-interest (ROI) analysis was performed with a fixed ROI for the striatum (STR) generated from the SPECT template by selecting all voxels with signal intensities exceeding a threshold of half the peak value (Figure 2). The occipital cortex (OCC) was selected as a reference region to estimate the concentration of free and non-specifically bound [123I] iodobenzamide and drawn 
Figure 2. SPECT template with striatal region of interest.
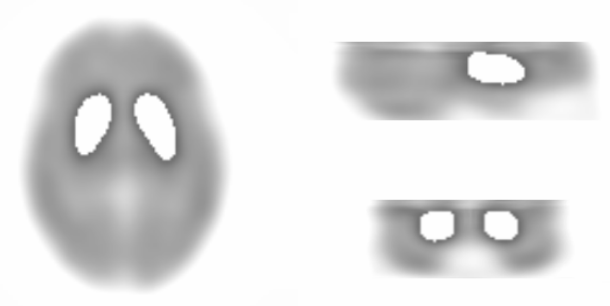

Transversal (left), sagittal (top right) and coronal (bottom right) cross sections of the DARTEL generated template of all 76 SPECT scans.

Superimposed in white: standard striatal region of interest generated by thresholding the template at 0.5 of the peak value.

manually on the SPECT template using itkSNAP software (version 2.1, PICSL, University of Pennsylvania). The non-displaceable binding potential $\left(\mathrm{BP}_{\mathrm{ND}}\right)$ was calculated as the ratio of specific to non-specific activity (Formula 1).

Formula 1: $\mathrm{BP}_{\mathrm{ND}}=\frac{\text { Activity }_{\mathrm{STR}}-\text { Activity }_{\mathrm{OCC}}}{\text { Activity }_{\mathrm{OCC}}}$

\section{Cortisol and cardiovascular response to amphetamine}

Saliva samples were requested for the measurement of dexamphetamine effects on cortisol. Blood pressure and heart rate were measured at baseline and every 2 minutes up to 22 minutes after the administration of dexamphetamine. See Figure 1 for a visual representation of the timing of measurements.

\section{Subjective Response to Amphetamine}

The affective response to amphetamine (Hypothesis 3) was monitored using a simplified four- item version of the Amphetamine Interview Rating Scale (Laruelle et al. 1996). Participants rated how good (euphoric), energetic, restless, and anxious they felt using a 0 - to $100-\mathrm{mm}$ Visual Analog Scale format at -2, 2, 6, 10, 14, 18, $22,35,55$, and 120 minutes after dexamphetamine administration.

The psychotic response to amphetamine (Hypotheses 3 and 4) was operationalized as the increase in positive symptoms on the CAPE-state questionnaire. Participants completed this questionnaire (Konings et al. 2006) twice, to assess the presence of these symptoms in the 2 hours before and the 2 hours the administration of dexamphetamine (Figure 1). The total CAPEstate score, including positive, negative, and depressive symptoms, was used as a measure of general symptomatic response to amphetamine.

\section{Statistical Analysis}

Group comparisons were performed with $\chi^{2}$-tests for categorical data and with Mann-Whitney $U$-tests for continuous data because non-normal distributions (right skewed) were observed for most questionnaires. Changes in $\mathrm{BP}_{\mathrm{ND}}\left(\Delta \mathrm{BP}_{\mathrm{ND}}\right.$ [ie, dopamine release]) for all participants and differences between groups over time were tested using repeated-measures multivariate analyses of covariance. Between-group differences in $\mathrm{BP}_{\mathrm{ND}}$ at baseline were tested with analysis of covariance. Non-parametric (Spearman rank) correlations were computed to explore the association between $\Delta \mathrm{BP}_{\mathrm{ND}}$ (percentage decrease from baseline) and measures of social defeat and psychotic symptoms. Repeated-measures analyses of variance, with the Greenhouse-Geisser correction for violation of sphericity, were used to assess possible differences in subjective responses to amphetamine.

Multivariate analyses of covariance and analysis of covariance included age (in months), and tobacco smoking (in pack-years) as continuous 
covariates because these factors were only approximately matched and are known to affect $\mathrm{D}_{2 / 3}$ receptor availability (Rinne et al. 1993; Fehr et al. 2008). Because an effect of inner-ear surgery on dopamine release cannot be excluded, a sensitivity analysis was conducted without the 3 participants with SHI who had a cochlear implant.

Repeated-measures analyses were performed using SPSS Statistics 21.0 for Windows (IBM Corp) and all other analyses were conducted with STATA 11.0 for Windows (StataCorp). The significance level for all analyses was set at two-tailed $\alpha=0.05$.

\section{RESULTS}

\section{Participants}

Scans were acquired for 19 participants with SHI and 19 healthy controls with normal hearing, forming a total of 19 matched SHI-control pairs. The mean (SD) level of hearing loss was 87 (17) $\mathrm{dB}$ for the SHI group and 9 (3) dB for the control group. Participants with SHI considered themselves deaf $(n=11)$, severely hearing impaired $(n=6)$ or moderately hearing impaired $(n=2)$ when not wearing hearing aids. When wearing hearing aids, they reported severe $(n=4)$, moderate $(n=10)$, slight $(n=4)$, or no $(n=1)$ hearing impairment. At the level of a loud conversation $(55 \mathrm{~dB})$ and using hearing aids, the mean (SD) percentage of syllables heard correctly by participants with SHI was 51\% (20\%). Participants with SHI and healthy controls did not differ in lifetime total CAPE scores $(U=156.5, z=-0.70$, $p=0.48$ ) or lifetime positive symptoms ( $U=140$, $z=-1.21, p=0.23)$. More healthy controls than participants with SHI had experimented with cannabis $\left(\chi_{1}^{2}=5.40, p=0.02\right)$, but only one of the controls and none of the participants with SHI reported a frequency of use ever exceeding once per month. Additional characteristics of the participants are given in Table 1.

\section{Indicators of Social Exclusion}

As expected for a group selected for social exclusion, the participants with SHI scored higher on the UCLA loneliness scale $(U=87.5, z=-2.72$, $p=<0.001)$ and the Social Defeat Scale $(U=109$, $z=-2.09, p=0.04)$. In addition, the participants with SHI scored lower on the Social Comparison Scale, comparing themselves less favorably to others than healthy controls, but the difference was not significant $(U=118, z=-1.83, p=0.07$ ) (Table 1).

\section{Baseline $D_{2 / 3}$ Receptor Availability}

The participants with SHI and the healthy controls did not significantly differ in baseline $\mathrm{BP}_{\mathrm{ND}}$, $F_{1,34}=3.38, p=0.08$ (Table 2). Age $\left(F_{1,34}=3.78\right.$, 
Table 1. Participant characteristics

\begin{tabular}{|c|c|c|c|c|c|}
\hline \multirow{2}{*}{$\begin{array}{l}\text { Characteristic } \\
\text { Age, mean (SD), y, mo }\end{array}$} & \multicolumn{2}{|c|}{$\begin{array}{l}\text { Healthy Controls } \\
\qquad(n=19)\end{array}$} & \multicolumn{2}{|c|}{$\begin{array}{l}\text { Participants with SHI } \\
\qquad(n=19)\end{array}$} & \multirow{2}{*}{$\begin{array}{c}P \text { Value }{ }^{1)} \\
0.71\end{array}$} \\
\hline & 25,10 & $(3,0)$ & 26,0 & $(3,0)$ & \\
\hline BMI, mean (SD) & 22.6 & $(2.0)$ & 24.1 & (3.4) & 0.12 \\
\hline \multicolumn{6}{|l|}{ Sex, No. of participants } \\
\hline Male & 3 & & 3 & & \\
\hline Female & 16 & & 16 & & \\
\hline \multicolumn{6}{|l|}{ Tobacco smoking status, No. of participants } \\
\hline Smoker & 4 & & 4 & & \\
\hline Nonsmoker & 15 & & 15 & & \\
\hline Cannabis use, No. of participants & & & & & 0.02 \\
\hline At least once & 15 & & 8 & & \\
\hline Never & 4 & & 11 & & \\
\hline Handedness, No. of participants & & & & & 0.20 \\
\hline Left & 2 & & 5 & & \\
\hline Right & 17 & & 14 & & \\
\hline Relationship status, No. of participants & & & & & 0.07 \\
\hline Living with partner & 8 & & 3 & & \\
\hline Without partner & 11 & & 16 & & \\
\hline Living with parents, No. of participants & & & & & 0.01 \\
\hline Yes & 0 & & 5 & & \\
\hline No & 19 & & 14 & & \\
\hline Education, No. of participants & & & & & 0.29 \\
\hline Higher professional or university & 18 & & 16 & & \\
\hline Intermediate or lower & 1 & & 3 & & \\
\hline \multicolumn{6}{|l|}{ Psychotic Experiences, mean (SD) score } \\
\hline CAPE Lifetime total & 13.3 & $(6.1)$ & 16.8 & (9.4) & 0.48 \\
\hline Positive & 2.3 & $(2.1)$ & 3.2 & (2.5) & 0.23 \\
\hline Negative & 6.2 & $(2.8)$ & 7.9 & (4.9) & 0.37 \\
\hline Depressive & 4.7 & $(1.8)$ & 5.7 & (3.3) & 0.45 \\
\hline \multicolumn{6}{|l|}{ Social Exclusion, mean (SD) score } \\
\hline Social defeat & 11.2 & $(6.7)$ & 16.3 & (8.1) & 0.04 \\
\hline Social comparison & 71.0 & $(13.1)$ & 63.8 & $(12.4)$ & 0.07 \\
\hline Loneliness & 39.6 & (8.1) & 47 & (7.1) & $<0.001$ \\
\hline
\end{tabular}

Abbreviations: BMI, body mass index (calculated as weight in kilograms divided by height in meters squared); CAPE, Community Assessment of Psychic Experiences; SHI, severe hearing impairment.

${ }^{1)}$ Determined by use of the $X^{2}$ test for categorical values and the Mann-Whitney $U$-test for continuous variables. 
Figure 3. Mean striatal nondisplaceable binding potential $\left(\mathrm{BP}_{\mathrm{ND}}\right)$ before and after administration of dexamphetamine sulfate.

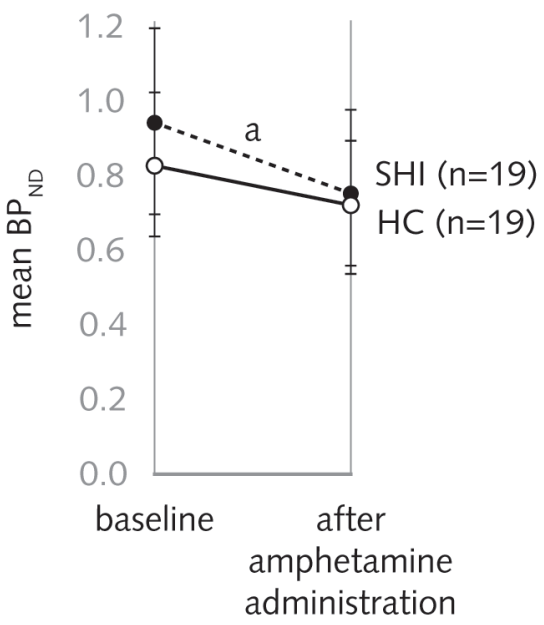

Mean striatal $\mathrm{BP}_{\mathrm{ND}}$ of [123!]iodobenzamide for normal-hearing healthy controls ( $\mathrm{HC}$, solid line) and participants with severe hearing impairment (SHI, dashed line), before and after the administration of dexamphetamine. Error bars represent SD. The mean (SD) percentage decrease in $\mathrm{BP}_{\mathrm{ND}}$ was $18.7 \%$ $(15.3 \%)$ for the SHI group and $10.5 \%$ (16.0\%) for the control group, which indicates a higher release of dopamine in the SHI group than in the control group.

aSignificant difference in slope (ie, dexamphetamineinduced dopamine release), in multivariate analysis with age and smoking as covariates. $p=0.04)$ was significantly related to baseline $\mathrm{BP}_{\mathrm{ND}}$, whereas smoking $F_{1,34}=1.55, p=0.22$ ) was not.

\section{Dexamphetamine-Induced Effects on $D_{2 / 3}$ Receptor Availability}

Being a smoker was significantly related to $\triangle \mathrm{BP}_{\mathrm{ND}}$ $\left(F_{1,34}=5.05, p=0.03\right)$, but age $\left(F_{1,34}=0.46, p=0.50\right)$ was not. There was a significant effect of SHI on $\triangle \mathrm{BP}_{\mathrm{ND}}$ after adjusting for age and tobacco smoking $\left(F_{1,34}=4.55, p=0.04\right.$, partial $\left.\eta^{2}=0.12\right)$. The mean (SD) percentage decrease in $\mathrm{BP}_{\mathrm{ND}}$ was $18.7 \%$ (15.3\%) for the SHI group and 10.5\% (16.0\%) for the control group, which indicates a higher release of dopamine in the SHI group than in the control group (Figure 3). When we repeated this analysis and excluded the participants with a cochlear implant, the effect of SHI on $\triangle \mathrm{BP}_{\mathrm{ND}}$ was very similar but no longer significant $\left(F_{1,31}=2.01, p=0.17\right)$, likely owing to reduced statistical power.

\section{Physiological response to amphetamine}

Table 2 shows that the administration of dexamphetamine led to increased salivary cortisol concentrations and an increase in blood pressure and heart rate in both groups. Repeated measures analyses of variance showed that there were no significant time-by-group interactions $\left(F_{1,34}=1.55, p=0.22 ; F_{1,36}<0.005, p=0.99 ; F_{1,36}=0.09\right.$, $p=0.76$, for the outcomes cortisol, heart rate, and systolic blood pressure respectively).

\section{Subjective response to amphetamine}

Changes in CAPE-state positive symptom scores after the administration of dexamphetamine did not differ between groups ( $U=168.5, z=-0.42$, $p=0.68)$. Total CAPE-state scores at baseline did not differ between groups ( $U=164, z=-0.49$, $p=0.62$ ), but after amphetamine administration total CAPE-state scores were higher in the SHI group than in the control group ( $U=113.5$, $z=-1.96, p=0.05)$. However, the changes in total CAPE-state scores following the administration of dexamphetamine were not significantly differ- 
Table 2. Effects of Dexamphetamine Administration on Striatal $D_{2 / 3}$ receptor availability and Physiological Measures and Subjective Experiences

\begin{tabular}{|c|c|c|c|c|c|}
\hline Measure & $\begin{array}{l}\text { Healthy } \\
\text { Controls } \\
(n=19)\end{array}$ & & $\begin{array}{r}\text { Participants } \\
\text { with SHI } \\
(n=19)\end{array}$ & & $P$ Value \\
\hline \multicolumn{6}{|l|}{ Striatal $D_{2 / 3}$ receptor availability, mean (SD) } \\
\hline Baseline $\mathrm{BP}_{\mathrm{ND}}$ & 0.82 & $(0.19)$ & 0.93 & $(0.25)$ & $0.12^{1}$ \\
\hline $\mathrm{BP}_{\mathrm{ND}}$ after amphetamine administration & 0.72 & $(0.17)$ & 0.74 & $(0.22)$ & $0.64^{1}$ \\
\hline \multicolumn{6}{|l|}{ Physiological measures, mean (SD) } \\
\hline \multicolumn{6}{|l|}{ Systolic BP, mm Hg } \\
\hline Baseline & 125 & (14) & 122 & $(12)$ & 0.561 \\
\hline$\Delta \max$ & 49 & (10) & 50 & $(12)$ & $0.76^{1}$ \\
\hline \multicolumn{6}{|l|}{ Diastolic BP, mm Hg } \\
\hline Baseline & 75 & (14) & 72 & (13) & $0.67^{1}$ \\
\hline$\Delta \max$ & 25 & (20) & 29 & (30) & $0.58^{1}$ \\
\hline \multicolumn{6}{|l|}{ Heart rate, beats/min } \\
\hline Baseline & 69 & (11) & 68 & (18) & $0.86^{1}$ \\
\hline$\Delta \max$ & 23 & (25) & 23 & (23) & $0.98^{1}$ \\
\hline \multicolumn{6}{|l|}{ Cortisol concentration, $\mu \mathrm{g} / \mathrm{dL}$} \\
\hline Baseline & 0.15 & $(0.07)$ & 0.10 & $(0.04)$ & $0.07^{2}$ \\
\hline After amphetamine administration & 0.32 & $(0.21)$ & 0.35 & $(0.18)$ & 0.392 \\
\hline \multicolumn{6}{|l|}{ Subjective experiences, mean (SD) } \\
\hline \multicolumn{6}{|l|}{ Total CAPE-state scores } \\
\hline Baseline & 4.60 & (3.58) & 6.22 & $(6.75)$ & $0.62^{2}$ \\
\hline After amphetamine administration & 3.52 & $(3.41)$ & 8.47 & $(8.72)$ & $0.05^{2}$ \\
\hline$\triangle$ Total CAPE-state & -1.07 & $(3.01)$ & 2.26 & $(10.74)$ & $0.20^{2}$ \\
\hline$\Delta$ Positive symptoms & 0.37 & $(1.46)$ & 1.05 & $(2.85)$ & $0.68^{2}$ \\
\hline$\Delta$ Negative symptoms & -1.60 & $(2.72)$ & -0.32 & $(6.46)$ & $0.41^{2}$ \\
\hline$\Delta$ Depressive symptoms & 0.16 & $(1.61)$ & 1.52 & $(3.20)$ & $0.20^{2}$ \\
\hline
\end{tabular}

Abbreviations: $\mathrm{BP}$, Blood Pressure; $\mathrm{BP}_{\mathrm{ND}}$, nondisplaceable binding potential;

CAPE-state, Community Assessment of Psychic Experiences-state version (refers to the preceding 2-hour interval); $\mathrm{SHI}$, severe hearing impairment; $\triangle$ max=maximum deviation from baseline across 9 measurements;

$\triangle$ Total CAPE-state=change in CAPE scores after amphetamine administration (also listed for the 3 subscales separately).

SI conversion factor: to convert cortisol to nanomoles per liter, multiply by 27.588

1) Determined by use of the $t$ test

2)Determined by use of the $U$ test 
Figure 4. Profile plots of the effects of dexamphetamine on affect.

$$
\bullet-\bullet \text { SHI } \mathrm{O} \longrightarrow \mathrm{HC}
$$
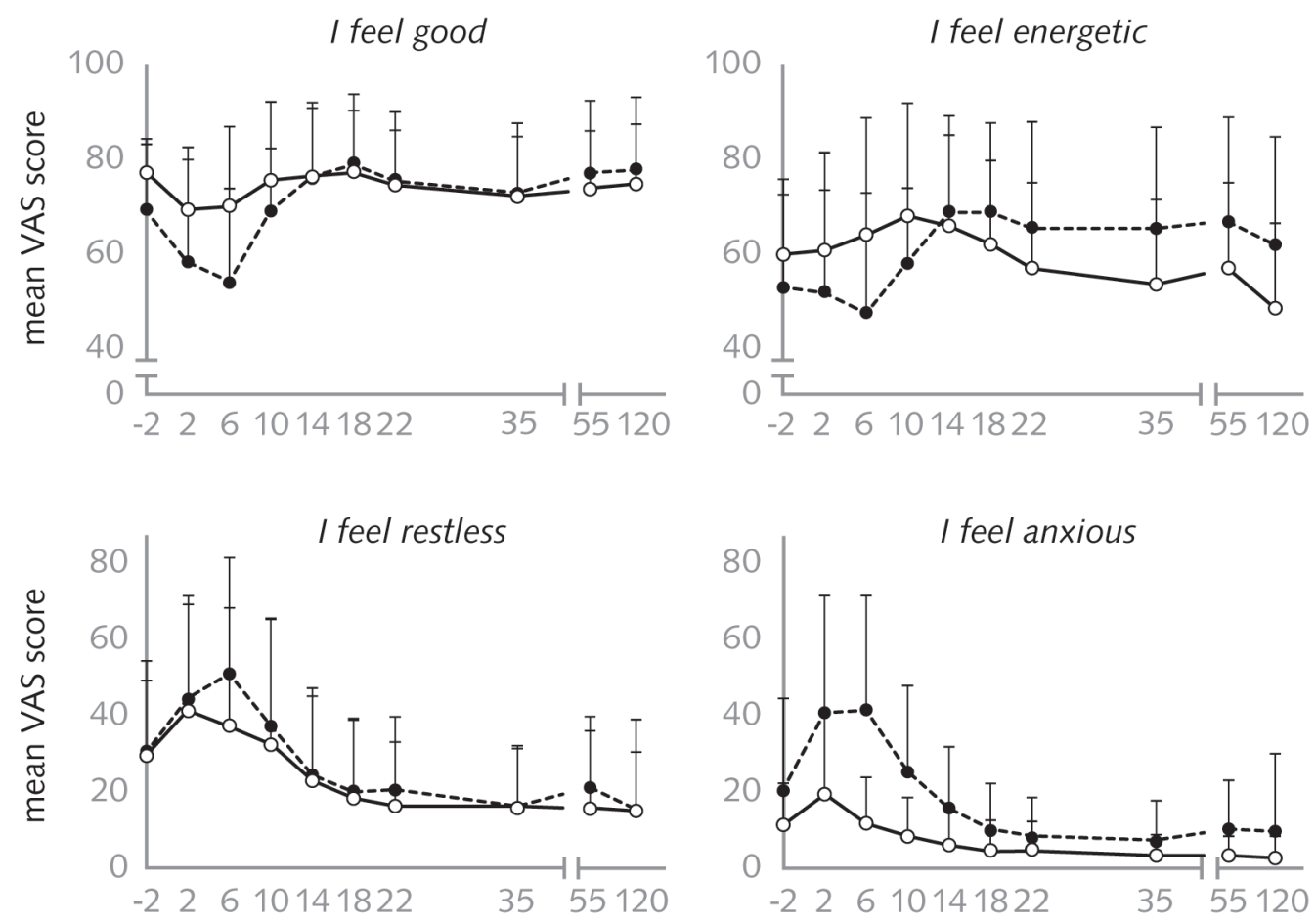

Mean Visual Analog Scale (VAS) scores for each of the 4 affect items (good, energetic, restless, anxious) across the 10 time points. Separate lines represent the participants with severe hearing impairment (SHI, dashed line) $(n=19)$ and the healthy controls (HC, solid line) $(n=19)$. Time is represented on the $x$-axis in minutes and relative to the start of dexamphetamine administration. Error bars represent SD. The first measurement was conducted before dexamphetamine administration, the second directly after. The 55-minute measurement was conducted immediately before the second single-photon emission computed tomography scan and the 120-minute measurement at the end of the experiment. 
ent between groups, probably owing to the large variation of change scores in the SHI group (Table 2).

The administration of dexamphetamine evoked a subjective response with significant time effects for all affective measures: (euphoria, $F_{4.45,142.32}=9.34, p<0.001$; energy, $F_{4.10,131.12}=2.90$, $p=0.02$; restlessness, $F_{4.70,150.43}=15.17, p<0.001$; anxiety, $\left.F_{3.85,123.14}=14.82, p<0.001\right)$. More importantly, there were significant group-bytime interactions for euphoria $\left(F_{4.45,142.32}=2.93\right.$, $p=0.02)$, energy $\left(F_{4.10,131.12}=4.17, p=0.003\right)$, and anxiety $\left(F_{3.85,123.14}=3.04, p=0.02\right)$, with a larger decrease in euphoria and energy and a greater increase in anxiety after administration of dexamphetamine in the SHI group compared with the control group (Figure 4).

\section{Associations between amphetamine-induced dopamine release and social exclusion or in- crease in positive symptoms}

There were no significant correlations between dopamine release and baseline measures of social defeat $(\rho=-0.19, p=0.27)$, social comparison ( $\rho=0.15, p=0.37)$, or loneliness $(\rho=-0.20, p=0.25)$. Also, dopamine release was not correlated with an increase in CAPE-state positive symptom scores $(\rho=-0.13, p=0.46)$.

\section{DISCUSSION}

Single-photon emission computed tomography was used to test whether the participants with SHI displayed increased dopaminergic activity and whether this increase was associated with measures of social exclusion and with amphetamine-induced positive (psychotic) symptoms. In accordance with our first three hypotheses, participants with SHI reported higher levels of social exclusion, displayed higher amphetamineinduced striatal dopamine release, and reported stronger affective responses to amphetamine. However, in contrast to our third hypothesis, participants with SHI did not report more amphetamine-induced positive symptoms, although they did show higher general symptom levels than did healthy controls after amphetamine exposure. Also, in contrast to the fourth hypothesis, dopamine release was not associated with subjective reports of social exclusion or increases in positive symptoms. Together, these results suggest that $\mathrm{SHI}$ is associated with a hypersensitive dopamine system. We cannot conclude whether or not social exclusion plays a causal role in the observed difference in dopamine functioning or in the previously observed increased risk for psychosis in people with hearing impairment.

To our knowledge, the present study is the first to suggest that the dopamine system in a group of socially excluded humans is sensitized. The results are in line with studies of rats, which showed dopamine alterations after being subjected to social defeat by a dominant animal (Tidey \& Miczek 1996; Burke et al. 2010), and a study of humans, which showed a relation between socioeconomic status and $\mathrm{D}_{2 / 3}$ receptor availability (Martinez et al. 2010).

Socioeconomic status, however, does not necessarily incorporate the experience of exclusion, which is central to the social defeat hypothesis. Positron emission tomography studies of 
humans using the Montreal Imaging Stress Task have shown that acute social stress causes a measurable release of dopamine (Pruessner et al. 2004) and that people at high risk for psychotic disorders display an increased release of dopamine compared with healthy controls (Mizrahi et al. 2012). The paradigm has not yet been applied to a socially excluded group such as people with SHI, yet Pruessner and colleagues (2004) have reported that a low level of maternal care during childhood is associated with a greater release of dopamine in response to the Montreal Imaging Stress Task. Such findings suggest that a pharmacological challenge and an experimental social stressor can represent different ways to measure dopaminergic sensitization, and they can achieve similar results.

In contrast to earlier studies (Laruelle et al. 1996; Thompson et al. 2013), we did not find any associations between dopamine release and changes in psychotic symptom scores. Previous studies using clinical interviews found such associations in patients, but importantly not in healthy controls. We selected the CAPE-state questionnaire because it is easy to use, and we expected it to be more sensitive to subtle symptomatic changes than a clinical interview (Konings et al. 2006). In retrospect, the short (2 hour) time window of structured activity, including one hour in a SPECT scanner, rendered a number of the CAPEstate positive symptom questions less relevant, for example: "In the past two hours, have you ever felt as if magazines or television programs contain messages that are directed especially at you?". The relatively low sensitivity to change of the CAPE-state positive symptom questions may be illustrated by the fact that 13 of the 19 healthy controls and 12 of the 19 participants with SHI had a positive symptom change score of 0 . Moreover, it is known that responses to dexamphetamine among patients with schizophrenia are quite heterogeneous: for some patients, positive symptoms worsen, whereas for other patients, these symptoms improve (Laruelle et al. 1996). The large variation in CAPE-state change scores in the SHI group supports this observation.

Our study shows group differences in the amphetamine effects on affect. On average, the SHI group displayed a greater adverse reaction to amphetamine. In contrast to earlier studies (Laruelle et al. 1996; Drevets et al. 2001) showing mainly euphoric effects, we observed a decrease in positive affect and an increase in negative affect after amphetamine administration. Two explanations may be brought to bear on this finding. First, although a subgroup of participants may have experienced the pleasurable effects of amphetamine, we found that, by using mean Visual Analog Scale scores ceiling and floor effects reduced the weight of those observations. Second, the current sample was entirely naive to illicit drugs and did not know what to expect and may have been overwhelmed by the effects of amphetamine.

The present study has both strengths and limitations. The most important strengths are the objective measurement of hearing impairment and the attention paid to potentially confounding factors (age, educational level, medication, neurological disorders, and brain abnormalities). The primary limitation is that that we could not directly measure the risk of psychosis in this sample, but epidemiological studies (David et al. 1995; Stefanis et al. 2006; van der Werf et al. 2010; Fors et al. 2013), which generally also include milder forms of hearing impairment, show that this risk is moderately elevated for individuals with SHI. However, in contrast to our expectation, the participants with SHI did not report a greater lifetime prevalence of psychotic symptoms or a greater increase in psychotic symptoms following the dexamphetamine challenge than normal-hearing healthy controls. Two factors could explain these unexpected findings. First, selection bias may have occurred, 
because people with hearing impairment who volunteer to come to the hospital and to get injected with a radiotracer and amphetamine are generally high functioning individuals and probably do not represent a more anxious and avoidant subpopulation that may present with more psychotic symptoms. The exclusion of people with first-degree family members with psychosis may have contributed to this selection bias. Second, the average age in our sample was 26 years, which made it unlikely that participants were still at a high risk for a first psychotic episode.

The second limitation is the relatively small sample size in our study. While differences in dopamine release between the 2 non-psychotic groups in this study were smaller than those found in studies comparing patients with schizophrenia and controls, this sample size sufficed to detect them. Furthermore, the restrictiveness of our criteria eliminated a number of important confounders and allows the results to be interpreted with confidence. However, to detect associations between clinical measures and dopamine release, a larger sample size would be required.

The third limitation is that despite the relatively high spatial resolution of our SPECT scans, reliable differentiation of striatal subregions was not feasible. With positron emission tomography tracers, better topographical categorization can be obtained (Martinez et al. 2003), and a recent study of patients with schizophrenia (Kegeles et al. 2010) suggests effects on dopamine $D_{2 / 3}$ receptor availability specific to the associative rather than the limbic (ventral) or sensorimotor striatum. However, the whole-striatum analysis in our study was fully automated and did not involve drawing individual regions of interest. Even while heterogeneous effects in different striatal subdivisions were averaged, a reliable and robust result was obtained, albeit with sizeable variability.
The fourth limitation is the possible effect of surgery on the 3 patients with a cochlear implant. When these patients were removed from the analysis, the difference in dopamine release between participants with SHI and healthy controls remained very similar, but it was no longer significant, possibly owing to a reduction in statistical power. This reduction may well be sizeable because the participant with a cochlear implant have greater hearing loss and reported higher levels of social exclusion than did the other participants in the SHI group.

The fifth and final limitation is that plasma concentrations of dexamphetamine were not measured in our study. We did, however, observe a consistent and strong cardiovascular response and a sharp increase in salivary cortisol concentrations, which implies that the administered dose was effective.

\section{Conclusions}

In conclusion, compared with normal-hearing healthy controls, the participants with SHI experienced a higher level of social exclusion and showed increased striatal dopamine release and a greater affective response to dexamphetamine administration. However, social exclusion scores and changes in psychotic symptoms were not associated with dopamine release. Overall, these findings suggest that individuals with SHI, a group at increased risk for psychosis, have a sensitized dopamine system. Replication of our study, using a larger sample and/or another socially excluded population at increased risk for psychotic disorders (eg, a stigmatized ethnic minority group), is needed to draw definitive conclusions. 


\section{Chapter 05: Psychotic reactions to daily life stress and dopamine function in people with severe hearing impairment}

Martin Gevonden

Inez Myin-Germeys

Wim van den Brink

Jim van Os

Jean-Paul Selten

Jan Booij

Psychological medicine, 2015. 45: 1665-1674.

This work was supported by a grant from the Stichting J.M.C.

Kapteinfonds to JPS; and supported by the European Community's Seventh Framework Program under grant agreement No.

HEALTH-F2-2009-241909 (Project EU-GEI). 


\section{ABST RACT}

Background: Minor stresses measured in daily life have repeatedly been associated with increased momentary psychotic experiences, both in individuals with psychotic disorders and in persons who are genetically at an increased risk for these disorders. Severe hearing impairment (SHI) is an environmental risk factor for psychotic disorder, possibly due to the experience of social exclusion. The aim of the current study is to investigate whether people with SHI exhibit higher levels of psychotic reactivity to social stressors in daily life than normal hearing controls and whether this reactivity is associated with decreased baseline dopamine (DA) $\mathrm{D}_{2 / 3}$ receptor availability and/or elevated DA release following a dexamphetamine challenge.

Methods: Experience sampling study in 15 young adults with SHI and 19 matched normal hearing controls who had previously participated in a Single Photon Emission Computed Tomography (SPECT) study measuring $\mathrm{DA}_{2 / 3}$ receptor availability and DA release in response to dexamphetamine.

Results: The association between social stress and momentary psychotic experiences in daily life was stronger among SHI participants than among normal hearing controls. Interactions between social stress and baseline striatal $\mathrm{DA} \mathrm{D}_{2 / 3}$ receptor availability or DA release were not significant in multilevel models of momentary psychotic experiences including age, sex and tobacco use.

Conclusions: While both elevated striatal DA release and elevated psychotic stress reactivity have been found in the same population defined by an environmental risk factor, SHI, their interrelation cannot be established. Further research is warranted to clarify the association between biological and psychological endophenotypes and psychosis risk.

\section{INTRODUCTION}

Hearing impairment (HI) is highly prevalent, it affects approximately $10 \%$ of the population (Stevens et al. 2013) making it the most common sensory deficit worldwide (Mathers et al. 2008). $\mathrm{HI}$ is strongly associated with mental health problems (Fellinger et al. 2007) and projected to enter the top ten in burden of disease in the coming decade (Mathers \& Loncar, 2006). People with HI more often have psychotic experiences (Stefanis et al. 2006; van der Werf et al. 2007, 2011) and more often develop psychotic disorders (Cooper 1976; David et al. 1995; Fors et al. 2013). The aetiology and pathogenesis of this increased psychosis risk are uncertain, but evidence suggests that chronic social exclusion may be an important element of aetiology (Selten \& Cantor-Graae, 2007; Selten et al. 2013). As far as pathogenesis is concerned, an environmental risk factor such as HI may induce, through a process of 'sensitization', elevated dopamine neurotransmission and/or cognitive biases facilitating the onset of psychotic symptoms (Collip et al. 2008).

Cognitive biases relevant to $\mathrm{HI}$ may consist of altered perceptions and responses in social situations, where people with hearing loss face more uncertainty than their normal hearing peers. To identify the speaker and understand a degraded speech signal through visual and contextual inference requires great cognitive effort and includes the possibility of miscommunication, which is likely to cause stress. Minor stresses, including social stress, measured in daily life have repeatedly been associated with increases in momentary psychotic experiences (MPE), both in individuals with psychotic disorders and in persons who are genetically at an increased risk for such disorders (Myin-Germeys et al. 2001, 2005a). Increased levels of such stress reactivity may represent a vulnerability marker for psychotic disorder, with again elevated mesolimbic dopamine neurotransmission as a possible underlying mechanism (Myin-Germeys \& van Os, 2007). 
This hypothesis has not yet been tested in persons who are at increased risk for psychosis due to an environmental risk factor. Social stress is of particular interest in relation to mesolimbic dopamine and psychosis since several experimental studies report increased striatal dopamine release in response to social stress in patients with schizophrenia and groups at clinical high risk (Soliman et al. 2008; Mizrahi et al. 2012). A similar association was found between daily life stress measures and plasma elevations of homovanillic acid, a proxy measure of dopaminergic reactivity, in individuals genetically at a high risk for schizophrenia, but not in controls (Myin-Germeys et al. 2005b). Recently, we showed greater striatal dopamine release in response to an amphetamine challenge in individuals with SHI compared to normal hearing peers (Gevonden et al. 2014a).

The aim of the current study is to examine whether individuals with SHI are sensitized to daily life social stress and whether elevated striatal dopamine neurotransmission underlies this sensitization. It was predicted that (i) individuals with SHI react with more momentary psychotic experiences to social stress in daily life than normal hearing controls and (ii) that such reactivity to social stress is associated with decreased baseline dopamine $\mathrm{D}_{2 / 3}$ receptor availability and/or elevated amphetamine-induced dopamine release. Since affective dysregulation may contribute to the pathogenesis of psychotic symptoms (Myin-Germeys \& van Os, 2007; Lataster et al. 2013), it was also predicted (iii) that individuals with SHI react with more negative affect to social stressors than normal hearing controls.

\section{METHODS}

\section{Participants}

The sample consisted of young adults with SHI and normal hearing - healthy controls, who had previously participated in a single photon emission computed tomography (SPECT) study (numbered NL24257.018.08) at the Academic Medical Centre in Amsterdam. They had originally been recruited through local media, audiology services and patient organizations and had agreed to be contacted for further research. A total of 15 of the 19 participants with SHI and 18 of the 19 controls from the imaging study (Gevonden et al. 2014a) could be included in the experience sampling method (ESM) study. Reasons for not participating in the ESM study were lack of time or motivation. One control participant who was not included in the analysis of the imaging study because of technical problems did participate in the current ESM study. The interval between the measurement of dopamine release following the dexamphetamine challenge and the measurement of stress reactivity in the ESM study ranged from 1 day to 2 years (median $=143$ days; interquartile range $=375$ days). This time interval between SPECT and ESM assessment did not differ between groups (mean $\mathrm{SHI}=189$ days; mean control=183 days; $t(32)=-0.094 ; p=0.93)$.

SHI was defined as having a Fletcher Index (FI) $>60 \mathrm{~dB}$, i.e., an average pure-tone audiometry threshold over 500, 1000, 2000, and $4000 \mathrm{~Hz}$ in the best ear $>60 \mathrm{~dB}$ for at least three years and normal hearing was defined as FI $<20 \mathrm{~dB}$. Other inclusion criteria for the SPECT study were: (1) age between 18 to 30 years old; (2) completed primary school; (3) born in the Netherlands to parents born in the Netherlands; and (4) white skin colour. Exclusion criteria were: (1) past or present history of neurological disorder (e.g. epilepsy, meningitis, structural brain damage); (2) abnormal electrocardiogram; (3) past or present history of substance abuse, 
psychosis, bipolar disorder or ADHD; (4) current major depression or use of antidepressant medication; (5) past or present use of medication known to affect dopamine $\mathrm{D}_{2 / 3}$ receptor binding (including all antipsychotics and methylphenidate); (6) history of use of any illicit drug other than cannabis; (7) past year radiation exposure for research purposes; (8) family history (first-degree) of psychotic disorder; (9) positive urine drug screen prior to SPECT imaging; and (10) for females, a positive urine pregnancy test or breast feeding. Additionally, individuals with SHI were excluded if they had attended a primary or secondary school in which they actively learned or used Dutch Sign Language, because being part of a signing deaf community could be protective against social exclusion (Fellinger et al. 2007). Control participants were excluded if they had any form of impairment that could lead to social exclusion (e.g., wheelchair user).

The study was approved by the local medical ethics committee of the Maastricht University Medical Center. All participants gave written informed consent and received a remuneration of $€ 50$,-. The study protocol was registered prior to inclusion of the first participant in the Dutch Trial Registry under number NTR2973.

\section{Measures of intelligence, perceived}

\section{discrimination and social exclusion}

General intelligence was estimated using a short version of the Wechsler Adult Intelligence Scale (Velthorst et al. 2013) and verbal intelligence using the Dutch version of the National Adult Reading Test (Schmand et al. 1991). Perceived discrimination was measured by asking participants if they had ever experienced discrimination in any of 12 different domains, including education, the job market and health care and counting the number of domains in which participants responded 'yes'. At the time of the SPECT study (Gevonden et al. 2014a), social exclusion was further measured with the Social Comparison
Scale (Allan \& Gilbert, 1995), where lower scores mean that participants compare themselves less favourable to others, as well as with the Social Defeat Scale (Gilbert \& Allan, 1998), and the UCLA Loneliness Scale (Russell, 1996), where higher scores indicate more feelings of defeat and loneliness.

\section{SPECT acquisition and analysis}

To measure baseline dopamine $\mathrm{D}_{2 / 3}$ receptor availability and the degree of amphetamineinduced dopamine release, participants underwent two [123I]IBZM (iodobenzamide) SPECT scans on the same day: the first before and the second after intravenous administration of dexamphetamine. Scans were made on a brain-dedicated scanner (Neurofocus 810, Inc., Medfield, Massachusetts, USA) using a bolus/continuous infusion paradigm (Booij et al. 1997). A region-of-interest (ROI) analysis was performed with a fixed ROI for the striatum and the occipital cortex as a reference region. The non-displaceable binding potential $\left(\mathrm{BP}_{\mathrm{ND}}\right)$ was calculated at baseline and after amphetamine administration as the ratio of specific to free and non-specific binding. Dopamine release was then quantified as the percentage change in $\mathrm{BP}_{\mathrm{ND}}$ from baseline. For full details of the scanning procedure and image analysis see (Gevonden et al. 2014a).

\section{Experience Sampling Method (ESM)}

Participants received an e-diary, the PsyMate, which was programmed to emit a beep-signal and vibrate at random moments in each of ten 90-min time blocks between 7.30 am and 10.30 pm on eight consecutive days (Myin-Germeys et al. 2009; Palmier-Claus et al. 2011). Participants were instructed to carry the PsyMate on their body at all times so the signal could be felt as well as heard. Many SHI participants were already accustomed to carrying their personal smartphone in this manner to attend to text messages, so bias due to not noticing the signal is expected to be minimal. The semi-random beep-design 
prevents anticipatory behaviour of participants, and ensures that the full time window between $7.30 \mathrm{am}$ and $10.30 \mathrm{pm}$ is covered for sampling of experience. After each beep, participants were asked to start the self-assessment promptly, thus collecting reports on the current context (activity, social context, location), appraisals of their current situation and affect and the presence of psychotic symptoms. Appraisals were measured with 7 point Likert scales. After 15 min the signal expired and participants could no longer start the assessment, as earlier work has shown that after this interval reports are less reliable and consequently less valid (Delespaul, 1995). To ensure a representative sample of daily life at least 27 valid reports (out of 80 ) were required for a participant to be included in the analyses. No participants were excluded for this reason. For each subset of ESM items that was used as a scale, Cronbach's alpha was computed and a coefficient $>0.7$ was considered to reflect good internal consistency.

Social stress was measured only on beeps when the respondent indicated that (s)he was in the company of others using the ESM items "I like the present company" (reverse-coded so that higher scores mean less pleasant company) and "I would rather be alone" (Cronbach's alpha: 0.74) (Myin-Germeys et al. 2001).

As in earlier work (Myin-Germeys et al. 2005b), a scale representing momentary psychotic experiences was constructed from the mean score of eight ESM items: "I feel suspicious", "My thoughts are difficult to express", "I can't let go of my thoughts", "My thoughts are influenced by other people", "I feel unreal", "I see things that aren't really there", "I hear voices", "I am afraid of losing control” (Cronbach’s alpha: 0.73).

A "negative affect" (NA) scale was constructed based on the mean score of the mood items "down", "guilty", "insecure", "lonely" and "anxious"
(Cronbach's alpha: 0.79) (Myin-Germeys et al. 2001).

\section{Statistical analyses}

All analyses were carried out in Stata12 for Windows with the significance level set at 0.05 (two-tailed). ESM data have a hierarchical structure with multiple observations (Level 1) nested within individuals (Level 2) (Schwartz \& Stone, 1998). Given that hierarchical clustering induces violation of the assumption of independence of observations, standard errors were corrected for clustering of observations within persons by applying multilevel random regression models (Goldstein, 2005).

Data were analysed using the XTMIXED multilevel linear regression routine. To account for possible bias inflating the Type 1 error rate, models included a random intercept and random slope at the beep level and were assumed to have an unstructured covariance matrix.

To study the effect of hearing impairment on reactivity to social stress two separate regression models were tested with momentary psychotic experiences and negative affect as the respective dependent variables and the interaction between group (SHI vs. control) and social stress as the comparison of interest.

The relationship between striatal dopamine neurotransmission and reactivity to social stress was again studied with MPE and NA as dependent variables. Each was tested in two separate models, one with the interaction between social stress and dopamine receptor availability $\left(\mathrm{BP}_{\mathrm{ND}}\right)$ and one with the interaction between social stress and dexamphetamine-induced dopamine release $\left(\triangle \mathrm{BP}_{\mathrm{ND}}\right)$. Age, sex and smoking status were included as person-level covariates as they are known to affect dopamine $\mathrm{D}_{2 / 3}$ receptor availability (Rinne et al. 1993; Pohjalainen et al. 1998; Fehr et al. 2008). 
Group comparisons for background variables were performed with $\chi^{2}$-tests for categorical data and t-tests for continuous data. To compare the group averages of ESM variables an individual mean was first calculated over all reports; these values were then aggregated to obtain the group mean and SD.

\section{Sensitivity analysis}

The distribution of momentary psychotic experiences in a healthy sample is generally strongly skewed. This was confirmed for the current sample by visual inspection of the data and therefore sensitivity analyses were conducted using the XTMELOGIT routine, with MPE dichotomised as 'no current psychotic experience' [score 1 on the continuous MPE scale; 1089 observations (55\%)] and 'at least one current psychotic experience' [score $>1$ on the continuous MPE scale; 883 observations (45\%)].

For further insight in the nature of the interaction effects in the analysis, odds ratios (OR) for the presence of psychotic experiences given a situation of social stress were computed using the LINCOM routine. For this analysis, a social stress situation was defined as any situation where the social stress score exceeded the individual median.

\section{RESULTS}

\section{Sample characteristics}

The data of one participant could not be analysed due to technical problems with the e-diary. The final sample thus included 34 participants: 15 (44\%) people with SHI and 19 (56\%) controls with normal hearing, who completed a total of 1972 valid ESM observations (mean $\pm \mathrm{SD}=58.00 \pm 9.48$ ). The groups did not differ in mean number of ESM reports (SHI group: 58.20 \pm 7.26 ; control group: $57.84 \pm 11.12 ; t(32)=0.11, p=0.91)$. Average hearing loss in the best ear was $9 \pm 3 \mathrm{~dB}$ in the control group and $88 \pm 16 \mathrm{~dB}$ in the SHI group. There were no differences between groups in education level or general intelligence, but the control group scored marginally better on the verbal IQ test. There was a significant difference in perceived discrimination between groups $\left(\chi^{2}(2)=10.90, p=.004\right)$. Half of the SHI participants reported experiencing discrimination in multiple domains, whereas this applied to only one control participant. SHI participants had lower scores on the Social Comparison Scale (Allan \& Gilbert, 1995), and higher scores on the Social Defeat Scale (Gilbert \& Allan, 1998), and the UCLA Loneliness Scale (Russell, 1996). This confirms that the SHI group experiences more social exclusion than the control group. Group means and standard deviations for background variables and ESM variables are summarized in Table 1.

\section{Social stress}

In 1234 observations (63\%) the respondent was not alone. Control participants gave more responses in the presence of others $(70 \pm 13 \%)$ than SHI participants $(55 \pm 19 \%)(t(32)=2.72$, $p=0.01$ ), but levels of social stress did not differ between SHI participants and controls (Table 1).

\section{Stress reactivity}

Mean levels of MPE and NA were higher in the SHI compared to the control group (Table 1). In order to test for the presence of group differences 
Table 1. Participant characteristics

\begin{tabular}{|c|c|c|c|c|c|c|}
\hline & Control $(n=19)$ & $\sigma$ & $\begin{array}{c}\text { Severe Hearing } \\
\text { Impairment }(n=15)\end{array}$ & $\sigma$ & test statistic & $p$ \\
\hline \multicolumn{7}{|l|}{ DEMOGRAPHICS } \\
\hline Age, years, months & $25 y 8 m$ & $(2 \mathrm{y} 11 \mathrm{~m})$ & $26 y 5 m$ & $(2 \mathrm{y} 11 \mathrm{~m})$ & $t(31)=-0.68$ & 0.502 \\
\hline Sex, $n(\%)$ & & & & & $X^{2}(1)=0.10$ & 0.749 \\
\hline male & $3(19)$ & & $3(20)$ & & & \\
\hline female & $16(81)$ & & $12(80)$ & & & \\
\hline Smoker, n (\%) & & & & & $X^{2}(1)=0.10$ & 0.749 \\
\hline smoker & $3(19)$ & & $3(20)$ & & & \\
\hline non-smoker & $16(81)$ & & $12(80)$ & & & \\
\hline Education, n (\%) & & & & & $X^{2}(1)=0.68$ & 0.410 \\
\hline higher & $18(95)$ & & $13(87)$ & & & \\
\hline mid or lower & $1(5)$ & & $2(13)$ & & & \\
\hline Discrimination, $\mathrm{n}(\%)$ & & & & & $X^{2}(2)=10.90$ & 0.004 \\
\hline none & $8(44)$ & & $4(29)$ & & & \\
\hline one domain & $9(50)$ & & $2(14)$ & & & \\
\hline $\begin{array}{l}\text { two domains } \\
\text { or more }\end{array}$ & $1(6)$ & & $8(56)$ & & & \\
\hline IQ & 110.83 & $(17.60)$ & 106.07 & $(16.16)$ & $t(31)=0.80$ & 0.428 \\
\hline VIQ & 105.72 & $(6.92)$ & 100.85 & (6.04) & $t(30)=2.08$ & 0.046 \\
\hline \multicolumn{7}{|l|}{ SOCIAL EXCLUSION } \\
\hline Social defeat & 10.89 & $(6.84)$ & 16.47 & (7.39) & $t(32)=-2.28$ & 0.030 \\
\hline Social comparison & 72.79 & (13.19) & 63.33 & $(12.16)$ & $t(32)=2.14$ & 0.040 \\
\hline Loneliness & 39.37 & (8.39) & 47.53 & $(7.17)$ & $t(32)=-3.00$ & 0.005 \\
\hline \multicolumn{7}{|l|}{ ESM $^{2}$} \\
\hline NA & 1.51 & $(0.40)$ & 1.98 & $(0.68)$ & $t(32)=-2.50$ & 0.018 \\
\hline MPE & 1.13 & (0.15) & 1.38 & (0.39) & $t(32)=-2.61$ & 0.014 \\
\hline Social Stress & 2.23 & (0.64) & 2.28 & $(0.76)$ & $t(32)=-0.20$ & 0.842 \\
\hline $\begin{array}{l}\text { STRIATAL } D_{2 / 3} \text { RECEP- } \\
\text { TOR AVAILABILITY }\end{array}$ & $\mathrm{n}=18$ & & $n=15$ & & & \\
\hline $\mathrm{BP}_{\mathrm{ND}}$ & 0.81 & (0.19) & 0.92 & $(0.21)$ & $t(31)=-1.64$ & 0.112 \\
\hline$\Delta \mathrm{BP}_{\mathrm{ND}}$ & -9.62 & (15.96) & -21.60 & $(14.45)$ & $t(31)=2.24$ & 0.032 \\
\hline
\end{tabular}

Data are given as mean (standard deviation) unless otherwise indicated.

1)For the daily life, experience sampling variables, which included multiple observations over time from each participant, an individual mean was first calculated over all reports; these values were then aggregated to obtain the group mean and SD.

$\mathrm{IQ}$ = Intelligence Quotient; $\mathrm{VIQ}=$ Verbal Intelligence Quotient; ESM=Experience Sampling Method; $\mathrm{NA}=$ Negative Affect; $M P E=$ Momentary Psychotic Experiences; $\mathrm{BP}_{\mathrm{ND}}=$ non-displaceable binding potential; $\triangle B P_{N D}=$ percentage change in $\mathrm{BP}_{\mathrm{ND}}$ after dexamphetamine administration. 
Table 2: Main and interaction effects of group and social stress on negative affect and momentary psychotic experiences

B

$95 \% \mathrm{Cl}$

SE

Z

$p$

Negative affect

\begin{tabular}{|c|c|c|c|c|c|c|c|}
\hline Group & 0.150 & -0.095 & to & 0.395 & 0.125 & 1.20 & 0.231 \\
\hline Social stress & 0.143 & 0.073 & to & 0.214 & 0.362 & 3.97 & $<0.001$ \\
\hline Group * social stress & 0.081 & -0.029 & to & 0.190 & 0.056 & 1.44 & 0.149 \\
\hline \multicolumn{8}{|c|}{ Momentary Psychotic Experiences } \\
\hline Group & 0.118 & 0.013 & to & 0.223 & 0.054 & 2.21 & 0.027 \\
\hline Social stress & 0.015 & -0.010 & to & 0.040 & 0.013 & 1.16 & 0.245 \\
\hline Group * social stress & 0.043 & 0.004 & to & 0.081 & 0.020 & 2.16 & 0.030 \\
\hline
\end{tabular}

Multilevel linear regression results for the main effects of stress and group and the interaction effect of social stress * group (severe hearing impairment vs. control) on negative affect and momentary psychotic experiences ( $n=34 ; 1234$ beeps).

$\mathrm{B}$, standardized regression coefficient; $\mathrm{Cl}$, Confidence Interval; SE, Standard Error.

in stress reactivity, the interaction effects between group (SHI vs. control) and social stress on MPE and NA were examined. The interaction between group and social stress was not significant in the model of NA, but it was significant in the model of MPE: SHI participants showed a stronger positive association between social stress and MPE than normal hearing controls (Table 2).

\section{Dopamine measures and stress reactivity}

When adjusting for age, sex and smoking, the interaction between social stress and $\mathrm{BP}_{\mathrm{ND}}$ was not associated with MPE ( $\mathrm{B}=0.01,95 \% \mathrm{CI}-0.095$ to $0.116, p=0.84)$ or NA ( $\mathrm{B}=0.17,95 \% \mathrm{CI}-0.106$ to $0.445, p=0.23$ ). Likewise, the interaction between social stress and $\triangle \mathrm{BP}_{\mathrm{ND}}$ was not associated with MPE $(\mathrm{B}<0.001,95 \% \mathrm{CI}-0.001$ to 0.001 , $p=0.90)$ or $\mathrm{NA}(\mathrm{B}<0.001,95 \% \mathrm{CI}-0.003$ to $-0.004, p=0.71)$. These analyses were repeated with the interval in days between SPECT and ESM as an additional covariate, but the results remained essentially unchanged.

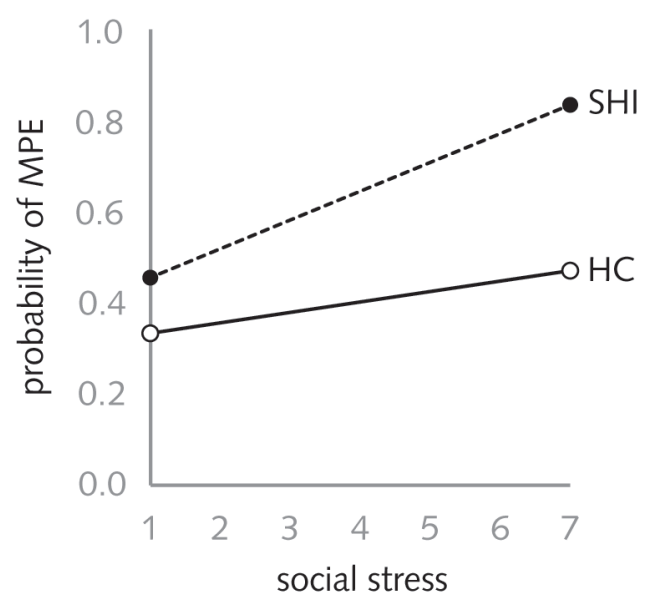

Figure 1. Probability of momentary psychotic experiences (MPE, dichotomous) as predicted by social stress rating, stratified by group: Healthy controls $(\mathrm{HC})$ and severe hearing impairment (SHI). 


\section{Sensitivity analysis}

In $43 \%$ of the 1,234 situations (beeps) where the respondent was not alone, at least one MPE was present according to the dichotomized measure. Using this alternative outcome measure, the interaction between group and social stress was not significant $(\mathrm{B}=0.35,95 \% \mathrm{CI}-0.036$ to 0.731 , $p=0.08$ ). Figure 1 illustrates that when social stress ratings increase, the probability of the occurrence of at least one psychotic experience increases more in the SHI than in the control group.

Using a within-person median split to dichotomize social stress, and computing the odds for any psychotic experience for low versus high social stress revealed that the OR was 1.80 (95\% CI 1.12-2.90) in the control group and 2.81 (95\% CI 1.48-5.32) in the SHI group.

\section{DISCUSSION}

This study examined whether individuals with SHI, previously found to report more social exclusion and to exhibit increased amphetamineinduced dopamine release in comparison to controls, have more psychotic experiences in response to real-life social stressors, and, if so, whether this psychotic hyperreactivity is associated with sensitivity of the dopamine system. The main result is that participants with SHI indeed report more psychotic experiences in response to social stress than normal hearing control participants. However, we found no association between psychotic reactivity to social stress in daily life and baseline dopamine $\mathrm{D}_{2 / 3}$ receptor availability or amphetamine-induced dopamine release in the striatum.

\section{Psychotic reactivity and social stress}

The main result, increased psychotic reactivity to social stress in a SHI group, is in line with earlier ESM studies showing increased psychotic reactivity in siblings of patients, a group at genetic risk for psychotic disorder (Myin-Germeys et al. 2005a, 2005b). The current study extends these findings to a group selected for exposure to an environmental risk factor and provides preliminary evidence for behavioural sensitization in this group. This sensitization is possibly a result of negative day-to-day experiences related to their outsider status. In patients with psychosis, negative life events and traumatic childhood experiences are associated with increased stress reactivity (Myin-Germeys et al. 2003; Lardinois et al. 2011). In fact, SHI participants in this study report more discrimination, which previously has been found to mediate the risk for psychotic symptoms in a sexual minority population (Gevonden et al. 2014b), and likely signals a much wider range of major and minor negative social experiences which have been collectively termed minority stress (Meyer, 2003). Earlier studies have shown that hearing problems can manifest themselves in difficulties at school 
(Järvelin et al. 1997; Sweeting \& West, 2001) and in the workplace (Hasson et al. 2011), which are often not (sufficiently) adapted to the needs of people with HI, resulting in unemployment and lower social status (Järvelin et al. 1997; Pierre et al. 2012; Stam et al. 2013). Repeated negative social experiences and could lead to the formation of cognitive biases, in effect internalizing the minority stress, for example by a growing expectation of rejection and increasingly negative self-image (Meyer, 2003). In turn, these cognitive biases could play an important role in the formation and exacerbation of psychotic symptoms (Garety et al. 2001, 2007), measured in this study as psychotic experiences in response to unpleasant company. An alternate explanation to consider are source monitoring problems, which have been reported in schizophrenia patients and their siblings (Keefe et al. 1999; Brunelin et al. 2007). While not measured in the current study, it is likely that people with SHI, who deal with degraded auditory signals and need to rely heavily on contextual and visual inference, will also show impairment on source monitoring tasks. This impairment in turn could fuel aforementioned cognitive biases and influence stress reactivity, for instance manifesting itself as increased paranoia. Finally, it should be noted that while recent work suggests a prominent role for affective stress reactivity in the development of positive symptoms (Lataster et al. 2013), no significant group effects on NA reactivity were found in this study.

However, a significant affective response to social stress was measured across both groups (Table 2), and SHI participants did give higher average moment-to-moment NA ratings than controls irrespective of stress (Table 1), suggesting that a subtle between-group difference may be present which we are unable to detect with the current sample size.

\section{Striatal dopamine and social stress}

The absence in this sample of an association between striatal dopamine neurotransmission and reactivity to social stress raises the question whether dopamine alterations underlie the development of psychotic symptoms in individuals with SHI. The result may seem at odds with Positron Emission Tomography (PET) studies using the Montreal Imaging Stress Task, which show that acute social stress causes measurable striatal and prefrontal dopamine release (Pruessner et al. 2004; Lataster et al. 2011) and that people at high risk for psychotic disorders display larger striatal dopamine release under stress than healthy controls (Mizrahi et al. 2012). However, in the preceding SPECT study in the same sample (Gevonden et al. 2014a) we found no association between dopamine release and increase in psychotic symptoms after amphetamine administration, or between dopamine release and direct measures of social exclusion. The absence of an association between striatal dopamine neurotransmission and psychotic reactivity in this ESM study mirrors that first result, but might also be related to fact that dopaminergic activity was measured at a different time than stress reactivity, or be a matter of limited statistical power as further discussed under the limitations below. Nevertheless, on the basis of these data it can only be established that elevated striatal dopamine neurotransmission and elevated stress reactivity cooccur in the same environmental-risk population. While striatal dopamine release may be a valid biological vulnerability marker for psychosis, in a healthy population it has limited value, if any, to predict stress reactivity, a behavioural vulnerability marker for the disorder.

\section{Strengths and limitations}

This study has several strengths, but also a number of methodological issues to consider. It is the first study of symptomatic reactivity to daily life stress in a sample at increased risk for psychosis which was selected on the basis of an environmental risk factor instead of selection based on already existing psychotic symptoms (ultra-high risk) or genetic liability (relatives of psychotic 
patients). Moreover, it is the first experience sampling study in individuals with hearing impairment, a socially excluded but otherwise healthy population. Finally, the study offers a rare combination of high quality dopamine imaging data and measurements of daily life experience suited to study the relation between biological and psychological endophenotypes of psychosis risk. This is important as extensive evidence (reviewed by Brunelin et al. 2013), including a number of studies in individuals at risk for psychosis (Howes et al. 2009; Mizrahi et al. 2012; Egerton et al. 2013), suggests that excess striatal dopamine constitutes an endophenotype of psychosis: nevertheless little is known about the way these abnormalities relate to psychological vulnerability markers such as MPE.

The main limitation of this study is the small sample size. However, the unilevel equivalents for our multilevel sample size (Snijders \& Bosker, 1999, pp. 23, 341-342) were 78 (psychosis) and 82 (negative affect), which should be adequate to find medium to large effects in tests of two-way interactions. Use of the appropriate statistical methods which take into account the multilevel structure of the data leads to conservative tests unlikely to yield false positives, and therefore the interaction effect between social stress and group can be interpreted with confidence. Even though this finding was no longer significant $(p=0.076$ ) when subjected to a sensitivity analysis, Figure 1 shows that the probability of the occurrence of at least one MPE seems to be influenced more by social stress in the SHI than in the control group.

Second, dopamine release was measured up to 2 years before this ESM study, not in relation to daily life and not in response to a social stressor. While [123I]IBZM SPECT is an established and validated method to measure striatal dopamine neurotransmission, including amphetamineinduced dopamine release (Laruelle et al. 1995; Booij et al. 1997), the timing of measurement matters. For example, while symptomatic schizophrenia patients differ from controls in amphetamine-induced dopamine release, patients who are in remission do not (Laruelle et al. 1999). Furthermore, it is possible that the dopaminergic response to a pharmacological challenge is qualitatively different from the dopaminergic response to a social stressor. Third, while the SPECT scans were made with a brain dedicated system with relatively high spatial resolution, we did not succeed in reliably identifying striatal subdivisions for analysis. Although we succeeded in measuring dopamine release in the entire striatum, PET brings greater possibilities to distinguish substriatal structures, zoom in on the area where dopaminergic alterations occur and obtain a better signal-to-noise-ratio (Mawlawi et al. 2001; Martinez et al. 2003). For example, a dopamine depletion PET study in schizophrenia patients suggests that dopamine $\mathrm{D}_{2 / 3}$ receptor availability differs in the associative striatum and not in the limbic (ventral) or sensorimotor striatum (Kegeles et al. 2010). Fourth, selection bias may have affected the outcomes of this study. Volunteers for a demanding imaging study are likely higher functioning individuals. Educational levels are high in both groups, while they were expected to be lower in the SHI population (Järvelin et al. 1997). The high-functioning SHI population in this study is likely to receive relatively high levels of social support which may act as a buffer to the effects of social exclusion (Meyer, 2003) and they may therefore present with fewer psychotic symptoms than the average person with SHI. However, SHI participants did score significantly higher than controls on all social defeat measures, with large group differences of approximately one standard deviation. Finally, since stress reactivity is defined as the affective and psychotic response to subjective stress, and since the analyses in this study are cross-sectional and do not incorporate a time factor, the possibility of reverse causality cannot be ruled out. Higher levels of NA or MPE could possibly alter environ- 
mental appraisals. Regardless of directionality however, a form of reactivity is measured which can be compared between individuals and groups.

\section{Conclusion}

To conclude, this study shows more psychotic reactivity to daily life stress in a healthy but socially excluded group of young adults with SHI compared to controls with normal hearing. An association between psychotic reactivity and striatal dopamine neurotransmission was also predicted but not detected. While both elevated striatal dopamine release and elevated psychotic stress reactivity have been found in the same population defined by an environmental risk factor, their interrelation cannot be established with the current data. The results of this study warrant further research to clarify the association between biological and psychological endophenotypes and psychosis risk. 


\section{Chapter 6: Summary and general discussion}

Martin Gevonden 


\section{SUMMARY}

Schizophrenia, a psychiatric disorder characterized by reality distortion, is estimated to affect $0.7 \%$ of the global population in their life time. Minority populations are much more likely to be afflicted and the social defeat hypothesis of schizophrenia provides an explanatory framework for this phenomenon. The hypothesis states that the negative experience of social exclusion is an important aetiological factor, and that the mechanism whereby social exclusion leads to schizophrenia is increased baseline activity of the mesolimbic dopamine system and/or sensitization of this system. The studies in this dissertation all aimed to test the social defeat hypothesis of schizophrenia (or predictions derived from this hypothesis) and to trace the pathogenic process in non-clinical minority populations.

In chapter 2, in two large general population samples, the cumulative incidence of psychotic symptoms was found elevated in sexual minorities. Childhood trauma, bullying and experience of discrimination were found to partly mediate that association, more so than sociodemographic or substance use factors. This shows that victimization experiences are important aetiological elements in this population. Such experiences likely contribute to the experience of social defeat.

The Moroccan-Dutch men studied in chapter 3 are a low-status migrant group in the Netherlands. They are exposed to rejection and victimization, known to be at increased risk for psychosis, and therefore may be considered a proxy group for high social defeat exposure. While increased stress reactivity may be a vulnerability marker for psychosis, compared to Dutch peers these men did not display increased reactivity to either experimentally induced social evaluative stress, or to social stress in daily life as assessed with the experience sampling method.
Young adults with severe hearing impairment, another group experiencing social exclusion and drawn from a population known to be at increased risk for psychosis, were studied in chapter 4. We first focused on the hypothesized biological mechanism underlying their increased risk for psychosis, by assessing striatal dopamine release in response to the administration of dexamphetamine, by means of single photon emission computed tomography with the iodine-123-labeled radiotracer iodobenzamide. As would be expected in case of a sensitized dopamine system, participants with hearing impairment had greater striatal dopamine release than normal hearing controls. In addition they also had stronger affective responses to the amphetamine administration, but these were not accompanied by a greater increase in psychotic symptoms than in the control participants.

The same hearing impaired and control populations were studied in daily life in chapter 5 .

With the same experience sampling paradigm as applied to the Moroccan-Dutch men in chapter 3 , a clear difference in stress reactivity was found between the two groups. Participants with hearing impairment responded with more momentary psychotic experiences under circumstances of social stress, than their normal hearing peers. Finally, we investigated whether both the possible vulnerability markers, biological and behavioural, which co-occurred in the same at-risk population, covaried quantitatively. However, no linear relationship was found between striatal dopamine release and psychotic reactivity to social stress so whether the former phenomenon is the biological basis of the latter could not be established. 


\section{GENERAL DISCUSSION}

At this stage, it is time to turn back to and evaluate the four questions formulated in the introduction. We will start at the macro-level and discuss what it means when a population is exposed to social defeat, and how to measure it. Then we will zoom in and shift our attention to the mechanisms by which exposure to aetiological elements exerts its pathogenic influence. Finally we will discuss how these different levels of analysis could be integrated into a single narrative, and what work would still be required to complete such a narrative.

\section{Elements of aetiology}

The first question of this dissertation was whether the prevalence of psychosis would be elevated in any minority group experiencing exclusion. Our observation that lesbians, gays, and bisexuals (LGBs) have an elevated prevalence of psychotic symptoms, combined with earlier reports that LGBs had higher odds of probable psychotic disorder (Bolton \& Sareen, 2011; Chakraborty et al. 2011), affirms the hypothesis that this would apply to sexual minorities. It should be noted that no studies have been conducted which specifically show increased prevalence of schizophrenia in the LGB population, which would be the most straightforward test of the predictions made by the social defeat hypothesis, since it was formulated specifically in terms of that disorder. At the same time, the authors of the hypothesis do not claim that the influence of social defeat is necessarily specific to schizophrenia, and may for instance also predict depression and other psychopathology. It is therefore worth considering what impact social defeat may have on other psychotic disorders, since in an excluded population such as LGBs we see both more non-clinical psychotic symptoms and probable psychotic disorders. These other disorders all share core symptoms with schizophrenia, and they collectively have been estimated to have a life time prevalence of 3\% (Perälä et al. 2007). They may also to a large extent have shared aetiology and a focus on schizophrenia may create a blind spot for these related disorders, which may in turn lead to underestimation of the effects of social defeat.

Another issue which remains to be resolved is about the measurement of the concept of social defeat itself. In this study, victimization experiences were the strongest mediator between sexual minority status and psychotic symptomatology. The essence of social defeat is considered by the authors of the hypothesis to be the negative experience of being an outsider, which is presumably the way such victimization experiences make a person feel. It is uncertain if victimization and rejection events are a prerequisite for the experience of social defeat to arise, or if feelings of social defeat can develop without continued external input. Of the examples often cited by the authors in support of the social defeat hypothesis, some are readily recognizable by the dominant majority as outsiders, whether it is by their skin colour, the fact that they live with their same-sex partner, or present with a mental or physical handicap. It is easy to imagine those people are ostracized, and deal with victimization experiences on a frequent basis. But the authors also cite increased psychosis incidence in the urban population, and among victims of childhood abuse in support of their hypothesis. These people are not visibly different to those around them, so it is not directly clear if and why their environment would perceive and treat them as outsiders. It appears that outsider status for these groups, who don't have a collective identity, is mostly an internally generated process.

The matter may be resolved if there were consensus on how to measure social defeat, but unfortunately at present that is not the case. The authors of the hypothesis themselves claim it is notoriously hard to measure as people tend to keep up appearances (Selten et al. 2013), but for the future of the field it is essential this challenge is 
taken up and that reliable ways to measure social defeat are found. In this dissertation we have chosen to ask about past experiences of discrimination or other forms of victimization. While there may be a reporting bias and the possibility of forgetting, this has seemed to work for the minority populations under study. However, for the defeated groups not, or not currently, exposed to victimization experiences a more direct measure of social defeat is required. The questionnaires currently available which attempt to measure low perceived social rank (Allan \& Gilbert, 1995) or the experience of social defeat (Gilbert \& Allan, 1998) have not been validated for minority populations. It is pertinent to ask what these questionnaires really measure and what we would want them to measure. An interesting possibility is that what we refer to as social defeat is in essence the same as the cognitive schemas formed under the influence of social experience. These schemas, which the individual uses to make sense of the world, will then steer the individual further towards defeating, and ultimately psychotic, interpretations of events (Howes \& Murray, 2014). It is worth asking the question, for instance, if negative views or expectations of other people may be an expression of social defeat. Since instruments such as the brief core schema scales (Fowler et al. 2006) are already available to measure such schemas, they could readily be incorporated in future research.

In conclusion, the findings in our study of LGBs firmly support the social defeat hypothesis of schizophrenia. It is now time to zoom in on the behavioural mechanism which may follow exposure and consider if we can see the effects of a single exposure as it occurs. That would strengthen the idea that the exposures we are looking at are indeed relevant.

\section{A possible behavioural mechanism}

The second question formulated in the introduction was whether minorities known to be at increased risk for psychosis show increased stress reactivity. This question relates to a possible behavioural mechanism by which social defeat may exert its effects. Although the social defeat hypothesis makes no predictions on this matter, it is possible that behavioural changes occur which are not merely reflected by an increase in prevalence of non-clinical or clinical psychotic symptoms. Our study in Moroccan-Dutch men showed no evidence of behavioural sensitization as a result of repeated exposures to defeating experiences; they had very similar psychotic responses to social stress as native Dutch men and their affective response may even be blunted. In contrast, the results of our study in people with hearing impairment clearly show increased psychotic reactivity to social stress as compared to controls. If increased stress reactivity is indeed a vulnerability marker for psychotic disorders, then why is it present in one at-risk group but not the other?

This question is not easily answered since both studies operationalised social defeat by proxy and the actual degree of exposure as well as actual increase in psychosis risk are unknown. The group with hearing impairment differed from controls in subjective measures of social exclusion or defeat, but the Moroccan-Dutch group did not. The only indicator of exposure which was consistent across both minority groups was a high degree of perceived discrimination.

These results were obtained with the experience sampling method, which has been validated in a variety of patient and control populations, but was now for the first time used in a young allmale ethnic minority population. Two possible courses of action to follow up on this null-result come to mind. First, an experience sampling study could be conducted in ethnic minority patients or their relatives, to assess if they display similar increases in stress reactivity as have been found in previous studies of (mostly) ethnic 
majority participants. While such an approach would contribute to the validation of the method in an ethnic minority population, the fundamental issue of social defeat being defined by proxy would remain unresolved. Second, and more interestingly, one could use the experience sampling method to zoom in more on the actual exposures. Such an approach would access the aetiological elements of importance, and try to measure their immediate consequences as they occur.

One opportunity to study the daily life exposures relevant to social defeat involves the ethnic density effect. Studies have shown that mental health deficits for minorities are dependent of the diversity of their immediate environment. For example, psychosis risk in the Moroccan-Dutch population is negatively associated with ethnic density (Veling et al. 2008; Termorshuizen et al. 2014), perhaps because the Moroccan-Dutch have more outsider status and less social support in native Dutch dominated neighbourhoods. If an important element of aetiology is being confronted with individuals from a higher-status minority, then this is likely to trigger a stress response. An experience sampling study of how the ethnic composition of the current company affects perception of social stress, and if that stress in turn is associated with changes in negative affect or psychotic experiences would be of great interest. If minorities are indeed more stressed in the presence of members of the dominant majority, it would legitimate the assumption that they experiences chronic social stress. And if they respond strongly to such stress, it would directly link the experience of social defeat to a plausible behavioural mechanism.

To conclude, while some excluded groups including people with serious hearing impairment appear to express increased reactivity to social stress, others including young Moroccan-Dutch men appear not to. At present it remains unclear whether these results are reliable and represent different behavioural patterns to exposure to social defeat, or are related to other factors.

\section{The likely biological mechanism}

The third question, whether an excluded population known to be at increased risk for psychosis shows evidence of dopaminergic sensitisation, was a crucial test for the social defeat hypothesis. While animal models demonstrated that social defeat could lead to dopaminergic changes, it has now for the first time been observed in a socially excluded group of humans. While we found no differences in striatal dopamine $\mathrm{D}_{2 / 3}$ receptor availability at baseline, we observed markedly increased striatal dopamine release in the participants with severe hearing impairment. This is an important result, and converges with other recent findings, such as a positive association between striatal dopamine release and exposure to childhood adversities (Oswald et al. 2014), which support dopaminergic sensitization as a plausible biological mechanism for the pathogenic effects of social defeat.

It should be noted however, that there may still be an unknown common genetic factor underlying both the dopaminergic abnormalities and the hearing loss in this population. The current results are in line with predictions made by the social defeat hypothesis, but also strengthen the case for performing an even stronger test. This could be a replication study in Afro-Caribbean migrants in the UK or Surinamese-Dutch, Antillean-Dutch and Moroccan-Dutch migrants in the Netherlands, as they are considered the prime examples of populations affected by social defeat by the authors of the hypothesis. An added advantage is that for these migrant groups it has been shown to be unlikely that genetics are a defining factor in their increased psychosis risk at population level (Cantor-Graae \& Selten, 2005).

Given that the environmental plasticity of the dopamine system has recently been shown to be 
large (Stokes et al. 2013), a prospective study of dopaminergic sensitization in humans would be a welcome contribution to the current state of the field. Since experimental manipulation of chronic social exclusion is rightfully off-limits for ethical reasons, performing a natural experiment is a reasonable alternative. For example, dopamine release could be quantified in an ethnically varied cohort of 18 year olds before their transition to tertiary education. The ethnic composition of their school environment could be recorded, their social status could be recorded in annual follow-ups and after five years a second assessment of dopamine release could be made. When a loss of perceived social status would be associated with an increase in striatal dopamine release, a significant addition would be reached over the existing cross sectional data. This type of longitudinal imaging study would also allow for the assessment of possible behavioural changes and possible shed more light on the behavioural consequences of striatal hyperdopaminergia. Alternatively, such a study could be conducted using $\left[{ }^{18} \mathrm{~F}\right]$ fallypride, with the medial prefrontal cortex as region of interest. Rats repeatedly exposed to social defeat in adolescence have decreased prefrontal dopamine release when again exposed to defeat later (Watt et al. 2013), and it would be interesting to see if a similar change occurs in socially excluded humans. Family members of patients with psychotic disorder have already been shown to display decreased prefrontal dopamine release in response to social stress using an $\left.{ }^{[18} \mathrm{F}\right]$ fallypride paradigm (Lataster et al. 2014). It should be noted that longitudinal imaging studies are always to an extent invasive for the participant and warrant careful ethical debate, especially so when the procedures involve radiation exposure and the administration of dexamphetamine to healthy individuals. On the other hand, nuclear imaging techniques are currently the most valid possibility to measure aspects of the human dopamine system in vivo, and the potential benefits of better understanding the pathogenesis of psychotic disorders, and of eventually finding new ways to prevent or treat them, make such debate worth the time.

To conclude, while baseline striatal dopamine $\mathrm{D}_{2 / 3}$ receptor availability was not altered in a socially excluded group of humans, they had markedly greater striatal dopamine release as compared to general population controls. This finding directly supports dopaminergic sensitization as a mechanism for the effects of exposure to social defeat.

\section{The integrative narrative of social defeat}

The fourth and final question was if there is evidence for dose response-relationships between social defeat, striatal dopamine release and psychotic experiences. While these aspects all are of interest by themselves, knowledge of them will be of increased value if they would prove to have predictive value at the level of the individual. All three aspects co-occurred in the hearing impaired population, but surprisingly we did not find any quantitative relationship between the extent of exposure, dopaminergic changes and possible behavioural vulnerability markers for psychotic disorders.

First, the scores of the social defeat and social comparison questionnaires were not correlated with striatal dopamine release. This may simply be a measurement problem. As mentioned previously, there are issues with the currently available questionnaires to measure social exclusion. A possible work-around would be the use of an objective measure such as hearing loss, but the number of decibels hearing impairment or the number of shades one's skin colour is darker than the average are still likely to be poor predictors of the degree of perceived exclusion at individual level. One could also attempt to use an implicit measure of self-esteem (Falk \& Heine, 2014), for instance with an implicit association test, which has been previously used to study 
feelings of inferiority in patients with schizophrenia (Moritz et al. 2006). Alternatively, the use of virtual reality environments offers opportunities to measure outsider status in innovative ways, such as the distance kept from other-ethnicity avatars (Veling et al. 2014).

Second, dopamine release did neither predict acute psychotic response to dexamphetamine, nor the psychotic response to stress in daily life. This may again be a measurement problem, this time concerning the quantification of dopamine function. We have used the bilateral striatal average of dopamine displacement to measure dopamine release, while the signal may have originated from a smaller striatal subregion and may have been partially masked by random activity in other striatal areas. Therefore, our signal to noise ratio may have been adequate to detect social exclusion effects averaged over all participants, but insufficient to generate measurements reliable enough to find an association at individual level with either exposure or outcomes. A possible alternative for future studies would be to use positron emission tomography, which offers opportunities for better topographical categorization (Martinez et al. 2003), and to better target the region where most dopamine release would be expected, thereby improving the measurement reliability.

We conclude that, while conceptually the biological mechanism of dopaminergic sensitization proposed by the social defeat hypothesis and the behavioural mechanism of stress sensitization go together well, with the data currently available their interrelatedness cannot be established.

\section{Conclusion}

Slowly we are discovering more about the aetiology and pathogenesis of psychotic disorders, but there are few certainties. Social defeat is as strong a candidate as ever now that there is more evidence for the associated biological and possibly also behavioural mechanisms. The challenge remains to connect the biological with the behavioural level of analysis, yet this has proven to be a difficult task across the entire field of psychiatry. Modest advances are made on either side of the chasm, and hypotheses abound, but so far these advances have not been connected as to actually bridge the gap between the two. 


\section{VALORISATION}

Scientists, especially when their studies have been paid for by public funding, as is the case for most of the work collected in this dissertation, have a responsibility to make their work matter. The university rightfully encourages us to do so, yet in my opinion this should not be limited to this addendum, an obligatory afterthought not part of the scientific work itself, but integrated into the fabric of what we do. For me personally, the thought it would matter was an important motivation to start this project and carry it through to the work you hold in your hands. I vividly remember speaking to Prof. dr. Jean-Paul Selten for the first time, hearing him tell me how the risk for psychotic disorders was so much higher in Moroccan-Dutch men and other ethnic minorities, and asking myself two questions: 'How does that happen?' and 'How do we remedy this?'

The preceding chapters have focused mainly on the first question, as we have expanded the scientific literature with new observations on psychotic outcomes in minority groups, possible underlying biological and behavioural mechanisms, and new ideas to be tested in follow-up studies. We know more now than we did 5 years ago, but also concluded that it is still too early to tell whether the narrative we propose on how it happens is correct. However, whether we have the underlying biology right does not necessarily matter for question 2 . The current findings on dopamine release may converge with other findings and much further down the line lead to improved pharmacotherapy for people who need it, but they are by no means the lowest hanging fruit. Better treatment is important, but I hope and believe this work will be recognized as especially relevant to early detection and prevention, as from a public health perspective this is where most gains can be made.

Living through a psychotic episode, and worse, developing schizophrenia and having such a frightening experience more than once is some- thing you do not wish upon anyone. In fact, in an elegant study where both clinicians and laypeople from communities around the globe had to make a series of choices on which of two fictitious people with different medical conditions was healthier, acute schizophrenia was weighted as representing the biggest health loss of the 220 conditions on the list, which included spinal cord lesions and terminal cancer (Salomon et al. 2012). We can certainly not prevent every case of schizophrenia, but I believe we can prevent more cases than we do now, and that it will turn out to be a cost-effective way to increase population health in general, and in particular for minority groups, who lag behind in many more health indicators. The idea that chronic stress and discrimination may be at the root of many of those disparities is not new (Adler \& Rehkopf, 2008; Williams \& Mohammed, 2008), but the case had not been made for psychotic disorders, and this dissertation will hopefully provide more ammunition to those who spread the message that social exclusion may make you sick.

This is a message that deserves to be heard by the general public, by organizations who represent the minority groups at risk, and by policy makers. The general public will probably not change any negative attitudes they may have towards minorities based on a single study, but it is important that they are informed. In the current day and age, where dissemination of opinions is cheap, people should know that if they are naming and shaming a minority group on television or the internet, it affects that group in more than a superficial way. Or, as an award-winning MoroccanDutch actor stated in a national newspaper, when interviewed about growing up in the context of a public debate about Moroccan immigrants and Islam with an increasingly negative tone "you need to have quite a thick skin" (Nasrdin Dchar in Trouw, 25 January 2015). 
Reception in minority communities has been positive. Over the course of working on this dissertation I have stepped out of the world of conferences attended only by my scientific peers, and talked about these topics in settings of varying formality with the people it may affect. I have given a talk at a symposium on gender-nonconformity organized by an LGBT student society, spoken to social workers, minority youths and their parents and at their community centers, football clubs and mosques, and explained our studies at a camp for hard of hearing youths. For groups that feel poorly understood by the dominant majority, it can be empowering to know that people are taking an interest and are conducting studies specifically about them.

Policy makers, finally, should be aware that minority mental health lags behind that of the general population. They have the power to implement policies or fund interventions that may have preventive effects, such as anti-stigma campaigns, the legalisation of gay marriage, the installation of auditory induction loops in public buildings, or the integration of diversity education into school curricula. When I have met with policy makers during the writing of this dissertation, whether it was within the context of this work or while volunteering for organisations which promote equality, I have made such suggestions with the argument that such investments are likely to pay themselves back. After all, a healthier population means more workforce participation, and less need for care. Even if the moral argument for closing the mental health gap should be sufficient, an economic argument only strengthens the case.

\section{SAMENVAT TING}

Schizofrenie, een psychiatrische stoornis die gekenmerkt wordt door verstoring van de realiteitszin, treft naar schatting $0.7 \%$ van de wereldbevolking gedurende hun levensspanne. Minderheidsgroepen hebben een veel grotere kans om te worden getroffen en de social defeat hypothese biedt een mogelijke verklaring voor dit verschijnsel. De hypothese stelt dat de negatieve ervaring van sociale uitsluiting een belangrijke etiologische factor is en dat een verhoogde basale activiteit van het mesolimbisch dopaminesysteem en/of de sensitisatie van dat systeem het mechanisme is waardoor sociale uitsluiting tot schizofrenie kan leiden. De in dit proefschrift gebundelde onderzoeken hadden gezamenlijk als doel om de social defeat hypothese (of hier van afgeleide voorspellingen) te toetsen en om de pathogenese in niet-klinische minderheidspopulaties te volgen.

In hoofdstuk 2 werd in twee grote steekproeven uit de algemene bevolking een verhoogde cumulatieve incidentie van psychotische symptomen gevonden bij seksuele minderheden. Jeugdtrauma, voorgeschiedenis van pesten en het ervaren van discriminatie werden in dit onderzoek geïdentificeerd als factoren die het verband gedeeltelijk mediëerden. Deze mediatie was sterker dan de mediatie door sociodemografische of middelenmisbruik-gerelateerde factoren. Dit geeft aan dat ervaringen waarin men zich in een slachtofferrol bevindt een belangrijk etiologisch element vormen voor deze populatie. Dergelijke ervaringen dragen waarschijnlijk bij aan de ervaring van social defeat.

Marokkaans-Nederlandse mannen, de groep die is onderzocht in hoofdstuk $\mathbf{3}$, zijn een migrantengroep met een relatief lage status in Nederland. Zij worden regelmatig blootgesteld aan discriminatie en afwijzing en het is bekend dat zij een hogere kans hebben om een psychose te ontwikkelen. Daarom kunnen zij beschouwd worden als een groep die model staat voor een hoge bloot- 
stelling aan social defeat. Hoewel een verhoogde reactie op stress als een aanwijzing voor verhoogde psychosekwetsbaarheid kan worden beschouwd, vertoonde de Marokkaans-Nederlandse groep in dit onderzoek geen verhoogde stress rectiviteit, noch wanneer ze experimenteel werden blootgesteld aan negatieve sociale evaluaties, noch wanneer blootstelling aan en reactie op sociale stress in het dagelijks leven werden gemeten met de experience sampling methode.

Jongvolwassenen met ernstig gehoorverlies, een andere groep die sociale uitsluiting ervaart en binnen een bredere slechthorende populatie valt waarvan bekend is dat deze een verhoogde kans op psychose heeft, waren het onderwerp van het onderzoek in hoofdstuk 4. Allereerst ging onze aandacht uit naar het hypothethisch biologisch mechanisme waaraan hun verhoogde risico op psychose ten grondslag zou kunnen liggen. De gehanteerde method was het meten van striatale dopamine afgifte in respons op het toedienen van dexamfetamine, met behulp van de beeldvormende techniek single photon emission computed tomography waarin als radiotracer gebruik gemaakt werd van jodium-123-gelabeld iodobenzamide. Conform de verwachte uitkomst bij sensitisatie van het dopaminesysteem in de slechthorende groep, hadden slechthorende deelnemers een grotere striatale dopamineafgifte dan de normaal horende controlegroep. Ook vertoonden zij sterkere affectieve reacties in respons op de toediening van dexamfetamine, hoewel deze niet vergezeld werden door een grotere toename van psychotische symptomen vergeleken met controlegroep.

Dezelfde slechthorende en controle populaties werden binnen de context van hun dagelijks leven bestudeerd in hoofdstuk 5. Met behulp van het zelfde experience sampling paradigma als werd toegepast op de Marokkaans-Nederlandse mannen in hoofdstuk 3, werd er een duidelijk verschil in stress reactiviteit tussen de twee groepen gevonden. Deelnemers met gehoorverlies reageerden met meer psychotische ervaringen wanneer zij zich in stressvolle sociale situatie bevonden dan hun normaal horende leeftijdsgenoten. Tenslotte hebben we onderzocht of de twee mogelijke indicatoren voor psychosekwetsbaarheid, een biologische en een gedragsmatige, die tegelijk in dezelfde verhoogd-risico populatie optraden, kwantitatief covarieerden. We vonden echter geen lineaire relatie tussen striatale dopamineafgifte en psychotische reactiviteit in respons op social stress, wat betekent dat niet kan worden vastgesteld of het eerste fenomeen de biologische basis vormt voor het tweede.

Langzaam maar gestaag ontdekken we meer over de etiologie en pathogenese van psychotische stoornissen, maar er zijn nog weinig zekerheden op dit gebied. Social defeat, is een sterke kandidaat nu er meer ondersteuning is voor de veronderstelde biologische en mogelijk ook gedragsmatige mechanismen. De uitdaging blijft om het biologische met het gedragsmatige analyseniveau te verbinden, maar dit is over de gehele breedte van de psychiatrie geen eenvoudige taak gebleken. Er worden bescheiden stappen voorwaarts gezet aan beide kanten van de kloof, en hypotheses zijn er ten overvloede, maar tot dusver hebben alle nieuwe bevindingen nog niet geleid tot een stabiele verbinding die het gat tussen beide overbrugt. 


\section{REFERENCES}

Abi-Dargham A, Kegeles LS, Zea-Ponce Y, Mawlawi O, Martinez D, Mitropoulou V, O’Flynn K, Koenigsberg HW, Van Heertum R, Cooper T, Laruelle M, \& Siever LJ (2004). Striatal amphetamine-induced dopamine release in patients with schizotypal personality disorder studied with single photon emission computed tomography and [123I] iodobenzamide. Biological psychiatry 55, 1001-1006.

Adler NE, \& Rehkopf DH (2008). U.S. Disparities in Health: Descriptions, Causes, and Mechanisms. Annual Review of Public Health 29, 235-252.

Adriaanse M, van Domburgh L, Hoek HW, Susser E, Doreleijers T a. H, \& Veling W (2015). Prevalence, impact and cultural context of psychotic experiences among ethnic minority youth. Psychological Medicine 45, 637-646.

Akdeniz C, Tost H, Streit F, Haddad L, Wüst S, Schäfer A, Schneider M, Rietschel M, Kirsch P, \& Meyer-Lindenberg A (2014). Neuroimaging evidence for a role of neural social stress processing in ethnic minority-associated environmental risk. JAMA Psychiatry 71, 672-680. Aldrich R (2004). Homosexuality and the City: An Historical Overview. Urban Studies 41, 1719-1737.

Allan S, \& Gilbert P (1995). A social comparison scale: Psychometric properties and relationship to psychopathology. Personality and Individual Differences 19, 293-299.

American Psychiatric Association (2013). The Diagnostic and Statistical Manual of Mental Disorders, Fifth Edition.: DSM 5. bookpointUS.

Andreasen NC, Flaum M, \& Arndt S (1992). The Comprehensive Assessment of Symptoms and History (CASH). An instrument for assessing diagnosis and psychopathology. Archives of General Psychiatry 49, 615-623.

Andriessen I, Fernee H, \& Wittebrood K (2014). Perceived discrimination in the Netherlands. Netherlands Institute for Social Research: The Hague.
Annes A, \& Redlin M (2012). Coming out and coming back: Rural gay migration and the city. Journal of Rural Studies 28, 56-68.

D’Augelli AR (2002). Mental Health Problems among Lesbian, Gay, and Bisexual Youths Ages 14 to 21. Clinical Child Psychology and Psychiatry 7, 433-456.

Bak M, Delespaul P, Hanssen M, de Graaf R, Vollebergh W, \& van Os J (2003). How are 'false' positive psychotic symptoms? Schizophrenia Research 62, 187-189.

Baron RM, \& Kenny DA (1986). The moderator-mediator variable distinction in social psychological research: Conceptual, strategic, and statistical considerations. Journal of Personality and Social Psychology 51, 1173-1182.

Berton O, McClung CA, DiLeone RJ, Krishnan V, Renthal W, Russo SJ, Graham D, Tsankova NM, Bolanos CA, Rios M, Monteggia LM, Self DW, \& Nestler EJ (2006). Essential Role of BDNF in the Mesolimbic Dopamine Pathway in Social Defeat Stress. Science 311, 864-868.

Bijl RV, Van Zessen G, Ravelli A, De Rijk C, \& Langendoen Y (1998). The Netherlands mental health survey and incidence study (NEMESIS): objectives and design. Social Psychiatry and Psychiatric Epidemiology 33, 581-586.

Boileau I, Dagher A, Leyton M, Gunn RN, Baker GB, Diksic M, \& Benkelfat C (2006). Modeling sensitization to stimulants in humans: an [11C] raclopride/positron emission tomography study in healthy men. Archives of General Psychiatry 63, 1386-1395.

Bolton S-L, \& Sareen J (2011). Sexual orientation and its relation to mental disorders and suicide attempts: findings from a nationally representative sample. Canadian Journal of Psychiatry. Revue Canadienne de Psychiatrie 56, 35-43.

Booij J, Korn P, Linszen DH, \& van Royen EA (1997). Assessment of endogenous dopamine release by methylphenidate challenge using iodine- 123 iodobenzamide single-photon emission tomography. European Journal of Nuclear Medicine and Molecular Imaging 24, 674-677. 
Boot E, Booij J, Zinkstok JR, Haan L de, Linszen DH, Baas F, \& van Amelsvoort T (2010). Striatal D2receptor binding in 22q11 deletion syndrome: an [123I]IBZM SPECT study. Journal of Psychopharmacology 24, 1525-1531.

Bourque F, van der Ven E, \& Malla A (2011). A metaanalysis of the risk for psychotic disorders among first-and second-generation immigrants. Psychological Medicine 41, 897-910.

Brunelin J, d'Amato T, Brun P, Bediou B, Kallel L, Senn M, Poulet E, \& Saoud M (2007). Impaired verbal source monitoring in schizophrenia: An intermediate trait vulnerability marker? Schizophrenia Research 89, 287-292.

Brunelin J, Fecteau S, \& Suaud-Chagny M-F (2013). Abnormal Striatal Dopamine Transmission in Schizophrenia. Current Medicinal Chemistry 20, 397-404.

Burke AR, Renner KJ, Forster GL, \& Watt MJ (2010). Adolescent social defeat alters neural, endocrine and behavioral responses to amphetamine in adult male rats. Brain Research 1352, 147-156.

Cannon M, Jones PB, \& Murray RM (2002). Obstetric Complications and Schizophrenia: Historical and Meta-Analytic Review. American Journal of Psychiatry 159, 1080-1092.

Cantor-Graae E, \& Selten JP (2005). Schizophrenia and migration: a meta-analysis and review. American Journal of Psychiatry 162, 12-24.

Cardno A, Marshall E, Coid B, Macdonald AM, Ribchester TR, Davies NJ, Venturi P, Jones LA, Lewis SW, Sham PC, Gottesman II, Farmer AE, McGuffin P, Reveley AM, \& Murray RM (1999). Heritability estimates for psychotic disorders: The maudsley twin psychosis series. Archives of General Psychiatry 56, 162-168.

Chakraborty A, McManus S, Brugha TS, Bebbington P, \& King M (2011). Mental health of the non-heterosexual population of England. The British Journal of Psychiatry 198, 143-148.
Collip D, Myin-Germeys I, \& Van Os J (2008). Does the Concept of "Sensitization" Provide a Plausible Mechanism for the Putative Link Between the Environment and Schizophrenia? Schizophrenia bulletin 34, 220.

Cooper AF (1976). Deafness and psychiatric illness.

The British Journal of Psychiatry 129, 216.

Cottler LB, Robins LN, Grant BF, Blaine J, Towle LH, Wittchen HU, \& Sartorius N (1991). The CIDI-core substance abuse and dependence questions: cross-cultural and nosological issues. The WHO/ADAMHA Field Trial. The British Journal of Psychiatry 159, 653.

Cottler LB, Robins LN, \& Helzer JE (1989). The Reliability of the CIDI-SAM: a comprehensive substance abuse interview. British Journal of Addiction 84, 801-814.

Crul M, \& Heering L (2009). The position of the Turkish and Moroccan second generation in Amsterdam and Rotterdam: the TIES study in the Netherlands. Amsterdam Univ Pr.

Das-Munshi J, Becares L, Dewey ME, Stansfeld SA, \& Prince MJ (2010). Understanding the effect of ethnic density on mental health: multi-level investigation of survey data from England. BMJ: British Medical Journal 341

David A, Malmberg A, Lewis G, Brandt L, \& Allebeck P (1995). Are there neurological and sensory risk factors for schizophrenia? Schizophrenia research 14, 247-251.

Dedovic K, Renwick R, Mahani NK, Engert V, Lupien SJ, \& Pruessner JC (2005). The Montreal Imaging Stress Task: using functional imaging to investigate the effects of perceiving and processing psychosocial stress in the human brain. Journal of Psychiatry and Neuroscience 30, 319-325.

Delespaul PA (1995). Assessing schizophrenia in daily life. UPM, Universitaire Pers Maastricht: Maastricht.

Drevets WC, Gautier C, Price JC, Kupfer DJ, Kinahan PE, Grace AA, Price JL, \& Mathis CA (2001). Amphetamineinduced dopamine release in human ventral striatum correlates with euphoria. Biological Psychiatry 49, 81-96. 
Egerton A, Chaddock CA, Winton-Brown TT, Bloomfield MAP, Bhattacharyya S, Allen P, McGuire PK, \& Howes OD (2013). Presynaptic Striatal Dopamine Dysfunction in People at Ultra-high Risk for Psychosis: Findings in a Second Cohort. Biological Psychiatry 74, 106-112.

Egerton A, Mehta MA, Montgomery AJ, Lappin JM, Howes OD, Reeves SJ, Cunningham VJ, \& Grasby PM (2009). The dopaminergic basis of human behaviors: A review of molecular imaging studies. Neuroscience \& Biobehavioral Reviews 33, 1109-1132.

Eilbracht L, Stevens GWJM, Wigman JTW, van Dorsselaer S, \& Vollebergh WAM (2015). Mild psychotic experiences among ethnic minority and majority adolescents and the role of ethnic density. Social Psychiatry and Psychiatric Epidemiology 50, 1029-1037.

Ender P (2008). Stata FAQ: How to perform Sobel-Goodman mediation tests in Stata? UCLA: Academic Technology Services, Statistical Consulting Group

Falk CF, \& Heine SJ (2014). What Is Implicit Self-Esteem, and Does it Vary Across Cultures? Personality and Social Psychology Review

Fehr MD, Yakushev MD, Hohmann DP, Buchholz MS, Landvogt MD, Deckers H, Eberhardt A, Kläger M, Smolka MD, Scheurich PD, Dielentheis MD, Schmidt MD, Rösch PD, Bartenstein MD, Gründer MD, \& Schreckenberger MD (2008). Association of Low Striatal Dopamine D2 Receptor Availability With Nicotine Dependence Similar to That Seen With Other Drugs of Abuse. American Journal of Psychiatry 165, 507-514.

Fellinger J, Holzinger D, Gerich J, \& Goldberg D (2007). Mental distress and quality of life in the hard of hearing. Acta Psychiatrica Scandinavica 115, 243-245.

Figee M, de Koning P, Klaassen S, Vulink N, Mantione M, van den Munckhof P, Schuurman R, van Wingen G, van Amelsvoort T, Booij J, \& Denys D (2014). Deep Brain Stimulation Induces Striatal Dopamine Release in ObsessiveCompulsive Disorder. Biological Psychiatry 75, 647-652.
Fors A, Abel KM, Wicks S, Magnusson C, \& Dalman C (2013). Hearing and speech impairment at age 4 and risk of later non-affective psychosis. Psychological Medicine 43, 2067-2076.

Fowler D, Freeman D, Smith B, Kuipers E, Bebbington P, Bashforth H, Coker S, Hodgekins J, Gracie A, Dunn G, \& Garety P (2006). The Brief Core Schema Scales (BCSS): psychometric properties and associations with paranoia and grandiosity in non-clinical and psychosis samples. Psychological Medicine 36, 749.

Frissen A, Lieverse R, Drukker M, Delespaul P, Lataster T, Myin-Germeys I, \& van Os J (2014). Evidence that childhood urban environment is associated with blunted stress reactivity across groups of patients with psychosis, relatives of patients and controls. Social Psychiatry and Psychiatric Epidemiology 49, 1579-87.

Fusar-Poli P, \& Meyer-Lindenberg A (2013). Striatal Presynaptic Dopamine in Schizophrenia, Part II: Meta-Analysis of [18F/11C]-DOPA PET Studies. Schizophrenia Bulletin $39,33-42$.

Garety PA, Bebbington P, Fowler D, Freeman D, \& Kuipers E (2007). Implications for neurobiological research of cognitive models of psychosis: a theoretical paper. Psychological Medicine 37, 1377-1391.

Garety PA, Kuipers E, Fowler D, Freeman D, \& Bebbington PE (2001). A cognitive model of the positive symptoms of psychosis. Psychological Medicine 31, 189-195.

Gevonden M, Booij J, van den Brink W, Heijtel D, van Os J, \& Selten J-P (2014a). Increased release of dopamine in the striata of young adults with hearing impairment and its relevance for the social defeat hypothesis of schizophrenia. JAMA Psychiatry 71, 1364-1372.

Gevonden MJ, Myin-Germeys I, van den Brink W, van Os J, Selten J-P, \& Booij J (2015). Psychotic reactions to daily life stress and dopamine function in people with severe hearing impairment. Psychological Medicine 45, 1665-74. 
Gevonden MJ, Selten JP, Myin-Germeys I, de Graaf R, Have M Ten, van Dorsselaer S, van Os J, \& Veling W (2014b). Sexual minority status and psychotic symptoms: findings from the Netherlands Mental Health Survey and Incidence Studies (NEMESIS). Psychological Medicine 44, 421-434.

Gilbert P, \& Allan S (1998). The role of defeat and entrapment (arrested flight) in depression: an exploration of an evolutionary view. Psychological Medicine 28, 585-598.

\section{Glaser J-P, van Os J, Portegijs PJM, \& Myin-Germeys I} (2006). Childhood trauma and emotional reactivity to daily life stress in adult frequent attenders of general practitioners. Journal of Psychosomatic Research 61, 229-236.

Goldstein H (2005). Multilevel Models. In Encyclopedia of Biostatistics. John Wiley \& Sons, Ltd.

de Graaf R, Have M ten, \& van Dorsselaer S (2010). The Netherlands Mental Health Survey and Incidence Study-2 (NEMESIS-2): design and methods. International Journal of Methods in Psychiatric Research 19, 125-141.

de Graaf R, Have M ten, van Gool C, \& van Dorsselaer S (2012). Prevalence of mental disorders and trends from 1996 to 2009. Results from the Netherlands Mental Health Survey and Incidence Study-2. Social Psychiatry and Psychiatric Epidemiology 47, 203-213.

de Graaf R, Sandfort TGM, \& Have M ten (2006). Suicidality and Sexual Orientation: Differences Between Men and Women in a General Population-Based Sample From The Netherlands. Archives of Sexual Behavior 35, 253-262.

Hall I, Strydom A, Richards M, Hardy R, Bernal J, \& Wadsworth M (2005). Social outcomes in adulthood of children with intellectual impairment: evidence from a birth cohort. Journal of Intellectual Disability Research 49, 171-182.
Hamerschmidt R, Moreira ATR, Wiemes GRM, Tenorio SB, \& Tambara EM (2013). Cochlear Implant Surgery With Local Anesthesia and Sedation: Comparison With General Anesthesia. Otology \& Neurotology 34, 75-78.

Hanssen M, Peeters F, Krabbendam L, Radstake S, Verdoux $\mathrm{H}$, \& van Os J (2003). How psychotic are individuals with non-psychotic disorders? Social Psychiatry and Psychiatric Epidemiology 38, 149-154.

Hasson D, Theorell T, Wallén MB, Leineweber C, \& Canlon $B$ (2011). Stress and prevalence of hearing problems in the Swedish working population. BMC Public Health 11, 130.

Hatzenbuehler ML, Keyes KM, \& McLaughlin KA (2011). The protective effects of social/contextual factors on psychiatric morbidity in LGB populations. International journal of epidemiology 40, 1071-1080.

Hatzenbuehler ML, McLaughlin KA, Keyes KM, \& Hasin DS (2010). The impact of institutional discrimination on psychiatric disorders in lesbian, gay, and bisexual populations: A prospective study. American journal of public health 100, 452.

Henquet C, Forti MD, Morrison P, Kuepper R, \& Murray RM (2008). Gene-Environment Interplay Between Cannabis and Psychosis. Schizophrenia Bulletin 34, 1111-1121.

Howes OD, Bose SK, Turkheimer F, Valli I, Egerton A, Valmaggia LR, Murray RM, \& McGuire P (2011). Dopamine Synthesis Capacity Before Onset of Psychosis: A Prospective [18F]-DOPA PET Imaging Study. American Journal of Psychiatry 168, 1311-1317.

Howes OD, Kambeitz J, Kim E, Stahl D, Slifstein M, Abi-Dargham A, \& Kapur S (2012). The nature of dopamine dysfunction in schizophrenia and what this means for treatment. Archives of general psychiatry 69, 776-786.

Howes OD, \& Kapur S (2009). The dopamine hypothesis of schizophrenia: version III-the final common pathway. Schizophrenia Bulletin 35, 549-562. 
Howes OD, Montgomery AJ, Asselin M-C, Murray RM, Valli I, Tabraham P, Bramon-Bosch E, Valmaggia L, Johns L, Broome M, McGuire PK, \& Grasby PM (2009). Elevated striatal dopamine function linked to prodromal signs of schizophrenia. Archives of general psychiatry 66, 13-20.

Howes OD, \& Murray RM (2014). Schizophrenia: an integrated sociodevelopmental-cognitive model. The Lancet 383, 1677-1687.

Huijnk W, \& Dagevos J (2012). Dichter bij elkaar? Sociaal en Cultureel Planbureau: Den Haag.

Huijnk W, Gijsberts M, \& Dagevos J (2014). Jaarrapport integratie 2013. Sociaal en Cultureel Planbureau: Den Haag.

Janssen I, Hanssen M, Bak M, Bijl RV, De Graaf R, Vollebergh W, McKenzie K, \& Van Os J (2003). Discrimination and delusional ideation. The British Journal of Psychiatry 182, 71-76.

Janssen I, Krabbendam L, Bak M, Hanssen M, Vollebergh W, Graaf R, \& van Os J (2004). Childhood abuse as a risk factor for psychotic experiences. Acta Psychiatrica Scandinavica 109, 38-45.

Järvelin MR, Mäki-Torkko E, Sorri MJ, \& Rantakallio PT (1997). Effect of hearing impairment on educational outcomes and employment up to the age of 25 years in northern Finland. British Journal of Audiology 31, 165-175.

Juster R-P, Smith NG, Ouellet É, Sindi S, \& Lupien SJ (2013). Sexual Orientation and Disclosure in Relation to Psychiatric Symptoms, Diurnal Cortisol, and Allostatic Load. Psychosomatic Medicine 75, 103-16.

Kapur S (2003). Psychosis as a State of Aberrant Salience: A Framework Linking Biology, Phenomenology, and Pharmacology in Schizophrenia. American Journal of Psychiatry $160,13-23$.

Kaymaz N, Drukker M, Lieb R, Wittchen H-U, Werbeloff N, Weiser M, Lataster T, \& van Os J (2012). Do subthreshold psychotic experiences predict clinical outcomes in unselected non-help-seeking population-based samples? A systematic review and meta-analysis, enriched with new results. Psychological medicine 42, 2239-53.

Keefe RSE, Arnold MC, Bayen UJ, \& Harvey PD (1999). Source monitoring deficits in patients with schizophrenia; a multinomial modelling analysis. Psychological Medicine 29, 903-914.

Kegeles LS, Abi-Dargham A, Frankle WG, Gil R, Cooper TB, Slifstein M, Hwang D-R, Huang Y, Haber SN, \& Laruelle M (2010). Increased synaptic dopamine function in associative regions of the striatum in schizophrenia. Archives of General Psychiatry 67, 231-239.

Kendler KS, Gallagher TJ, Abelson JM, \& Kessler RC (1996). Lifetime Prevalence, Demographic Risk Factors, and Diagnostic Validity of Nonaffective Psychosis as Assessed in a US Community Sample: The National Comorbidity Survey. Archives of general psychiatry 53, 1022-1031.

Kendler KS, Ohlsson H, Sundquist J, \& Sundquist K (2014). IQ and Schizophrenia in a Swedish National Sample: Their Causal Relationship and the Interaction of IQ With Genetic Risk. American Journal of Psychiatry 172 259-65.

Kessler RC, Mickelson KD, \& Williams DR (1999). The Prevalence, Distribution, and Mental Health Correlates of Perceived Discrimination in the United States. Journal of Health and Social Behavior 40, 208-230.

Keuzenkamp S (2011). Acceptatie van homoseksualiteit in Nederland. Internationale vergelijking, ontwikkelingen en actuele situatie. no. 2001-26. Sociaal en Cultureel Planbureau: Den Haag.

King M, Nazroo J, Weich S, McKenzie K, Bhui K, Karlson S, Stansfeld S, Tyrer P, Blanchard M, Lloyd K, McManus S, Sproston K, \& Erens B (2005). Psychotic symptoms in the general population of England. Social Psychiatry and Psychiatric Epidemiology 40, 375-381. 
King M, Semlyen J, Tai SS, Killaspy H, Osborn D, Popelyuk D, \& Nazareth I (2008). A systematic review of mental disorder, suicide, and deliberate self harm in lesbian, gay and bisexual people. BMC psychiatry 8, 70 .

Kirkbride JB, Jones PB, Ullrich S, \& Coid JW (2014). Social Deprivation, Inequality, and the Neighborhood-Level Incidence of Psychotic Syndromes in East London. Schizophrenia Bulletin 40, 169-180.

Kirschbaum C, Pirke K-M, \& Hellhammer DH (1993). The 'Trier Social Stress Test'-a tool for investigating psychobiological stress responses in a laboratory setting. Neuropsychobiology 28, 76-81.

Konings M, Bak M, Hanssen M, van Os J, \& Krabbendam L (2006). Validity and reliability of the CAPE: a self-report instrument for the measurement of psychotic experiences in the general population. Acta Psychiatrica Scandinavica $114,55-61$.

Krabbendam L, \& van Os J (2005). Schizophrenia and Urbanicity: A Major Environmental Influence-Conditional on Genetic Risk. Schizophrenia Bulletin 31, 795-799.

Kuyper L, \& Fokkema T (2011). Minority stress and mental health among Dutch LGBs: Examination of differences between sex and sexual orientation. Journal of Counseling Psychology 58, 222-233.

Landolt M, Bartholomew K, Saffrey C, Oram D, \& Perlman D (2004). Gender Nonconformity, Childhood Rejection, and Adult Attachment: A Study of Gay Men. Archives of Sexual Behavior 33, 117-128.

Lardinois M, Lataster T, Mengelers R, Van Os J, \& Myin-Germeys I (2011). Childhood trauma and increased stress sensitivity in psychosis. Acta Psychiatrica Scandinavica $123,28-35$.

Laruelle M, Abi-Dargham A, Van Dyck CH, Gil R, D’Souza CD, Erdos J, McCance E, Rosenblatt W, Fingado C, Zoghbi SS, \& others (1996). Single photon emission computerized tomography imaging of amphetamine-induced dopamine release in drug-free schizophrenic subjects. Proceedings of the National Academy of Sciences of the United States of America 93, 9235-9240.

Laruelle M, Abi-Dargham A, van Dyck CH, Rosenblatt W, Zea-Ponce Y, Zoghbi SS, Baldwin RM, Charney DS, Hoffer PB, Kung HF, \& Innis RB (1995). SPECT Imaging of Striatal Dopamine Release after Amphetamine Challenge. Journal of Nuclear Medicine 36, 1182-1190.

Laruelle M, Abi-Dargham A, Gil R, Kegeles L, \& Innis R (1999). Increased dopamine transmission in schizophrenia: relationship to illness phases. Biological Psychiatry 46, 56-72.

Lataster J, Collip D, Ceccarini J, Haas D, Booij L, van Os J, Pruessner J, Van Laere K, \& Myin-Germeys I (2011). Psychosocial stress is associated with in vivo dopamine release in human ventromedial prefrontal cortex: A positron emission tomography study using [18F]fallypride. NeuroImage 58, 1081-1089.

Lataster J, Collip D, Ceccarini J, Hernaus D, Haas D, Booij L, van Os J, Pruessner J, Laere KV, \& Myin-Germeys I (2014). Familial Liability to Psychosis Is Associated With Attenuated Dopamine Stress Signaling in Ventromedial Prefrontal Cortex. Schizophrenia Bulletin 40, 66-77.

Lataster T, Os J, Drukker M, Henquet C, Feron F, Gunther N, \& Myin-Germeys I (2006). Childhood victimisation and developmental expression of non-clinical delusional ideation and hallucinatory experiences. Social Psychiatry and Psychiatric Epidemiology 41, 423-428.

Lataster T, Valmaggia L, Lardinois M, van Os J, \& Myin-Germeys I (2013). Increased stress reactivity: a mechanism specifically associated with the positive symptoms of psychotic disorder. Psychological Medicine 43, 1389-1400.

Lieberman JA, Kane JM, \& Alvir J (1987). Provocative tests with psychostimulant drugs in schizophrenia. Psychopharmacology 91, 415-433. 
Linscott RJ, \& van Os J (2013). An updated and conservative systematic review and meta-analysis of epidemiological evidence on psychotic experiences in children and adults: on the pathway from proneness to persistence to dimensional expression across mental disorders. Psychological Medicine 43, 1133-1149.

Marshal MP, Friedman MS, Stall R, King KM, Miles J, Gold MA, Bukstein OG, \& Morse JQ (2008). Sexual orientation and adolescent substance use: a meta-analysis and methodological review*. Addiction 103, 546-556.

Martinez D, Orlowska D, Narendran R, Slifstein M, Liu F, Kumar D, Broft A, Van Heertum R, \& Kleber HD (2010). Dopamine Type 2/3 Receptor Availability in the Striatum and Social Status in Human Volunteers. Biological Psychiatry 67, 275-278.

Martinez D, Slifstein M, Broft A, Mawlawi O, Hwang D-R, Huang Y, Cooper T, Kegeles L, Zarahn E, Abi-Dargham A, Haber SN, \& Laruelle M (2003). Imaging Human Mesolimbic Dopamine Transmission With Positron Emission Tomography. Part II: Amphetamine-Induced Dopamine Release in the Functional Subdivisions of the Striatum. Journal of Cerebral Blood Flow \& Metabolism 23, 285-300.

Mathers CD, Fat DM, \& Boerma J (2008). The global burden of disease: 2004 update. World Health Organization: Geneva.

Mathers CD, \& Loncar D (2006). Projections of Global Mortality and Burden of Disease from 2002 to 2030. PLoS Med 3, e442.

Mawlawi O, Martinez D, Slifstein M, Broft A, Chatterjee R, Hwang D-R, Huang Y, Simpson N, Ngo K, Van Heertum R, \& Laruelle M (2001). Imaging Human Mesolimbic Dopamine Transmission With Positron Emission Tomography: I. Accuracy and Precision of D2 Receptor Parameter Measurements in Ventral Striatum. Journal of Cerebral Blood Flow \& Metabolism 21, 1034-1057.

McCabe SE, Bostwick WB, Hughes TL, West BT, \& Boyd CJ (2010). The Relationship Between Discrimination and
Substance Use Disorders Among Lesbian, Gay, and Bisexual Adults in the United States. American Journal of Public Health 100, 1946-1952.

McGrath J, Saha S, Chant D, \& Welham J (2008). Schizophrenia: a concise overview of incidence, prevalence, and mortality. Epidemiologic reviews 30, 67.

McGrath J, Saha S, Welham J, Saadi O El, MacCauley C, \& Chant D (2004). A systematic review of the incidence of schizophrenia: the distribution of rates and the influence of sex, urbanicity, migrant status and methodology. BMC Medicine 2, 13.

Meyer IH (1995). Minority stress and mental health in gay men. Journal of Health and Social Behavior 36, 38-56. Meyer IH (2003). Prejudice, Social Stress, and Mental Health in Lesbian, Gay, and Bisexual Populations: Conceptual Issues and Research Evidence. Psychological Bulletin $129,674-697$.

Miller P, Lawrie SM, Hodges A, Clafferty R, Cosway R, \& Johnstone EC (2001). Genetic liability, illicit drug use, life stress and psychotic symptoms: preliminary findings from the Edinburgh study of people at high risk for schizophrenia. Social Psychiatry and Psychiatric Epidemiology 36, 338-342.

Miyamoto S, Duncan GE, Marx CE, \& Lieberman JA (2004). Treatments for schizophrenia: a critical review of pharmacology and mechanisms of action of antipsychotic drugs. Molecular Psychiatry 10, 79-104.

Mizrahi R, Addington J, Rusjan PM, Suridjan I, Ng A, Boileau I, Pruessner JC, Remington G, Houle S, \& Wilson AA (2012). Increased Stress-Induced Dopamine Release in Psychosis. Biological Psychiatry 71, 561-567.

Moore TH, Zammit S, Lingford-Hughes A, Barnes TR, Jones PB, Burke M, \& Lewis G (2007). Cannabis use and risk of psychotic or affective mental health outcomes: a systematic review. The Lancet 370, 319-328. 
Morgan C, Charalambides M, Hutchinson G, \& Murray RM (2010). Migration, ethnicity, and psychosis: toward a sociodevelopmental model. Schizophrenia bulletin 36, 655 .

Moritz S, Werner R, \& Collani G von (2006). The inferiority complex in paranoia readdressed: A study with the Implicit Association Test. Cognitive Neuropsychiatry 11, 402-415.

Myin-Germeys I, Delespaul P, \& Van Os J (2005a). Behavioural sensitization to daily life stress in psychosis. Psychological Medicine 35, 733-741.

Myin-Germeys I, Krabbendam L, Delespaul P a. EG, \& Van Os J (2003). Do life events have their effect on psychosis by influencing the emotional reactivity to daily life stress? Psychological Medicine 33, 327-333.

Myin-Germeys I, Marcelis M, Krabbendam L, Delespaul P, \& van Os J (2005b). Subtle Fluctuations in Psychotic Phenomena as Functional States of Abnormal Dopamine Reactivity in Individuals at Risk. Biological Psychiatry 58, 105-110.

Myin-Germeys I, Oorschot M, Collip D, Lataster J, Delespaul P, \& van Os J (2009). Experience sampling research in psychopathology: opening the black box of daily life. Psychological Medicine 39, 1533-1547.

Myin-Germeys I, \& van Os J (2007). Stress-reactivity in psychosis: Evidence for an affective pathway to psychosis. Clinical Psychology Review 27, 409-424.

Myin-Germeys I, van Os J, Schwartz JE, Stone AA, \& Delespaul PA (2001). Emotional reactivity to daily life stress in psychosis. Archives of General Psychiatry 58, 1137-1144.

van Nierop M, van Os J, Gunther N, Myin-Germeys I, de Graaf R, Have M ten, van Dorsselaer S, Bak M, \& van Winkel R (2012). Phenotypically Continuous With Clinical Psychosis, Discontinuous in Need for Care: Evidence for an Extended Psychosis Phenotype. Schizophrenia Bulletin 38, 231-238.
Nijenhuis J te, de Jong M-J, Evers A, \& van der Flier H (2004). Are cognitive differences between immigrant and majority groups diminishing? European Journal of Personality 18, 405-434.

Nurnberg JI, Blehar MC, Kaufmann CA, York-Cooler C, Simpson SG, Harkavy-Friedman J, Severe JB, Malaspina D, \& Reich T (1994). Diagnostic interview for genetic studies: rationale, unique features, and training. Archives of General Psychiatry 51, 849-859.

van Os J, Hanssen M, Bijl RV, \& Ravelli A (2000). Strauss (1969) revisited: a psychosis continuum in the general population? Schizophrenia Research 45, 11-20.

van Os J, Hanssen M, Bijl RV, \& Vollebergh W (2001). Prevalence of psychotic disorder and community level of psychotic symptoms: an urban-rural comparison. Archives of General Psychiatry 58, 663-668.

van Os J, Kenis G, \& Rutten BPF (2010). The environment and schizophrenia. Nature 468, 203-212.

van Os J, Verdoux H, Maurice-Tison S, Gay B, Liraud F, Salamon R, \& Bourgeois M (1999). Self-reported psychosislike symptoms and the continuum of psychosis. Social Psychiatry and Psychiatric Epidemiology 34, 459-463.

Oswald LM, Wand GS, Kuwabara H, Wong DF, Zhu S, \& Brasic JR (2014). History of childhood adversity is positively associated with ventral striatal dopamine responses to amphetamine. Psychopharmacology 231, 2417-2433.

Palmier-Claus JE, Myin-Germeys I, Barkus E, Bentley L, Udachina A, Delespaul P a. EG, Lewis SW, \& Dunn G (2011). Experience sampling research in individuals with mental illness: reflections and guidance. Acta Psychiatrica Scandinavica 123, 12-20.

Paradies Y (2006). A systematic review of empirical research on self-reported racism and health. International Journal of Epidemiology 35, 888-901. 
Perälä J, Suvisaari J, Saarni SI, Kuoppasalmi K, Isometsä E, Pirkola S, Partonen T, Tuulio-Henriksson A, Hintikka J, Kieseppä T, Härkänen T, Koskinen S, \& Lönnqvist J (2007). Lifetime prevalence of psychotic and bipolar I disorders in a general population. Archives of General Psychiatry 64, 19-28.

Perlis RH, Uher R, Ostacher M, Goldberg JF, Trivedi MH, Rush AJ, \& Fava M (2011). Association between bipolar spectrum features and treatment outcomes in outpatients with major depressive disorder. Archives of General Psychiatry $68,351-360$.

Phinney JS (1992). The multigroup ethnic identity measure: A new scale for use with diverse groups. Journal of Adolescent Research 7, 156-176.

Pierre PV, Fridberger A, Wikman A, \& Alexanderson K (2012). Self-reported hearing difficulties, main income sources, and socio-economic status; a cross-sectional population-based study in Sweden. BMC Public Health 12, 874.

Pohjalainen T, Rinne JO, Någren K, Syvälahti E, \& Hietala J (1998). Sex Differences in the Striatal Dopamine D2 Receptor Binding Characteristics in Vivo. American Journal of Psychiatry 155, 768-773.

Preacher KJ, \& Hayes AF (2004). SPSS and SAS procedures for estimating indirect effects in simple mediation models. Behavior Research Methods, Instruments, \& Computers 36, 717-731.

Pruessner JC, Champagne F, Meaney MJ, \& Dagher A (2004). Dopamine Release in Response to a Psychological Stress in Humans and Its Relationship to Early Life Maternal Care: A Positron Emission Tomography Study Using [11C]Raclopride. The Journal of Neuroscience 24, 2825-2831.

Rieger G, Linsenmeier JAW, Gygax L, \& Bailey JM (2008). Sexual orientation and childhood gender nonconformity: Evidence from home videos. Developmental Psychology 44, 46-58.
Rinne JO, Hietala J, Ruotsalainen U, Säkö E, Laihinen A, Någren K, Lehikoinen P, Oikonen V, \& Syvälahti E (1993). Decrease in Human Striatal Dopamine D2 Receptor Density with Age: A PET Study with [11C]Raclopride. Journal of Cerebral Blood Flow \& Metabolism 13, 310-314.

Robins LN, Wing J, Wittchen HU, Helzer JE, Babor TF, Burke J, Farmer A, Jablenski A, Pickens R, Regier DA, \& others (1988). The Composite International Diagnostic Interview: an epidemiologic instrument suitable for use in conjunction with different diagnostic systems and in different cultures. Archives of General Psychiatry 45, 1069.

Rössler W, Joachim Salize H, van Os J, \& Riecher-Rössler A (2005). Size of burden of schizophrenia and psychotic disorders. European Neuropsychopharmacology 15, 399-409. Russell DW (1996). UCLA Loneliness Scale (Version 3): reliability, validity, and factor structure. Journal of Personality Assessment 66, 20-40.

Salomon JA, Vos T, Hogan DR, Gagnon M, Naghavi M, Mokdad A, Begum N, Shah R, Karyana M, Kosen S, Farje MR, Moncada G, Dutta A, Sazawal S, Dyer A, Seiler J, Aboyans V, Baker L, Baxter A, Benjamin EJ, Bhalla K, Abdulhak AB, Blyth F, Bourne R, Braithwaite T, Brooks P, Brugha TS, Bryan-Hancock C, Buchbinder R, Burney P, Calabria B, Chen H, Chugh SS, Cooley R, Criqui MH, Cross M, Dabhadkar KC, Dahodwala N, Davis A, Degenhardt L, Díaz-Torné C, Dorsey ER, Driscoll T, Edmond K, Elbaz A, Ezzati M, Feigin V, Ferri CP, Flaxman AD, Flood L, Fransen M, Fuse K, Gabbe BJ, Gillum RF, Haagsma J, Harrison JE, Havmoeller R, Hay RJ, Hel-Baqui A, Hoek HW, Hoffman H, Hogeland E, Hoy D, Jarvis D, Jonas JB, Karthikeyan G, Knowlton LM, Lathlean T, Leasher JL, Lim SS, Lipshultz SE, Lopez AD, Lozano R, Lyons R, Malekzadeh R, Marcenes W, March L, Margolis DJ, McGill N, McGrath J, Mensah GA, Meyer A-C, Michaud C, Moran A, Mori R, Murdoch ME, Naldi L, Newton CR, Norman R, Omer SB, Osborne R, Pearce N, Perez-Ruiz F, Perico N, Pesudovs K, Phillips D, Pourmalek F, Prince M, Rehm JT, et al. (2012). Common values in assessing health outcomes from disease and injury: disability weights measurement study for the Global Burden of Disease Study 2010. The Lancet 380, 2129-2143. 
Sandfort TGM, de Graaf R, \& Bijl RV (2003). Same-Sex Sexuality and Quality of Life: Findings from the Netherlands Mental Health Survey and Incidence Study. Archives of Sexual Behavior 32, 15-22.

Sandfort TGM, de Graaf R, Bijl RV, \& Schnabel P (2001). Same-sex sexual behavior and psychiatric disorders: findings from the Netherlands Mental Health Survey and Incidence Study (NEMESIS). Archives of General Psychiatry 58, 85-91.

Savin-Williams R, \& Ream G (2007). Prevalence and Stability of Sexual Orientation Components During Adolescence and Young Adulthood. Archives of Sexual Behavior 36, 385-394.

Schmand BA, Bakker D, Saan RJ, \& Louman J (1991). De Nederlandse Leestest voor Volwassenen: een maat voor het premorbide intelligentieniveau. Tijdschrift voor Gerontologie en Geriatrie 22, 15-19.

Schrier AC, van de Wetering BJM, Mulder PGH, \& Selten JP (2001). Point prevalence of schizophrenia in immigrant groups in Rotterdam: data from outpatient facilities. European Psychiatry 16, 162-166.

Schwartz JE, \& Stone AA (1998). Strategies for analyzing ecological momentary assessment data. Health Psychology: Official Journal of the Division of Health Psychology, American Psychological Association 17, 6-16.

Selten JP (2001). Incidence of psychotic disorders in immigrant groups to The Netherlands. The British Journal of Psychiatry 178, 367-372.

Selten JP, \& Cantor-Graae E (2005). Social defeat: risk factor for schizophrenia? The British Journal of Psychiatry $187,101-102$.

Selten JP, \& Cantor-Graae E (2007). Hypothesis: social defeat is a risk factor for schizophrenia? The British Journal of Psychiatry 191, s9-s12.
Selten JP, \& Sijben N (1994). First admission rates for schizophrenia in immigrants to the Netherlands. Social Psychiatry and Psychiatric Epidemiology 29, 71-77.

Selten JP, van der Ven E, Rutten BP, \& Cantor-Graae E (2013). The Social Defeat Hypothesis of Schizophrenia: An Update. Schizophrenia Bulletin 39, 1180-1186.

Snijders TAB, \& Bosker RJ (1999). Multilevel Analysis: An Introduction to Basic and Advanced Multilevel Modeling. Sage Publications.

Soliman A, O'Driscoll GA, Pruessner J, Holahan A-LV, Boileau I, Gagnon D, \& Dagher A (2008). Stress-Induced Dopamine Release in Humans at Risk of Psychosis: a [11C]Raclopride PET Study. Neuropsychopharmacology 33, 2033-2041.

Stam M, Kostense PJ, Festen JM, \& Kramer SE (2013). The relationship between hearing status and the participation in different categories of work: Demographics. Work (Reading, Mass.)

STATA (2009). Statistical software: release 11.0. English. TXS Stata corporation: College Station, TX.

Stefanis N, Thewissen V, Bakoula C, van Os J, \& MyinGermeys I (2006). Hearing impairment and psychosis: a replication in a cohort of young adults. Schizophrenia Research 85, 266-272.

Stevens G, Flaxman S, Brunskill E, Mascarenhas M, Mathers CD, \& Finucane M (2013). Global and regional hearing impairment prevalence: an analysis of 42 studies in 29 countries. The European Journal of Public Health 23, $146-152$.

Stokes PRA, Shotbolt P, Mehta MA, Turkheimer E, Benecke A, Copeland C, Turkheimer FE, Lingford-Hughes AR, \& Howes OD (2013). Nature or Nurture? Determining the Heritability of Human Striatal Dopamine Function: an $\left[{ }^{18} \mathrm{~F}\right]-D O P A ~ P E T ~ S t u d y . ~ N e u r o p s y c h o p h a r m a c o l o g y 38$, 485-491. 
Strakowski SM, Sax KW, Setters MJ, \& Keck Jr PE (1996). Enhanced response to repeated d-amphetamine challenge: Evidence for behavioral sensitization in humans. Biological Psychiatry 40, 872-880.

Sullivan PF, Kendler KS, \& Neale MC (2003). Schizophrenia as a complex trait: Evidence from a meta-analysis of twin studies. Archives of General Psychiatry 60, 1187-1192.

Sweeting H, \& West P (2001). Being different: correlates of the experience of teasing and bullying at age 11. Research Papers in Education 16, 225-246.

\section{Termorshuizen F, Smeets HM, Braam AW, \& Veling W} (2014). Neighborhood ethnic density and psychotic disorders among ethnic minority groups in Utrecht City. Social Psychiatry and Psychiatric Epidemiology 49, 1093-1102.

Thompson JL, Urban N, Slifstein M, Xu X, Kegeles LS, Girgis RR, Beckerman Y, Harkavy-Friedman JM, Gil R, \& Abi-Dargham A (2013). Striatal dopamine release in schizophrenia comorbid with substance dependence. Molecular Psychiatry 18, 909-915.

Tidey JW, \& Miczek KA (1996). Social defeat stress selectively alters mesocorticolimbic dopamine release: an in vivo microdialysis study. Brain Research 721, 140-149.

Vanheusden K, Mulder CL, van der Ende J, Selten J-P, van Lenthe FJ, Verhulst FC, \& Mackenbach JP (2008). Associations between ethnicity and self-reported hallucinations in a population sample of young adults in The Netherlands. Psychological Medicine 38, 1095-1102.

Varese F, Smeets F, Drukker M, Lieverse R, Lataster T, Viechtbauer W, Read J, van Os J, \& Bentall RP (2012). Childhood Adversities Increase the Risk of Psychosis: A Meta-analysis of Patient-Control, Prospective- and Crosssectional Cohort Studies. Schizophrenia Bulletin 38, 661-671.

Veling W, Moritz S, \& van der Gaag M (2014). Brave New Worlds-Review and Update on Virtual Reality Assessment and Treatment in Psychosis. Schizophrenia Bulletin 40, 1194-1197.
Veling W, Selten JP, Veen N, Laan W, Blom JD, \& Hoek HW (2006). Incidence of schizophrenia among ethnic minorities in the Netherlands: a four-year first-contact study. Schizophrenia Research 86, 189-193.

Veling W, Susser E, van Os J, Mackenbach JP, Selten J-P, \& Hoek HW (2008). Ethnic Density of Neighborhoods and Incidence of Psychotic Disorders Among Immigrants. American Journal of Psychiatry 165, 66-73.

Velthorst E, Levine SZ, Henquet C, de Haan L, van Os J, Myin-Germeys I, \& Reichenberg A (2013). To cut a short test even shorter: Reliability and validity of a brief assessment of intellectual ability in Schizophrenia-a controlcase family study. Cognitive Neuropsychiatry 18, 574-593.

Verdoux H, van Os J, Maurice-Tison S, Gay B, Salamon R, \& Bourgeois M (1998). Is early adulthood a critical developmental stage for psychosis proneness? A survey of delusional ideation in normal subjects. Schizophrenia Research 29, 247-254.

Watt MJ, Roberts CL, Scholl JL, Meyer DL, Miiller LC, Barr JL, Novick AM, Renner KJ, \& Forster GL (2013). Decreased prefrontal cortex dopamine activity following adolescent social defeat in male rats: role of dopamine D2 receptors. Psychopharmacology 231, 1627-1636.

van der Werf M, van Boxtel M, Verhey F, Jolles J, Thewissen V, \& van Os J (2007). Mild hearing impairment and psychotic experiences in a normal aging population. Schizophrenia Research 94, 180-186.

van der Werf M, Thewissen V, Dominguez MD, Lieb R, Wittchen H, \& van Os J (2011). Adolescent development of psychosis as an outcome of hearing impairment: a 10-year longitudinal study. Psychological Medicine 41, 477485 .

van der Werf M, van Winkel R, van Boxtel M, \& van Os J (2010). Evidence that the impact of hearing impairment on psychosis risk is moderated by the level of complexity of the social environment. Schizophrenia Research 122, 193-198. 
Williams DR, \& Mohammed SA (2008). Discrimination and racial disparities in health: evidence and needed research. Journal of Behavioral Medicine 32, 20-47.

Wittchen HU (1994). Reliability and validity studies of the WHO-Composite International Diagnostic Interview (CIDI): a critical review. Journal of Psychiatric Research 28, 57-84.

Wittchen HU, Robins LN, Cottler LB, Sartorius N, Burke JD, \& Regier D (1991). Cross-cultural feasibility, reliability and sources of variance of the Composite International Diagnostic Interview (CIDI). The Multicentre WHO/ ADAMHA Field Trials. The British Journal of Psychiatry 159,645 .

Woodberry KA, Giuliano AJ, \& Seidman LJ (2008).

Premorbid IQ in Schizophrenia: A Meta-Analytic Review. American Journal of Psychiatry 165, 579-587.

Woodward ND, Cowan RL, Park S, Ansari MS, Baldwin RM, Li R, Doop M, Kessler RM, \& Zald DH (2010). Correlation of Individual Differences in Schizotypal Personality Traits With Amphetamine-Induced Dopamine Release in Striatal and Extrastriatal Brain Regions. American Journal of Psychiatry 168, 418-426.

World Health Organization (1990). Composite International Diagnostic Interview (CIDI), Version 1.0

Zammit S, Allebeck P, David AS, Dalman C, Hemmingsson T, Lundberg I, \& Lewis G (2004). A longitudinal study of premorbid IQ Score and risk of developing schizophrenia, bipolar disorder, severe depression, and other nonaffective psychoses. Archives of General Psychiatry 61, 354-360.

Zammit S, Lewis G, Rasbash J, Dalman C, Gustafsson J-E, \& Allebeck P (2010). Individuals, schools, and neighborhood: A multilevel longitudinal study of variation in incidence of psychotic disorders. Archives of General Psychiatry $67,914-922$.
Zietsch BP, Verweij KJH, Heath AC, Madden PAF, Martin NG, Nelson EC, \& Lynskey MT (2012). Do Shared Etiological Factors Contribute to the Relationship Between Sexual Orientation and Depression? Psychological Medicine 42, 521-532. 


\section{PUBLICATIONS}

Gevonden, M.J., Myin-Germeys, I., van den Brink W., van Os J., Selten J.P, \& Booij, J. (2015). Psychotic reactions to daily life stress and dopamine function in people with severe hearing impairment. Psychological Medicine, 45, 16651674.

Gevonden, M.J., Booij J., van den Brink W., Heijtel D.F.R., van Os J., \& Selten J.P. (2014). Increased release of dopamine in the striata of young adults with hearing impairment and its relevance for the social defeat hypothesis of schizophrenia. JAMA Psychiatry, 71 (12), 1364-1372.

Gevonden, M.J., Selten J.P., Myin-Germeys I., de Graaf R., Ten Have M., van Dorsselaer S., van Os J., \& Veling W. (2014). Sexual minority status and psychotic symptoms: findings from the Netherlands Mental Health Survey and Incidence Studies (NEMESIS). Psychological Medicine, 44 (02), 421-433.

Gevonden, M.J. (2007). Researching the self: the need for interdisciplinarity. In E. Grünewald and W. E. Frankenhuis (Eds.), Researching the self: Interdisciplinary perspectives. (pp. 1-22).

Newcastle (UK): Cambridge Scholars Publishing.

\section{PRESENTATIONS MH\&NS/EURON}

Gevonden, M.J., Wichers, M., Booij, J., van den Brink W., van Winkel, R., Myin-Germeys, I., \& Selten J.P. (2014). Reactivity to social stress in second-generation Moroccan-Dutch men. Poster presented at MH\&NS Research Day, Maastricht, the Netherlands.

Gevonden, M.J., Booij J., van den Brink W., van Os J., \& Selten J.P. (2013). Social Exclusion and Sensitization of the Mesolimbic Dopamine System: A [123I]IBZM-SPECT Study in Young Adults with Serious Hearing Impairment. Paper presented at EURON PhD Days, Luik, Belgium.

Gevonden, M.J., Booij J., van den Brink W., van Os J., \& Selten J.P. (2013). Social Exclusion, Dopamine Function and Psychosis Risk: A [ $\left.{ }^{123} \mathrm{I}\right]$ IBZM-SPECT Study in Young Adults with Serious Hearing Impairment. Poster presented at MH\&NS Research Day, Maastricht, the Netherlands.

Gevonden, M.J., Booij J., van den Brink W., \& Selten J.P. (2012). Effects of social exclusion on dopamine function in the human brain. A SPECT study in young adults with serious hearing impairment. Poster presented at EURON PhD Days, Maastricht, the Netherlands.

Gevonden, M.J., Myin-Germeys, I., Wichers, M., van Winkel, R., \& Selten J.P. (2012). IMPRESS: Increased Migrant Psychosis Risk, Exclusion and Stress Sensitisation. Poster presented at Conference Closing in on the Envirome in Mental Health, Maastricht, the Netherlands.

Gevonden, M.J., Myin-Germeys, I., Wichers, M., van Winkel, R., \& Selten J.P. (2012). IMPRESS: Increased Migrant Psychosis Risk, Exclusion and Stress Sensitisation. Poster presented at MH\&NS Research Day, Maastricht, the Netherlands. 


\section{OTHER PRESENTATIONS}

Gevonden, M.J., Myin-Germeys, I., Wichers, M., Booij, J., van den Brink W., van Winkel, R., \& Selten J.P. (2015). Psychotic and affective reactivity to daily life and experimental social stress in second-generation Moroccan-Dutch men. Paper presented at Society for Ambulatory Assessment Conference, State College, PA, USA.

Gevonden, M.J., Myin-Germeys, I., Wichers, M., Booij, J., van den Brink W., van Winkel, R., \& Selten J.P. (2015). Reactivity to daily life and experimental social stress in second-generation Moroccan-Dutch men. Poster presented at Annual Meeting of Society of Biological Psychiatry, Toronto, ON, Canada.

Gevonden, M.J., Myin-Germeys, I., Booij, J., van den Brink W., van Os J., \& Selten J.P. (2014). Psychotic reactions to daily life stress and dopamine function in people with severe hearing impairment. Poster accepted at Annual Meeting of Society of Biological Psychiatry, New York, NY, USA.

Gevonden, M.J., Selten J.P., Myin-Germeys I., de Graaf R., Ten Have M., van Dorsselaer S., van Os J., \& Veling W. (2014). Sociale uitsluiting en psychotische symptomen onder de nietheteroseksuele bevolking: een toets van de social defeat hypothese. Paper presented at ASV GAY symposium on gender non-conformity, Amsterdam, the Netherlands.

Gevonden, M.J., Booij J., van den Brink W., Heijtel D.F.R., van Os J., \& Selten J.P. (2014). De Social Defeat Hypothese Getoetst: Een [123I] IBZM-SPECT Studie naar de Dopaminehuishouding van Slechthorende Jongvolwassenen. Paper presented at Voorjaarscongres Nederlandse Vereniging voor Psychiatrie, Maastricht, the Netherlands.
Gevonden, M.J., Booij J., van den Brink W., Heijtel D.F.R., van Os J., \& Selten J.P. (2014). Social exclusion and sensitization of the dopamine system: A [123I]IBZM-SPECT study in young adults with serious hearing impairment. Paper presented at 4th Biennial Schizophrenia International Research Society Conference, Florence, Italy.

Gevonden, M.J., Myin-Germeys, I., Booij, J., van den Brink W., van Os J., \& Selten J.P. (2014). Social stress and psychotic symptoms in the daily life of young adults with hearing impairment. Poster presented at 4th Biennial Schizophrenia International Research Society Conference, Florence, Italy.

Gevonden, M.J., Booij J., van den Brink W., van Os J., \& Selten J.P. (2013). Social Exclusion, Dopamine Function and Psychosis Risk: A [123I] IBZM-SPECT Study in Young Adults with Serious Hearing Impairment. Poster presented at Annual Congress of the European Association of Nuclear Medicine, Lyon, France.

Gevonden, M.J., Booij J., van den Brink W., van Os J., \& Selten J.P. (2013). De Social Defeat Hypothese Getoetst: Een [123I]IBZM-SPECT Studie naar de Dopaminehuishouding van Jonge Slechthorende Volwassenen. Paper presented at Wetenschapsmiddag Stichting Rivierduinen, Leiden, the Netherlands.

Gevonden, M.J., Booij J., van den Brink W., van Os J., \& Selten J.P. (2012). Social exclusion and dopamine function in the human brain: A SPECT study in young adults with serious hearing impairment. Poster presented at Annual Congress of the European Association of Nuclear Medicine, Milan, Italy.

Gevonden, M.J., Myin-Germeys, I., Wichers, M., van Winkel, R., \& Selten J.P. (2012). IMPRESS: Welbevinden van jonge autochtone en Marokkaans-Nederlandse mannen in hun 
dagelijkse omgeving. Paper presented at Wetenschapsmiddag Stichting Rivierduinen, Leiden, the Netherlands.

Gevonden, M.J., Selten J.P., Myin-Germeys I., de Graaf R., Ten Have M., van Dorsselaer S., van Os J., \& Veling W. (2012). Sexual minority status and psychotic symptoms: findings from the Netherlands Mental Health Survey and Incidence Studies (NEMESIS). Paper and Poster presented at Voorjaarscongres Nederlandse Vereniging voor Psychiatrie, Maastricht, the Netherlands.

Selten J.P., Gevonden, M.J., Myin-Germeys I., de Graaf R., Ten Have M., van Dorsselaer S., van Os J., \& Veling W. (2012). Testing the social defeat hypothesis in another minority: are psychotic symptoms more prevalent in the non-heterosexual population? Paper presented at 3rd Biennial Schizophrenia International Research Society Conference, Florence, Italy.

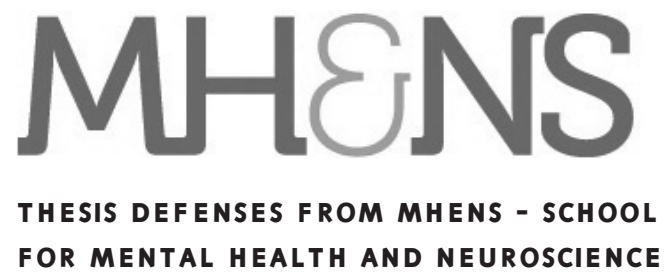

2013

Rob Havermans: Bipolar disorder in daily life;

Mood and cortisol responses to naturally occurring events. Supervisor: Prof.dr. M. de Vries; Co-Supervisor: Dr. N. Nicolson.

Véronique Moers-Hornikx: Deep brain stimulation and the cerebellum. Supervisors: Prof.dr. J. Vles / Prof.dr. Y. Temel; Co-Supervisor: Dr. G. Hoogland.

Nicole Veldhorst-Janssen: Intranasal delivery of rapid acting drugs. Supervisors: Prof.dr. M. Marcus / Prof.dr. C. Neef; Co-Supervisor: Dr. P.H. van der Kuy.

Stéphanie Knippenberg: Vitamin D and Multiple Sclerosis: immunological and clinical outcome. Supervisor: Prof.dr. J. Cohen-Tervaert; Co-Supervisors: Dr. J. Damoiseaux / Dr. Y. Bols.

Erik D. Gommer: Dynamic Cerebral Autoregulation: from methodology towards clinical application. Supervisors: Prof.dr. W.H. Mess / Prof.dr. R.B. Panerai, UK; Co-Supervisor: Dr.ir. J.P.H. Reulen.

Olga A.H. Reneerkens: Can PDE inhibition improve cognition ? Translational insights. Supervisor: Prof.dr. H.W.M. Steinbusch; Co-Supervisor: Dr. J. Prickaerts;.

Lyzel S. Elias-Sonnenschein: Clinical and biomarker correlates of genetic risk factors for Alzheimer's disease. Supervisor: Prof.dr. F.R.J. Verhey; Co-Supervisor: Dr. P.J. Visser. 
Diego F. Mastroeni: Epigenetic Dysregulation and the Pathophysiology of of Alzheimer's Disease. Supervisors: Prof.dr. H.W.M. Steinbusch / Prof.dr. P.D. Coleman, Sun City, Arizona; CoSupervisors: Dr. B.P.F. Rutten / Dr. D.L.A. van den Hove.

Leonidas Chouliaras: Epigenetic Regulation in Aging and Alzheimer's disease: A translational perspective. Supervisor: Prof.dr. H.W.M. Steinbusch; Co-Supervisors: Dr. B.P.F. Rutten / Dr. D.L.A. van den Hove.

Liesbeth Knaepen: Perinatal events and altered pain sensitivity in later life. Supervisors: Prof.dr. E.A.J. Joosten / Prof.dr. D. Tibboel, EUR; CoSupervisor: Dr. J. Patijn.

Marisela Martinez-Claros: Hippocampal plasticity and corticosterone: From dendrites to behaviour. Supervisor: Prof.dr. H.W.M. Steinbusch; Co-Supervisors: Dr. J.L. Pawluski / Dr. J. Prickaerts.

Marcus D. Lancé: A circle of improvement in bleeding management: from laboratory to clinic and back. Supervisors: Prof.dr. M.A.E. Marcu / Prof.dr. J.W.M. Heemskerk; Co-Supervisor: Dr. Y.M.C. Henskens.

Hilde Braakman: Imaging the brain; neuronal correlates of cognitive impairment in children with frontal lobe epilepsy. Supervisors: Prof.dr. A.P. Aldenkamp / Prof.dr. J.S.H. Vles; Co-Supervisors: Dr.ir. W.H. Backes / Dr. P.A.M. Hofman.

Willem H. van Zwam: Aneurysmal subarachnoid hemorrhage: imaging strategies and cost-effectiveness aspects in diagnostic work-up and post-therapeutic follow-up. Supervisors: Prof.dr. J.T. Wilmink / Prof.dr. J.E. Wildberger; Co-Supervisor: Dr. P.A.M. Hofman.
Klara De Cort: The Pathogenesis of Panic Disorder. Supervisors: Prof.dr. I. Myin-Germeys / Prof.dr. E.J.L. Griez; Co-Supervisors: Dr. K.R.J. Schruers / Dr. I. Van Diest, Leuven.

Kim van Wijck: Mind the Gap; experimental studies on splanchnic hyperfusion and gastrointestinal integrity loss in man. Supervisors: Prof.dr. W.A. Buurman / Prof.dr. C.H.C. Dejong; Co-Supervisor: Dr. K. Lenaerts.

Yvette Roke: Antipsychotic-induced hyperprolactinemia in children and adolescents with mainly autism spectrum disorders. Prevalence, symptoms, clinical consequences and genetic risk factors. Supervisors: Prof.dr. P.N. van Harten / Prof.dr. J.K. Buitelaar (RUN); CoSupervisor: Dr. A. Boot (UMCG).

Fleur Goezinne: Retinal detachment surgery: pre and postoperative prognostic factors. Supervisors: Prof.dr. F. Hendrikse / Prof.dr. C.A.B. Webers; Co-Supervisor: Dr. E.C. La Heij (Amsterdam).

Ralph L.J.G. Maassen: The Merits of Videolaryngoscopy during Glottic Visualisation for Endotracheal Intubation. Supervisors: Prof.dr. M. Marcus / Prof.dr. A. van Zundert (University of Queensland).

Maria J. de Sousa Guerreiro: The role of sensory modality in age-related distraction. Supervisor: Prof.dr. C.M. van Heugten; Co-Supervisor: Dr. P.W.M. van Gerven.

Ine Rayen: Effects of developmental fluoxetine exposure on neurobehavioral outcomes. Supervisor: Prof.dr. H.W.M. Steinbusch; Co-Supervisors: Dr. J.L. Pawluski / Dr. T.D. Charlier (Ohio University, USA). 
Nynke M.G. Bodde: Psychogenic non-epileptic seizures; a separate disorder or part of a continuum? Supervisors: Prof.dr. R. van Oostenbrugge / Prof.dr. K. Vonck (UZ Gent); Co-Supervisors: Dr. R. Lazeron / Dr. A. de Louw (Epilepsiecentrum Kempenhaeghe, Heeze).

Alejandro M. Gomez: Novel strategies for making myasthenia less gravis: targeting plasma cells and the neuromuscular junction. Supervisor: Prof.dr. M.H. De Baets; Co-Supervisors: Dr. M. Losen / Dr. P. Martinez-Martinez.

Mohammad S. Rahnama'i: Prostaglandins and Phosphodiesterases in the Urinary Bladder Wall. Supervisors: Prof.dr. Ph. Van Kerrebroeck / Prof.dr. S. de Wachter (Universiteit Antwerpen); Co-Supervisor: Dr. G. van Koeveringe.

Mariken B. de Koning: Studying biomarkers in populations at genetic and clinical high risk for psychosis. Supervisors: Prof.dr. T. Amelsvoort / Prof.dr. J. Booij (AMC).

Fabien Boulle: Epigenetic regulation of BDNF/ TrkB signaling in the pathophysiology and treatment of mood disorders. Supervisors: Prof. dr. H.W.M. Steinbusch / Prof.dr. L. Lanfumey (Universiteit Parijs); Co-Supervisors: Dr. D. van den Hove / Dr. G. Kenis.

\section{4}

Iris Nowak-Maes: Tinnitus; assessment of quality of life \& cost-effectiveness. Supervisors: Prof.dr. M. Peters / Prof.dr. B. Kremer; Co-Supervisors: Dr. M. Joore / Dr. L. Anteunis.

Marjolein Huijts: Cognitive function in patients with cerebral small vessel disease. Supervisor: Prof.dr. R.J. van Oostenbrugge; Co-Supervisors: Dr. A.A. Duits / Dr. J. Staals.
Markus Gantert: Fetal inflammatory injury as origin of long term disease: Lessons from animal models. Supervisors: Prof.dr. B. Kramer / Prof.dr. L. Zimmermann; Co-Supervisor: Dr.

A. Gavilanes.

Elke Kuypers: Fetal development after antenatal exposures: Chorioamnionitis and maternal glucocorticoids. Supervisors: Prof.dr. B.W. Kramer / Prof.dr. H.W. Steinbusch / Prof.dr. Suhas G. Kallapur (University of Cincinnati, Ohio, USA).

Pieter Kubben: Ultra low-field strength intraoperative MRI for Glioblastoma Surgery. Supervisor: Prof.dr. J.J. van Overbeeke; Co-Supervisor: Dr. H. van Santbrink.

Laura Baijens: Surface electrical stimulation of the neck for oropharyngeal dysphagia in Parkinson's disease: therapeutic aspects and reliability of measurement. Supervisor: Prof.dr. B. Kremer; Co-Supervisor: Dr. R. Speyer, Townsville.

Janneke Hoeijmakers: Small fiber neuropathy and sodium channels; a paradigm shift. Supervisor: Prof.dr. R.J. van Oostenbrugge; Co-Supervisors: Dr. C.G. Faber / Dr. I.S.J. Merkies.

Stephanie Vos: The Role of biomarkers in preclinical and prodromal Alzheimer's disease. Supervisor: Prof.dr. F.R. Verhey; Co-Supervisor: Dr. P.J. Visser.

Muriël Doors: The Value of Optical Coherence Tomography in Anterior Segment Surgery. Supervisors: Prof.dr. R.M. Nuijts / Prof.dr. C.A. Webers; Co-Supervisor:

Dr. T.T.J.M. Berendschot.

Anneke Maas: Sleep problems in individuals with genetic disorders associated with intellectual disability. Supervisors: Prof.dr. I. Curfs / Prof.dr. R. Didden. 
Sebastiaan van Gorp: Translational research on spinal cord injury and cell-based therapies; a focus on pain and sensorimotor disturbances. Supervisors: Prof.dr. B. Joosten / Prof.dr. M. van Kleef; Co-Supervisors: Dr. J. Patijn /Dr. R. Deumens, KU Leuven.

Andrea Sannia: High risk newborns and brain biochemical monitoring. Supervisor: Prof.dr. J.S.H. Vles; Co-Supervisors: Dr. D. Gazzolo, Alessandria, Italy / Dr. A.W.D. Gavilanes.

Julie A.D.A. Dela Cruz: Dopamine mechanisms in learning and memory: Evidence from rodent studies. Supervisors: Prof.dr. H.W.M. Steinbusch / Prof.dr. R.J. Bodnar, New York; Co-Supervisor: Dr. B.P.F. Rutten.

René Besseling: Brain wiring and neuronal dynamics; advances in MR imaging of focal epilepsy. Supervisors: Prof.dr. A.P. Aldenkamp / Prof.dr.ir. W.H. Backes; Co-Supervisor: dr. J.F.A. Jansen.

Maria Quint-Fens: Long-term care after stroke; development and evaluation of a long-term intervention in primary care. Supervisors: Prof. dr. J.F.M. Metsemakers / Prof.dr. C.M. van Heugten / Prof.dr. M. Limburg, Almere; Co-Supervisor: dr. G.H.M.I. Beusmans.

Veronique Moulaert: Life after survival of a cardiac arrest; the heart of the matter. Supervisors: Prof.dr. J.A. Verbunt / Prof.dr. C.M. van Heugten / Prof.dr. D.T. Wade, Oxford, UK.

Feikje Smeets: The hallucinatory-delusional state: a crucial connection in the psychosis symptom network. Supervisor: Prof.dr. J. van Os; Co-Supervisor: Dr. T. Lataster.

Lies Clerx: Alzheimer's disease through the MR-eye; novel diagnostic markers and the road to clinical implementation. Supervisor: Prof.dr.
F. Verhey; Co-Supervisors: Dr. P.J. Visser /
P. Aalten.

Sonny Tan: The subthalamic nucleus in Parkinson's disease. Supervisors: Prof.dr. Y. Temel / Prof.dr. H.W.M. Steinbusch / Prof.dr. T. Sharp, Oxford, UK / Prof.dr. V. Visser-Vandewalle, Koln.

Koen van Boxem: The use of pulsed radiofrequency in the management of chronic lumbosacral radicular pain. Supervisors: Prof.dr. M. van Kleef / Prof.dr. E.A.J. Joosten; Co-Supervisor: Assoc. Prof.dr. J. van Zundert.

Jérôme Waterval: Hyperostosis cranialis interna. Supervisors: Prof.dr. J.J. Manni / Prof.dr. R.J. Stokroos.

Sylvie Kolfschoten-van der Kruijs: Psychogenic non-epileptic seizures; the identification of neurophysiological correlates. Supervisors: Prof. dr. A.P. Aldenkamp / Prof.dr. K.E.J. Vonck, Universiteit Gent; Co-Supervisors: Dr. J.F.A. Jansen / Dr. R.H.C. Lazeron, Kempenhaeghe.

Wouter Pluijms: Spinal cord stimulation and pain relief in painful diabetic: polyneuropathy, a translational approach. Supervisors: Prof.dr. M. van Kleef / Prof.dr. E.A. Joosten; Co-supervisor: Dr. C.G. Faber.

Ron Handels: Health technology assessment of diagnostic strategies for Alzheimer's disease. Supervisors: Prof.dr. F.R.J. Verhey / Prof.dr. J.L. Severens (EUR); Co-Supervisor: Dr. M.A. Joore / Dr. C.A.G. Wolfs.

Evelyn Peelen: Regulatory T cells in the pathogenesis of Multiple Sclerosis: potential targets for vitamin $\mathrm{D}$ therapy. Supervisors: Prof.dr. R.M.M. Hupperts / Prof.dr. J.W. Cohen Tervaert; Co-Supervisor: Dr. J.G.M.C. Damoiseaux / Dr. M.M.G.L.Thewissen, Diepenbeek. 
Reint Jellema: Cell-based therapy for hypoxicischemic injury in the preterm brain. Supervisors: Prof.dr. B.W.W. Kramer / Prof.dr. H.W.M. Steinbusch; Co-Supervisor: Dr. W.T.V. Germeraad / Dr. P. Andriessen, Veldhoven.

Maria Wertli: Prognosis of Chronic Clinical Pain Conditions: The Example of Complex Regional Pain Syndrome 1 and Low Back Pain. Supervisors: Prof.dr. M. van Kleef; Co-Supervisor: Dr. F. Brunner, Zürich / Dr. R. Perez, VUmc.

\section{Dagmar Zeef: An experimental model of} Huntington's disease: Validation \& Stimulation. Supervisors: Prof.dr. Y. Temel / Prof.dr. H.W.M. Steinbusch; Co-supervisor: Dr. A. Jahanshahi.

Jeroen Decoster: Breaking Down Schizophrenia into phenes, genes and environment. Supervisors: Prof.dr. I. Myin-Germeys / Prof.dr. M. De Hert, KU Leuven; Co-Supervisor: Dr. R. van Winkel.

Eaja Anindya Sekhar Mukherjee: Fetal Alcohol Spectrum Disorders: exploring prevention and management. Supervisor: Prof.dr. L.M.G. Curfs; Co-Supervisor: Prof. S. Hollins,

St. George's University of London, UK.

Catherine van Zelst: Inside out; On stereotype awareness, childhood trauma and stigma in psychosis. Supervisors: Prof.dr. Ph. Delespaul / Prof.dr. J. van Os.

Ibrahim Tolga Binbay: Extended Psychosis Phenotype in the Wider Social Environment. Supervisor: Prof.dr. J. van Os; Co-Supervisor: Dr. M. Drukker.

Frank Van Dael: OCD matters in psychosis. Supervisors: Prof.dr. J. van Os / Prof.dr. I. Myin-Germeys.
Pamela Kleikers: NOXious oxidative stress: from head toe too and back. Supervisors: Prof.dr. H.H.H.W. Schmidt / Prof.dr. H.W.M. Steinbusch; Co-Supervisor: Dr. B. Janssen.

José Luis Gerardo Nava: In vitro assay systems in the development of therapeutic interventions strategies for neuroprotection and repair. Supervisors: Prof.dr.med. J. Weis / Prof.dr. H.W.M. Steinbusch; Co-Supervisor: Dr. G.A. Brook, RWTH Aachen.

Eva Bollen: Cyclic nucleotide signaling and plasticity. Supervisors: Prof.dr. H.W.M. Steinbusch / Prof.dr. R. D’Hooge, KU Leuven; Co-Supervisor: Dr. J. Prickaerts.

2015

Jessica A. Hartmann: A good laugh and a long sleep; Insights from prospective and ambulatory assessments about the importance of positive affect and sleep in mental health. Supervisor: Prof.dr. J. van Os; Co-Supervisors: C.J.P. Simons / Dr. M. Wichers.

Bart Ament: Frailty in old age; conceptualization and care innovations. Supervisors: Prof.dr. G.I.J.M. Kempen / Prof.dr. F.R.J. Verhey; CoSupervisor: Dr. M.E. de Vugt.

Mayke Janssens: Exploring course and outcome across the psychosis-continuum. Supervisor: Prof.dr. I. Myin-Germeys; Co-Supervisor: Dr. T. Lataster.

Dennis M.J. Hernaus: Dopayours is not dopamine: genetic, environmental and pathological variations in dopaminergic stress processing. Supervisor: Prof.dr. I. Myin-Germeys; Co-Supervisors: Prof.dr. F.M. Mottaghy / Dr. D. Collip. 
Ingrid M.H. Brands: The adaptation process after acquired brain injury Pieces of the puzzle. Supervisors: Prof.dr. C.M. van Heugten / Prof.dr. D.T. Wade, Oxford UK; Co-Supervisors: Dr. S.Z. Stapert / Dr. S. Köhler.

Francesco Risso: Urinary and salivary S100B monitoring in high risk infants. Supervisor: Prof.dr. J.S.H. Vles; Co-Supervisors: Dr. D. Gazzolo, Genoa,Italy / Dr. A.W.D. Gavilanes.

Alessandro Borghesi: Stem and Progenitor Cells in Preterm Infants: Role in the Pathogenesis and Potential for Therapy. Supervisor: Prof.dr. L. Zimmermann; Prof.dr. B. Kramer; Co-Supervisors: Dr. D. Gazzolo, Genoa,Italy / Dr. A.W.D. Gavilanes.

Claudia Menne-Lothmann: Affect dynamics; A focus on genes, stress, and an opportunity for change. Supervisor: Prof.dr. J. van Os; Co-Supervisors: Dr. M. Wichers / Dr. N. Jacobs.

Martine van Nierop: Surviving childhood new perspectives on the link between childhood trauma and psychosis. Supervisors: Prof.dr. I. Myin-Germeys / Prof.dr. J. van Os; Co-Supervisor: Dr. R. van Winkel.

Sylvia Klinkenberg: VNS in children; more than just seizure reduction. Supervisors: Prof.dr. J. Vles / Prof.dr. A. Aldenkamp; Co-Supervisor: Dr. H. Majoie.

Anouk Linssen: Considerations in designing an adult hearing screening programme. Supervisor: Prof.dr. B. Kremer; Co-Supervisors: Dr. L. Anteunis / Dr. M. Joore.

Janny Hof: Hearing loss in young children; challenges in assessment and intervention. Supervisors: Prof.dr. B. Kremer / Prof.dr. R. Stokroos / Prof.dr. P. van Dijk, RUG; Co-Supervisor: Dr. L. Antheunis.
Kimberly Cox-Limpens: Mechanisms of endogenous brain protection; Clues from the transcriptome. Supervisors: Prof.dr. J. Vles / Prof. dr. L. Zimmermann; Co-Supervisor: Dr. A. Gavilanes.

Els Vanhoutte: Peripheral Neuropathy outcome measures; Standardisation (PeriNomS) study part 2: Getting consensus. Supervisors: Prof.dr. C. Faber / Prof.dr. P. van Doorn; Co-Supervisor: Dr. I. Merkies, Spaarne ziekenhuis Hoofddorp.

Mayienne Bakkers: Small fibers, big troubles; diagnosis and implications of small fiber neuropathy. Supervisors: Prof.dr. C. Faber / Prof.dr. M. de Baets; Co-Supervisor: Dr. I. Merkies, Spaarne ziekenhuis Hoofddorp.

Ingrid Kramer: Zooming into the micro-level of experience: An approach for understanding and treating psychopathology. Supervisor: Prof.dr. J. van Os; Co-Supervisors: Dr. M. Wichers, UMC Groningen / Dr. C. Simons.

Esther Bouman: Risks and Benefits of Regional Anesthesia in the Perioperative Setting. Supervisors: Prof.dr. M. van Kleef / Prof.dr. M. Marcus, HMC, Qatar / Prof.dr. E. Joosten; Co-Supervisor: Dr. H. Gramke.

Mark Janssen: Selective stimulation of the subthalamic nucleus in Parkinson's disease; dream or near future. Supervisors: Prof.dr. Y. Temel / Prof.dr. V. Visser-Vandewalle, Keulen / Prof.dr. A. Benazzouz, Bordeax, France.

Reina de Kinderen: Health Technology Assessment in Epilepsy; economic evaluations and preference studies. Supervisors: Prof.dr. S. Evers / Prof.dr. A. Aldenkamp; Co-Supervisor: Dr. H. Majoie / Dr. D. Postulart, GGZ O-Brabant. 
Saskia Ebus: Interictal epileptiform activity as a marker for clinical outcome. Supervisors: Prof. dr. A. Aldenkamp / Prof.dr. J. Arends, TUE / Prof. dr. P. Boon, Universiteit Gent, België.

Inge Knuts: Experimental and clinical studies into determinants of panic severity. Supervisor: Prof.dr. I. Myin-Germeys; Co-Supervisor: Dr. K. Schruers; Influencing panic.

Nienke Tielemans: Proactive coping post stroke: The Restored4Stroke Self-Management study. Supervisors: Prof.dr. C. van Heugten / Prof.dr. J. Visser-Meily, UMC Utrecht;

Co-Supervisor: Dr. V. Schepers, UMC Utrecht.

Tom van Zundert: Improvements Towards Safer Extraglottic Airway Devices. Supervisors: Prof. dr. A.E.M. Marcus / Prof.dr. W. Buhre / Prof.dr. J.R. Brimacombe, Queensland, Australia / Prof.dr. C.A. Hagberg.

Tijmen van Assen: Anterior Cutaneous Nerve Entrapment Syndrome Epidemiology and surgical management. Supervisors: Prof.dr. G.L. Beets / Prof.dr. M. van Kleef / Dr. R.M.H. Roumen / Dr. M.R.M. Scheltinga, MMC Veldhoven.

Rohit Shetty: Understanding the Clinical, Immunological and Genetic Molecular Mechanisms of Keratoconus. Supervisors: Prof.dr. R.M.M.A. Nuijts / Prof.dr. C.A.B. Webers.

Christine van der Leeuw: Blood, bones and brains; peripheral biological endophenotypes and their structural cerebral correlates in psychotic disorder. Supervisor: Prof.dr. J. van Os; Co-supervisor: Dr. M. Marcelis.

Sanne Peeters: The Idle Mind Never Rests; functional brain connectivity across the psychosis continuum. Supervisor: Prof.dr. J. van Os; Co-supervisor: dr. M. Marcelis.
Nick van Goethem: $\alpha 7$ nicotinic acetylcholine receptors and memory processes: mechanistic and behavioral studies. Supervisor: Prof.dr. H.W.M. Steinbusch; Co-supervisor: Dr. J. Prickaerts.

Nicole Leibold: A Breath of fear; a translational approach into the mechanisms of panic. Supervisor: Prof.dr. H.W.M. Steinbusch; Cosupervisors: Dr. K.R.J. Schruers / Dr. D.L.A. van den Hove. 


\section{DANKWOORD}

Een avontuur dat vijf jaar geleden officiëel begon is nu ten einde, maar de basis werd al veel vroeger gelegd. Ik ben veel mensen dankbaar voor hun bijdrage. Direct aan dit werk, maar ook indirect, als onderdeel van de sociale omgeving waardoor $\mathrm{ik}$, ook al was ik wel eens 'the odd one out', nooit chronische sociale uitsluiting heb hoeven ervaren. Deze lijst is lang, maar nog altijd onvolledig.

Allereerst de deelnemers aan de verschillende onderzoeken, zonder wie dit boekje gevuld zou moeten worden met pure speculatie. Tienduizenden vragen hebben jullie beantwoord, honderden buisjes met speeksel en bloed gevuld, tientallen uren geduldig stilgelegen voor scherpe hersenplaatjes, het is nogal wat en het is zeker niet voor niets geweest. Bovendien waren het voor mij de allerleukste werkdagen; de gesprekken die ik tussen de bedrijven door met jullie heb kunnen voeren gaven dit promotietraject extra kleur.

Natuurlijk vooral ook aandacht voor mijn promotoren. Jean-Paul, de bevlogenheid waarmee je de social defeat hypothese op de kaart zet is grenzeloos. Daarmee creëer je ook kansen voor beginnende onderzoekers zoals ik om spannend en relevant onderzoek te doen, wat tot mooie publicaties leidt en een uitstekende kick-start van een carrière betekent, dank daarvoor!

Jan, je nieuwsgierigheid en het plezier in de wetenschap dat je uitstraalt is aanstekelijk. Geen dip was te diep, een kop koffie in combinatie met jouw relativerende woorden op maandagmorgen en ik kon er weer tegenaan.

Inez, ondanks dat de afstand groot was, ben je een cruciale mentorrol voor mij gaan vervullen. Daarnaast delen we een voorliefde voor karaoke en hoop ik dat we ons laatste duet nog niet hebben gezongen.
Leden van de leescommissie, Therese, Philippe, Lieuwe en Koen, dank voor jullie kundig oordeel en jullie aanwezigheid bij mijn promotie. Ik verheug me op een prikkelende gedachtenwisseling.

Mijn not-quite promotores, maar wel ontzettend inspirerende mensen om mee te praten en artikelen mee te schrijven, Jim en Wim, thanks, jullie hielden me scherp en bij zinnen.

Co-auteurs van het NEMESIS artikel Saskia, Margreet en Ron, wat een schitterende dataset is dat! En Wim, dank voor je geduld, dat eerste artikel was voor mij het moeilijkste.

Co-auteurs van de Marokkanen-studie Marieke en Ruud, geen tranen door jullie taakje in deze studie, wel een erg interessant experiment om uit te voeren. Dank voor jullie goede ideeën.

De verdere collega's van Maastricht, we hebben inmiddels een grote diaspora gevormd, maar ik heb zeer warme herinneringen aan de research retreats, waar we allemaal bij elkaar waren om haka te dansen, karaoke te zingen, weerwolven te spelen en ook nog wetenschap te bedrijven. Debora, jouw rol in het succes als coördinator van deze onderzoeken mag niet worden onderschat en je bent een fijn mens (en als jij er niet was dan stonden Wendy en Truda wel voor me klaar). Johan, ons gesprek tijdens een winters congres in Amsterdam heeft me goed gedaan. Ehsan, you were another beacon of sanity. Collega AiO's Dennis, Claudia, Jeroen, Martine, Catherine, Mayke, Sanne, Dina, Nicole, Petra, Jindra, Yori, Zuzana, Stijn, Feikje, ik heb jullie allemaal wel eens om raad gevraagd, net als Wolfgang, Marjan, Tineke, Ron, Maarten, Bart en Nancy. De kennis in de groep was eindeloos, de ondersteuning van Trees en Jolanda uitstekend en de nieuwbrief van Leni was elke maand weer een hoogtepuntje voor een promovendus in den vreemde. 
Team JPS bij Leiden-lang, hoe gezellig hebben we het wel niet gehad toen we elkaar gevonden hadden? Elles, je bent echt de meest attente collega die iemand zich kan wensen en goed in wat je doet, het was een voorrecht om me bij je te mogen voegen en samen met Elsje een team te vormen dat elkaar ook buiten de werkvloer om graag zag. Dank voor die eerste lift naar Kopenhagen! Jonas, wat een fijne vent ben jij, aan wie een pilsje en een goed slechte horror film ook wel besteed is en die nu wij zijn afgezwaaid de rol van senior-member in team JPS vast met verve vervult. Jean-Paul, dank je wel voor het aannemen van zulke toffe mensen. Verder bij Rivierduinen, de raad van bestuur voor de benodigde goedkeurigen en financiën, de collega's bij de wijkteams die me op weg hebben geholpen bij de ROM, Mariët en Jackie, die me wegwijs hebben gemaakt en telkens wisten uit te nodigen voor het kerstontbijt, Melissa, voor de hand-en-span, Tinie en mijn studente Mirjam, die de dataverzameling bij IMPRESS op de rails hebben gekregen, Yara, die dat voor HIPRESS heeft gedaan en Bert, die onderzoek een bijzonder warm hart toedraagt en erg goed gezelschap is op congressen.

My new supervisor Arik and my new colleague Vic. Thanks for giving me the opportunity to finish this dissertation and go home to defend it while we are so busy cracking the code of predicting PTSD. I couldn't have wished for a warmer welcome in New York, despite the fact that I arrived in a blizzard.

Mijn gidsen in de wereld van slechthorendheid verdienen in deze context ook een bedankje, met name Wouter en de mensen bij SHJONG. Op het gebied van de audiologie, is Jan de Laat van het LUMC een grote hulp geweest en op het AMC heb ik me laten adviseren door Maaike van Doorn-Bierman, was de planning altijd in orde dankzij Inge en waren de metingen altijd betrouwbaar door de kunde van Thirza en alle andere assistenten. Daarnaast ben ik de mannen die hebben geholpen om Marokkaans-Nederlandse jongens te interesseren voor ons onderzoek zeer erkentelijk, met name Achie, Inan, Ilias en Zaka in Amsterdam en Brahim, Robin en Said in Leiden.

Lieuwe, dank dat ik mocht aanschuiven bij jouw groep en zo aansluiting had met de andere psychoseonderzoekers op het AMC. Floor, Daniella, Laura, Jet, Marise, Rianne, Albertine, Sara, Lindy, Erik, Oswald, Carin, Karin, Tamar en alle andere vroege-psychose onderzoekers, fijn om met jullie Florence en Desmet op stelten te kunnen zetten! Eva, dankzij jou heb ik nu een stekkie in New York, ik kan je daarvoor niet genoeg bedanken! En gelukkig heb ik daar alle gelegenheid toe!

De afdeling nucleaire geneeskunde, waar ik al die mooie plaatjes heb kunnen maken op de op leeftijd zijnde SME omdat de TO haar telkens wisten op te lappen, Bastiaan en Erik bedankt. Tim, dank voor alle tips en achtergrondinfo. Berthe, Roel en vooral ook Hein, en alle assistenten en laboranten die me verder hebben geholpen bij het prikken en de dexamfetamine toediening, jullie maakten het spannendste stukje van het protocol ook voor de deelnemers zo prettig mogelijk. Matthijs, er moest regelmatig geschoven worden in de planning, het met jouw hulp en die van Rianne en Soer telkens weer gelukt, ook omdat Cynthia en Jan het hotlab goed op orde hadden. Cathy, Marjan en de andere dames van de balie, het was altijd gezellig om even een aanvraag te komen doen en Corry, je bent een kei.

Van al mijn werkkringen was Z0 thuis, vanaf mijn eerste aankomst in kamer 174 tot ik er vorig jaar eigenlijk niet meer weg wilde. Ik kom mijn spullen echt nog eens opruimen! Mijn kamergenootjes van het eerste uur, jullie zaten al een tijdje samen en namen me meteen in jullie doldwaze midden op. Cleo, dank dat ik op jouw 
buik vol Maia mocht leren electrodes plakken, Elsmarieke, je was tijdens mijn promotie een groot voorbeeld met je proefschrift-aller-proefschriften en ik kon heerlijk met je kletsen over aperitivi in Milaan of tijdens etentjes in Amsterdam, Marieke, ik mis de grapjes en de prietpraat en piratendansjes van toen je binnen handbereik zat en Anne, paarse laarzen, uitgesproken meningen, taartjes bij jou thuis, je was een bad-ass roomie.

Z0-174 versie 2.0 , bedankt voor de gezellige bende die volgde, vol kindersurprise expedities en krokodillenworstelen! Anouk, ons zonnetje in huis (of in outer space) Eline, nooit te beroerd om ons met een "nou jongens" tot de orde te roepen, JP, op congres naar Lyon met jou was episch, van snickertaart for breakfast, tot de reprimande van de dronken Brit voor een middernachtelijke kop thee, Geor, je bent toch echt veel leuker dan een harige Hongaar, Esther, I feel you babe!

Het was ook boffen met de buren, bubbelpoppen, pintjes vatten en potjes toepen bij Willem, met Pim, Martijn en André, de immer nerdy mails waardoor ik nooit van de lijst af wil van Kevin, Wouter en Ot, ons internationale contingent, Jordi, Lena en Valentina, de andere softies tussen de ingenieurs, Sanne, Myrle en Hyke, mede-lowlanders Jos, Anne-Marije en Oliver, Bram, de allerleukste collega om te foppen, Tanja, de baas en Dennis, dank voor het mogelijk maken van een toppublicatie en dat ik eindelijk een handlanger had om een seizoenskaart aan te schaffen!

Aart, dank voor de gastvrijheid, Paul, bedankt voor het toegankelijk maken van de techniek, Matthan, je advies op het gebied van analyses was zeer verhelderend, Sandra, fijn dat ik mijn korte scans zelf kon leren maken, en Joena, je bent de koningin van $\mathrm{Z} 0$ !
Dank aan team van mijn basisschool de Klaverweide en middelbare school OSG de Meergronden, die er voor gezorgd hebben dat ik leren leuk vond en altijd ben blijven vinden. De klasgenoten uit $6 \mathrm{~V}$ hebben natuurlijk ook een belangrijke rol in dat plezier. Laura, wat was het leuk om jouw paranimf te mogen zijn, hopelijk vieren we binnenkort ook de promotie van Joke, met Kim, Renee, Janine en Johan van de partij.

Dank aan de medewerkers van UvA Psychologie, voor een uitstekende vooropleiding die me ontzettend veel kansen heeft opgeleverd. In het bijzonder Fred Cornelisse, voor het geven van de vrije hand in ons eerste echte onderzoeksproject. En aan Jeroen Raaijmakers, Hans Phaf, en de overige staf van de vakgroep Brein \& Cognitie, voor een springplank naar Rich Shiffrin in Indiana (thanks for hosting me and organising the conference withe best format in science), een assistentenbaan en de bagage voor een promotieplek.

Thanks to the Executive Committee of the Society for Ambulatory Assessment, for creating a new position in their midst for an early-career enthusiast. Being involved in other ways than writing papers is part of the fun of science for me.

En ook een dikke dankjewel voor de muzungus en de ONE youth ambassadors. De boodschap van mijn onderzoek is dat ongelijkheid ongezond is, maar daar hoefde ik jullie niet van te overtuigen, jullie hadden de handschoen al opgepakt. Een grote bron van inspiratie!

Familie de Bats, voor ons weekend kom ik natuurlijk terug. Cinta \& Wim, ik mis onze etentjes en opera avondjes nu ik zo ver weg zit! Nardus, Lottie, Pieter, Else en Paulus, wat fijn dat ik bij jullie terecht kon in Maastricht als de trein me er niet vroeg genoeg kon brengen of met de carnaval. Familie Gevonden, het is tijd voor 


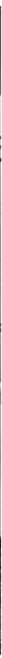

een rondje babybezoek geloof ik! Het is fijn om altijd te weten dat jullie er zijn.

Lieve vrienden, de wanderlust slaat soms, zo weten jullie, bij mij toe. Ook nu ben ik er eventjes van tussen, maar elke dag realiseer ik me hoe bijzonder het is dat we elkaar al zo lang kennen. Geen haar op mijn hoofd die er aan denkt om 'm permanent te peren (hoewel een terugkeer in de polder ook niet voor de hand ligt).

Nick, door dik en dun. De grafiekjes in dit boekje zien er door jouw hulp strak uit, maar dat is nog het minste. Gilles, de opkomst van de Snoogies was een van de gelukkigste ontwikkelingen van de afgelopen jaren. Met trommels is het kwaad hazen vangen. Geoffrey, Dirk, brouwmeesters, buren, bovenbeste vrienden, wat was het fijn om jullie tijdens het werken aan dit proefschrift zo dicht bij te hebben! Geof, je illustraties geven dit boekje schwung! Jasper, Kelvin, Sanne, my homies, Allie represent!

De tijd de ik bij de VSPA heb doorgebracht heeft me gevormd en heel veel goede vrienden opgeleverd, ik hoop dat de vereniging dat nog voor velen na mij ook kan doen. Malou, Kim, Heleen,
Greke, Emiel, Myra, Isabel, Daan, Jasmien, René, Richtje, Eva, Rob, waar ik jullie ook ter wereld tegen kom, het is altijd goed. Jelle, MW, WZAWZDB (hadden ze in de ArenA maar betere copywriters). MW, je gevraagd en ongevraagd advies en je support waren en blijven meer dan welkom. Ellen, dank je voor het doen van de layout van dit boekje, het is schitterend geworden!

Quirien en Rosa, voor de logeerpartijtjes als ik vroeg in Leiden moest zijn, of laat was gebleven omdat jullie me kennis hadden laten maken met het fenomeen 3 oktober. Largevriendjes, Mark, Charlot, Wilco, Janneke, bedankt voor het ontwikkelen van mijn wansmaak, waarvan hopelijk niet al te veel door dit boekje sijpelt. Floris, soms far en inbetween, maar al wel meer dan 30 jaar. Go fish? Pita, je je bent een lieverd en ik verheug me ook op jouw promotie!

Soof, in extra tijd en de verlenging kwam je binnen de lijnen en was je er voor mij, daar ben ik heel erg blij om!

Tenslotte, mijn paranimfen, met wie ik de Maastricht-Amsterdam connectie deelde en nog zo ontzettend veel meer. Jullie zaten in de eerste 


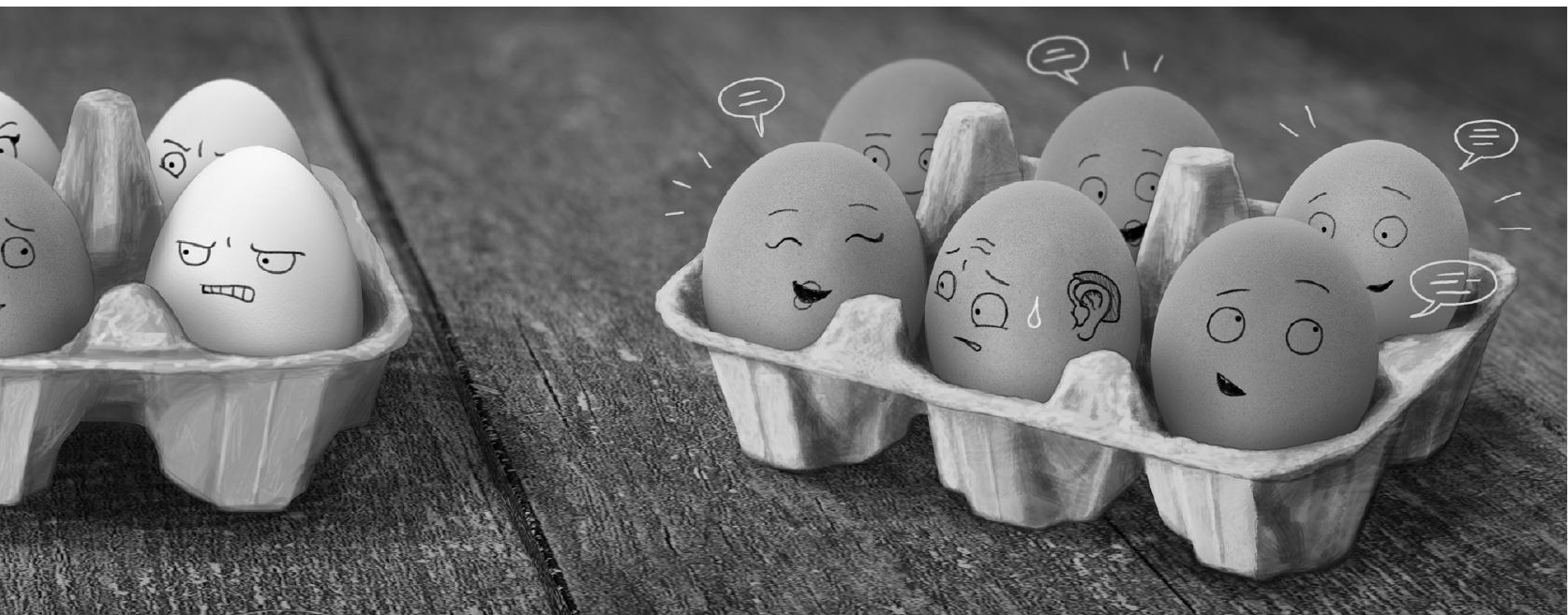

lijn bij crisis en ik had geen betere buffers voor mijn frustraties, wanhoop en teleurstelling die ook verplichte onderdelen van een promotietraject zin knnen wensen. Maar bovenal was het ontzettend gezellig. Elsje, je was echt een steun en toeverlaat, een klankbord voor allerlei gekke plannen die ik de afgelopen jaren heb gehad en bijzonder goede partner in crime. Bedankt voor deze doorlopende vaart, op de friendship!

Claudia, Claupia, Mien, Chucky, toen jij begon was ik al over de helft, maar het leek alsof je er de hele tijd al was geweest. Op het werk, na het werk, we hadden al snel een heel arsenaal aan binnenpretjes, rituelen en koosnaampjes opgebouwd. Ik heb misbruik gemaakt van het feit dat jij vaker naar Maastricht moest dan ik, jij op jouw beurt dat je geen mannen kende in Amsterdam behalve Dennis en ik. Nu ligt dat laatste gelukkig anders en heb je een zeer geschikte verhuizer/muizenvanger tot je beschikking. Kom je snel op uitwisseling naar New York?

Papa en Mama, ik kan een boekwerk vullen met lieve woorden over jullie, maar het volstaat hier om te zeggen dat jullie aan de basis van dit alles staan. Eikesdriekes. Altijd. 
ISBN: 978-90-9029204-5

Printer: CPI Koninklijke Wöhrmann

Illustrations: Geoffrey Cramm

Graph editor: Nick Naber

Design \& Layout: Ellen De Jong

Copyright: Martin Gevonden 